Daugavpils University

PROBLEMS

IN MUSIC

PEDAGOGY

Volume 16(2), 2017 


\title{
PROBLEMS IN MUSIC PEDAGOGY
}

\author{
Volume 16(2), 2017
}

\author{
EDITOR-IN-CHIEF \\ Jelena DAVIDOVA, Daugavpils University, Latvia \\ INTERNATIONAL EDITORIAL BOARD \\ Rose O. ANYANGO, Maseno University, Kenya \\ Ming-Jen CHUANG, National Taichung University, Taiwan \\ Margaretha GRAHN, Linköping University, Sweden \\ Debra HEDDEN, University of Kansas, USA \\ Antti JUVONEN, University of Eastern Finland, Finland \\ Nigel A. MARSHALL, University of Sussex, London, United Kingdom \\ Leonidas MELNIKAS, Lithuanian Academy of Music and Theatre, Lithuania \\ Mara MENEZES, Federal University of Bahia, Brazil \\ Asta RAUDUVAITE, Lithuanian University of Educational Sciences, Lithuania \\ Heikki RUISMÄKI, University of Helsinki, Finland \\ Inkeri RUOKONEN, University of Helsinki, Finland \\ Tiina SELKE, Tallinn University, Estonia \\ Michael SHAUGHNESSY, Eastern New Mexico University, Portales, New Mexico \\ Stefanie STADLER ELMER, The Schwyz University of Teacher Education \& \\ University of Zurich, Switzerland \\ Lorna WANZEL, Nova Scotia Registered Music Teachers' Association Research \\ Group, Halifax, Nova Scotia, Canada
}

\section{EDITORIAL STAFF}

Nellija BOGDANOVA, computer compose matter

Bronislava KALNINA, managing editor

Problems in Music Pedagogy is an international refereed journal concerned with all aspects of music pedagogy. Topic areas include music teaching/learning process in a new education paradigm context, music learning outcomes, assessment in music pedagogy process, music teaching and learning activities, music teacher competence in the context of sustainable development, music education institutional responses to current trends. The journal is committed to promoting excellence in these fields by providing an international forum for the debate and evaluation of a wide range of music pedagogy issues and professional concerns.

The journal aims to publish articles which will contribute to improving theory and practice in the field of music pedagogy.

These articles may variously:

- raise and debate contemporary issues;

- report on new research;

- relate new research to theory;

- relate theory to practice;

- offer informed comment on contextual and professional matters;

- describe cases and their implications for a wider field;

- discuss a historical movement in terms of its relevance to present and future situations.

The articles appearing in the Journal are indexed and abstracted in EBSCO, ERIH PLUS, ProQuest. Journal webpage: http://pmp.du.Iv 
Daugavpils University

\section{PROBLEMS}

IN MUSIC

PEDAGOGY

Volume $16(2) \cdot 2017$ 

PROBLEMS IN MUSIC PEDAGOGY

VOLUME 16(2), 2017

\section{CONTENTS}

Editorial

5

CONSTRUCTION AND VALIDITY OF PEDAGOGICAL TEST

OF MUSICAL ABILITIES

Lidija NIKOLIĆ

MODELS AND SCIENTIFIC MODELLING IN MUSIC CONTEXT

Gerhard LOCK

THEORETICAL FUNDAMENTALS OF THE PROCESS OF ACQUIRING

THE DIDACTIC MODEL FOR STYLE MODELLING

IN MUSICAL IMPROVISATION

Jurijs SPIGINS

TEACHING ARRANGING TO CLASSICAL AND CONTEMPORARY MUSIC STUDENTS IN HIGHER EDUCATION

Annie K. MITCHELL

AXIOLOGICAL MODEL OF MASTERING PIANO PLAYING

AS A BASIS OF THE COMPETENCE APPROACH

Larisa MALKOVA

PROBLEMS OF MUSIC EDUCATION FOR BLIND AND

VISUALLY IMPAIRED PEOPLE IN ESTONIA

Tiiu ERNITS \& Kadri KUTSAR 



\section{EDIT ORIAL}

The current issue of "Problems in Music Pedagogy" (PMP) contains research papers written by the participants of the10th International Scientific Conference "Problems in Music Pedagogy", which was held on September 28 - 29, 2017 at Daugavpils University, Latvia.

The primary factor for success in music and the condition without which it is impossible to talk about music learning and acquiring of vocal and instrumental performing competencies, are musical abilities. The goal of the research of Lidija NIKOLIĆ (Croatia) was to create a Test of Musical Abilities (TMA) and determine its psychometric properties. This test was defined as an objective measuring instrument whose approach to testing of musical abilities is similar to the way music educators select candidates for teacher studies - the ones who will have adequate musical abilities enabling them to follow the higher education music lessons and to acquire and develop the necessary skills in music. Reliability and validity of the TMA make it a suitable measuring instrument for future research of issues in music education of students - future teachers not only in Croatia.

Gerhard LOCK (Estonia) introduced his twelve strategic steps for modelling/analysis of models (partly inspired by Purwins et al. 2008), presented his enlargement of Justi and Gilbert's (2002) Model of Modelling and compared it with the twelve strategic steps. The author hopes that this article will enhance the understanding of modelling, as well as will assist in creating models in sciences in the field of music and music education.

The study of Jurijs Spigins (Latvia) is concerned with the analysis of the theoretical fundamentals of the process of acquiring the didactic model for style modelling in musical improvisations. The research results open new opportunities for a theoretical activity of pedagogues and students on studying and acquiring the nature of theoretical fundamentals of author's Didactic Model of Style Modelling in Musical Improvisation.

Annie MITCHELL (Australia) discusses new teaching and learning approaches to develop arranging skills necessary for pre-service teachers and musicians entering the contemporary music industry, the challenges non-classically trained musicians encounter in understanding classical composition techniques and structures, and how these problems can be overcome through the application of traditional compositional techniques to contemporary repertoire.

The study of Larisa MALKOVA (Latvia) is concerned with the Axiological Model of Mastering Piano Playing developed by the author as the basis for the competence approach to teaching and learning. Focusing on and constructing the problems of the subjects of musical axiological pedagogy in the model are related to a) the awareness 
about the preciousness of learners' personality and to promoting its development; $b$ ) the analysis of the content values of mastering piano playing; c) bringing forward those pedagogical conditions that activate the educational process of piano playing.

The research of Tiiu ERNITS and Kadri KUTSAR (Estonia) was focused on several problems of learning music for the blind and visually impaired in Estonia. The research results have indicated that the main limitations are connected with the Braille music notation and insufficient availability of modern accessible technology in music learning and teaching for the blind, the lack of mother language tools.

At becoming acquainted with the research findings of the representatives from various countries we enrich our experience, broaden our vision of a music study process and reach the conclusion that we have much more in common than different: the experience of any music teacher, student and scientist is unique.

Editor-in-chief Jelena DAVIDOVA 


\title{
CONSTRUCTION AND VALIDITY OF PEDAGOGICAL TEST OF MUSICAL ABILITIES
}

\author{
Lidija NIKOLIĆ \\ Faculty of Education, University of Osijek, Croatia \\ e-mail:Inikolic@foozos.hr
}

\begin{abstract}
The purpose of this research is to make a psychometrically sound and valid test of musical abilities for students of primary teacher education studies, based on the method of musical abilities testing most commonly conducted by music educators in Croatia and region, but lacking objectivity and reliability. The goal of the research is to create a Test of Musical Abilities (TMA) and determine its psychometric properties. The research was conducted with 105 students of teacher studies at the Faculty of Education in University of Osijek, Croatia. Validity of TMA was confirmed through content analysis and factor analysis. TMA has good internal consistency ( $\alpha=0.94)$ and significant coefficient of reliability $(r=0.96)$ and it meets the criteria of discrimination, objectivity and normativity, therefore it has been estimated as a reliable measurement instrument. It has been shown that TMA has a great number of characteristics of a good test with a potential ability to predict the achievement in musical tasks, thus being suitable for use as an entrance exam to the faculties of education in Croatia and the region with the same or similar musical idiom. Keywords: entrance examination, musical competence of teachers, musical idiom, test of musical abilities
\end{abstract}

\section{Introduction}

\section{Measurement and evaluation of musical abilities}

Musical abilities could be described as the capacities of person which enable his/her psychological, physical, aesthetic and affective reception, perception and production of music. It is impossible to include all aspects of person's capacity for success in music into any attempt to measure music abilities, because there are many differences among various types of musicians and there is a need for special 'equipment' for each of them. Tests of musical abilities are based on different understandings of the nature of musical abilities, and since there is no 'right' theory of musicality there is no single 'correct' measurement instrument (Radoš, 2010). 
In the 20th century, psychometric tests of musical abilities were created in line with different definitions of musical abilities as an object of measurement, which led to differences in tests created by different authors. In this paper the analysis of components of most significant tests of musical abilities in their original forms was carried out (Table 1).

Table 1. Examples of the most significant tests of musical abilities in their original forms (according to Lundin, 1967; Rojko, 1981; Mirković Radoš, 1989; Radoš, 2010)

\begin{tabular}{|c|c|}
\hline TESTS OF MUSICAL ABILITIES & $\begin{array}{l}\text { YEAR OF THE ORIGINAL } \\
\text { FORM OF THE TEST }\end{array}$ \\
\hline Measure of Musical Talents (Seashore) & 1919 \\
\hline K-D Music Tests (Kwalwasser \& Dykema) & 1930 \\
\hline Wing Standardized Tests of Musical Intelligence (Wing) & 1939 \\
\hline Tilson-Gretsch Musical Aptitude Test (Tilson) & 1941 \\
\hline Gaston Test of Musicality (Gaston) & 1942 \\
\hline Tests of Musical Ability (Lundin) & 1949 \\
\hline Whistler-Thorpe Musical Aptitude Test (Whistler \& Thorpe) & 1950 \\
\hline Drake Musical Aptitude Tests (Drake) & 1954 \\
\hline Musical Aptitude Profile - MAP (Gordon) & 1965 \\
\hline Measures of Musical Ability (Bentley) & 1966 \\
\hline Musikleisungstest (Wagner) & 1970 \\
\hline Primary Measures of Audiation (Gordon) & 1979 \\
\hline Intermediate Measures of Audiation (Gordon) & 1982 \\
\hline Advanced Measures of Music Audiation (Gordon) & 1989 \\
\hline
\end{tabular}

Regardless of the way of defining musical abilities, the most frequently questioned component in all tests is the perception and discrimination of pitch. Testing of this element has been done in several ways, such as examining the perception of lowest or highest tone, the perception of the smallest difference between the pitch of two tones, the relationship between the pitch of two tones, or identifying a particular tone within a chord. Perception and memorization of the melody have been examined by asking participants to identify repetitions or changes in the repeated melody, recognize the direction of the melody, identify melodic transposition, or show preference for melody, create a melody to the given text and design the end of the melody. Perception and performing of rhythm have been examined in the musical and extra-musical context by way of asking participants to identify the shorter and longer tone, identify changes in the rhythm in pairs of the rhythmic assemblies, perceive the same or different rhythm in the repeated music and show general preference for rhythmic accentuation. The aforementioned tests of musical abilities measure the perception of harmony too, through tasks of discovering alteration of one of the tones in the repeated chord, chord distinction according to the structure, and decision-making about which of the two harmonisations is more suitable. Furthermore, tasks of spotting quieter or louder tone, and choice of the more appropriate way to vary the dynamics of the melody measure the dynamic component of musical abilities. Tasks of detecting differences of timbre measure that ability. A sense of structure and balance of musical phrase have been examined by tasks of detecting the same or different phrase in a repeated melody and selecting more appropriate phrasing in two versions. There have also been tasks of comparing melodic and rhythmic assembly of the heard melody to the one in the notation (in the K-D Music Tests). All analysed tests are auditory (except Wagner's 
Musikleisungstest which, besides auditory perception, examines reproduction by singing and tapping as well) and are limited by the age of examinee for whom they provide predictions about future musical success.

Findings of recent psychological research on the nature of musical abilities and development of certain forms of musical expression have changed the understandings of what measuring instruments should be based on, as well as the types of tasks and the age limits within which some type of musical behaviour is determined (Radoš, 2010). Radoš (2010) asserts that today the basic components of musicality are not questionable, but rather the kinds of tasks which would effectively guarantee two primary functions of the tests, the diagnostic and the predictive one. However, it has still not been resolved whether the tests should use the 'sound material' or 'real music', therefore there are still discussions about the effectiveness of psychological tests in measuring the innate ability rather than the learned skills (Radoš, 2010).

Measurements of musical abilities that are carried out by psychologists are focused on a range of auditory, perceptual abilities, as opposed to the assessment of musicians who tend to examine perceptive and reproductive (performing) abilities. Gordon (1989) thinks that the best procedure for the evaluation of students' musical abilities is to combine objective tests and subjective opinions of teachers, and in his/her opinion this represents an ideal setting for assessment and counselling of students of music.

In Croatia and the region, as a part of the common practice, music educators assess musical potential of the candidates for active engagement in music as a part of the educational process. The individual examinations are conducted, which include singing a song of candidate's choice, singing the individual tones played on the piano, repeating rhythmic examples clapping their hands or tapping their hand on the table and singing short melodic examples melodic motives - after the piano.

The advantages of such 'traditional' way of assessing musical abilities are the possibility to check perceptive and reproductive musical abilities, and direct communication between the examiner and the examinee. Teacher's expertise, experience and straightforwardness in contact with a person who wants to learn music, provide an important assessment of musical abilities.

The disadvantages of a usual way of assessing musical abilities are reflected in the low objectivity and reliability. The assessment of musical potential for active engagement in music (singing, playing) is based on a general assessment by the teacher, and possibly the assessment by several music teachers. Such a test procedure is not systematic, and the quality and quantity of tasks depend on the expertise and experience of the examiner, and can vary among different examiners and examinees. The problem may be the fact that tasks of perception and reproduction of pitch and melody are set by piano, which might be difficult for the respondents with no musical experience because the piano timbre is not a part of their auditory experience, and therefore their reproduction might be evaluated as weaker. A common selection is based on the ability to sing, which is related to motor abilities and as such is dependent on training. The relationship between the tonal ability and the use of 'singing voice' can be problematic and therefore can lead to discrepancy between the actual music potential of the respondents and evaluation by teachers. Singing is a musical skill that must be 
practiced, and it is actually a type of musical performance, so testing musical abilities by way of singing becomes the test of music achievement.

\section{Assessing musical abilities of students of teacher studies}

The primary factor for success in music and the condition without which it is impossible to talk about music learning and acquiring of vocal and instrumental performing competencies, are musical abilities in the broadest sense of the term (Bogunović, 2010). Education tradition in Croatia and the region includes compulsory music education of future teachers (and kindergarten teachers) through university study programs, and students should acquire adequate musical competencies as well as vocal and instrumental performing skills. Students are expected to master singing and playing of a musical instrument (synthesizer, piano, accordion, and guitar) in order to be able to play musical contents suitable for music instruction in lower grades of primary school. To acquire these competencies an elementary level of musical abilities is needed which involves the perception and reproduction (by singing) within the children's voice pitch range, a sense of musical meter and rhythm, as well as musical memory.

By defining musical abilities necessary for the acquisition of music competencies of students/teachers, we determined the subject of measurement which will consequently condition the form of a test of musical abilities and its metric nature. The choice of the test that would be the best indicator of musical abilities of a population of students/teachers should depend on the specific musical abilities necessary for particular types of musical activities, psychometric characteristics of the test of musical abilities, cultural conditioning of the test content, and costs of the test (test time, costs, examiners, test conditions).

To create grounds for a homogeneous group of students at music courses that will result in adequate musical achievements and unobstructed acquisition and development of musical competencies, it is necessary to find a test that would satisfy the aforementioned criteria. Music instruction practice in teacher education in Croatia does not use standardized tests of musical potential or abilities. Having in mind that such tests are most often tied to a specific population, there is a need to create a specific test of musical abilities intended for the population of students - future teachers, and based on the objective measurement of perceptual and reproductive aspects of musical abilities, including some music skills (singing, coordinate vocalization and hand movements).

The purpose of this research is to make a psychometrically sound and valid test of musical abilities for students of primary teacher education studies, based on the method of musical abilities testing most commonly conducted by music educators in Croatia and region (but lacking objectivity and reliability). The goal of the research is to create a Test of Musical Abilities (TMA) and determine its psychometric properties. The underlying hypothesis of the research is that it is possible to create a test of musical abilities in the manner in which it is conducted by the music educators, but that it has the characteristics of validity, reliability, objectivity and discrimination. 


\section{Methods and sample}

\section{Participants}

The research was conducted with students of teacher studies at the Faculty of Education in University of Osijek, Croatia prior to the vocal and instrumental instruction. The selected sample was representative of the target population, and it included 105 female students aed 19 to $22(M=19.62 ; S D=0.73)$. The sample represents a non-selected population as far as the musical abilities are concerned, because the entrance exams to the faculty had not been implemented.

\section{Instruments}

Test of Musical Abilities was created in accordance with the customary model of musical abilities assessment, widely applied in Croatia and the region, which music educators use during exams to examine the perception and reproduction of music elements. On the basis of those elements the level of perceptive abilities, the level of reproductive performance (voice and rhythm) and musical memory are assessed.

TMA consists of six series (see Table 2), each of them consisting of six tasks (a total of 36 tasks), which are set by the examiner playing the piano, using their voice and/or manually performing, whereas the examinees reproduce vocally and manually (see Appendix 1).

Table 2. The series of tasks in a Test of Musical Abilities (TMA)

\begin{tabular}{clc}
\hline & \multicolumn{1}{c}{ ORDINAL NUMBER OF SERIES } & ABBREVIATION \\
\hline 1. & Singing of individual tones set by voice & STV \\
2. & Singing of individual tones set by the piano & STP \\
3. & Singing of individual tone of a chord & STC \\
4. & Singing of melodic motive set by voice & SMV \\
5. & Singing of melodic motive set by the piano & SMP \\
6. & Performing a rhythmic motive & RM \\
\hline
\end{tabular}

In the first series (STV) the task is to sing individual tones that the examiner is singing in neutral style ('na'). In the second series (STP) the task is the same, except that each tone is first played on the piano. In the third series (STC) the task is to sing in a neutral style one of the tones heard in a chord played on the piano. The fourth and fifth series of tasks contain melodic motives which examinees need to repeat after the examiner in the SMV series, or the piano in the SMP series. In the sixth series (RM) the task is to check both perception and memorization of rhythm, and coordination of voice and hand by having the examinees repeat the rhythmic tasks vocalised by the examiner in neutral style, continuously tapping the measure.

Questionnaire for examinees containing questions about the age and gender of the students, and a statement ("Instructions given by the examiner were clear") and Likert scale of five degrees (from 1 to "I agree completely" to 5 for „I do not agree at all").

\section{Test procedure}

TMA was conducted individually with each student, and the examiner was a music teacher in the teacher education programme. All subjects were tested using the same TMA and the same procedure, and the tasks were given in the same order as they appear 
in the test. The examiner tried to establish friendly atmosphere to gain students' trust, and gave instructions on test expectations and methods.

If the respondents were not able to repeat the task correctly on the first try, the task was set once again. For the correctly repeated assignment a plus sign (+) was noted in the Evaluation Sheetfor TMA. The final result of the TMA was obtained by summing up the plus signs ( + ) where each was awarded one point (1). The maximum possible result of the test was thirty-six (36), whereas the minimum possible score was zero (0).

All the tasks that were repeated relatively well were taken as correct, due to the fact that the respondents were musically inexperienced, untrained and with underdeveloped motor skills needed for this type of musical performance: listening, singing, and voice and hand compliance. Therefore, the following was tolerated: 'wavering' of the voice (until reaching the precise intonation), small tonal variations in a series of reproductions of melodic motives, and minor deviations in the manual reproduction of rhythmic motives. When performing melodic and rhythmic tasks incorrect execution of any of the given elements (tones, beats) or their complete absence were not tolerated, which means that the task was not marked as correct, if the respondent made this kind of mistake.

Immediately after the testing, respondents filled out an anonymous Questionnare.

This type of test required the classroom equipped with a piano where examiner was sitting. A table was set between the examiner and the examinee. Respondents accessed testing one by one.

\section{Results and discussion}

Metric characteristics of TMA were confirmed through:

- validity: a) content analysis of the test, b) task analysis - factor analysis;

- reliability;

- objectivity;

- discrimination;

- normativity.

\section{Validity of the test}

Consistent with Standards for Educational and Psychological Testing (APA, AERA \& NCME, 1999), evidence for validity was structured around the areas of test content and internal structure of the TMA, and evidence for reliability trough application of the splithalf technique and coefficient of internal consistency.

\section{Content analysis of the test}

Test content was created and ways of testing were designed in line with the knowledge of the advantages and disadvantages of usual ways of musical abilities testing, forms of standardized psychological tests, and characteristics of musical idiom that the respondents adopted growing up in a specific musical environment. Musical idiom represents the musical expression of an area. Listener's intuition represents the unconscious knowledge of the listener on musical structures - knowledge that is largely, and to some extent dependent on early experience, i.e. the musical idiom to which the 
listener was exposed in childhood (Antović, 2004). The characteristics of the person who observes, their previous musical experience, and musical experiences of a particular culture are responsible for creating links with certain musical idiom typical of this culture, which leads to perceiving of certain structural features of the music, such as tunes (Radoš, 2010). What follows is an explanation of principles used to create and assess the difficulty of certain tasks compared to the research on perception and reproduction of music, as well as music instruction practice.

The validity of the TMA test will be confirmed by content analysis of the tasks which examine certain aspects of musical abilities considered necessary to participate in the vocal and instrumental lessons at university teacher studies. In order to participate in music lessons and be able to acquire and develop the necessary musical competences, students should be able to sing and play certain music content. Therefore, in all tasks of the TMA, musical reproduction is requested. This, along with the perception of musical elements, tests the ability to sing, as well as the ability to coordinate vocalization and hand movement while tapping.

Musical abilities tested in TMA are assessed in most of the tests on musical abilities. Considering that the ability to perceive harmony, the ability of aesthetic judgment and other abilities are considered to be conditioned by music education, they are not essential for the population of students/teachers with regard to the elementary level of music education at teacher studies.

The easier tasks are followed by the more difficult ones in each of the series, and the criteria of the difficulty of the tasks will be explained for each of the analysed element. The ordering of tasks according to their level of difficulty is justified by the understanding that the process of singing is under the influence of affective states of subject, therefore dealing with a difficult task at the beginning of testing might have a frightening effect on the examinee and he/she might show weaker performance on tasks that follow, perhaps significantly easier. This would obstruct the testing.

\section{Perception and reproduction of individual tones}

All the researchers of musical abilities, regardless of the concept they pursue, agree that the ability to distinguish pitch is the basic attribute for the diagnosis of musical abilities. In testing of the distinction of pitch, different authors (Seashore, Kwalwasser \& Dykema, Tilson, Whistler \& Thorpe, Gaston, Wing, Bentley, Ortman, according to Rojko, 1981) have tried to create a measurement instrument that will enable better diagnostic assessment, therefore the distinction of higher or lower tone compared to the first tone were tested (the identification of direction), and the differences ranged from a pure tone of the tempered system to discrimination of the smallest possible interval between the set of tones (although such relationships will not run in the musical practice). Some authors (Whistler \& Thorpe, Wagner, according to Rojko, 1981) made the observation of the pitch and direction of movement more complicated by asking participants to track pitch within chords.

It is known from the experience in music instruction and the assessment of musical abilities of students/teachers that musically inexperienced students do not react to timbre of the musical instrument, but rather respond to human voice in their speech voice range. Studies have shown that the perception of pitch changes with gaining experience of music, with respect to the timbre of musical instrument and octaves in 
which music is performed (Radoš, 2010; Vurma, Raju \& Kuuda, 2011). Therefore, the tasks of reproduction of individual tones and melodic motives will be dictated by the voice first, and then by the instrument. In addition, examiners' singing should reduce the examinee's resistance towards singing and provide opportunity for the examiner to create and maintain emotional contact more easily, which is a prerequisite for students to feel relaxed so they could sing in a test situation.

Tones which will be used to test the perception and reproduction of the pitch are determined by the desirable range of voice for teachers, ranging from hes to $d^{2}$ for girls. Those tasks which are not within the usual range of voice of female students of teacher studies from $c^{1}$ to $g^{1}$ (Nikolić \& Ercegovac-Jagnjić, 2010) are considered difficult tasks.

The examination via the Test of Musical Abilities started by the examiner setting a series of six tones using her voice (STV). The first note of the series was $d^{1}$ which is neutral for girls, whereas other tones were set using consonant intervals in the range from $c^{1}$ to $h e s^{1}$. The second series of six tasks, set by the piano (STP), began with the tone hes and continued with the use of consonant intervals ranging from hes to $d^{2}$ (except the interval between $c^{2}$ and $d^{2}$ ). In the second series, the span of the vocal range was larger because it was expected that the respondents' voice will warm up during the first series and will be able to respond better in the second series.

\section{Perception and reproduction of the chord tone}

Singing a single chord tone (STC) is an indicator that a person has a highly developed ear for music. All six tasks contained chords in the range from $d^{1}$ to $g^{1}$, so that the inability to vocalize would not be a preventing factor. Chords were set in form of major triads, the first inversions of the triad and second inversions of the triad. The first task was to sing the lowest tone in the chord. Despite the fact that the highest tone is the most notable in a chord, the experience of working with the population of students/teachers has shown that inexperienced singers strive to sing deeper tones, which requires less effort in singing. ${ }^{1}$ This tendency to sing deeper tones should make this task the easiest of the three. The next task was to sing the highest note, and then the middle tone of the chord, the latter being the most difficult task of the STC series, since the middle tone is framed by the other two tones of a chord, thus being the hardest to notice.

\section{Perception, memorizing and performing of tunes}

Test of Musical Abilities contains tasks that require singing of the melodic motives. Preparation of these tasks was guided by the attitude of Sergeant (1973), who believes that, if one wants to measure musical abilities and skills, stimulus should be compatible with the context in which these abilities are used, or with the context of music learning. Therefore, it is necessary to determine the context in which students will learn music, in this case the inventory of folk and children's songs. They were analysed with the goal of creating and selecting sequences which will be used in testing the perception and memorization of melodies, as well as the perception and performing of the rhythm.

${ }^{1}$ In the analysis of how successfully this series of tasks was done, it has been shown that there is a certain number of students (from $21 \%$ to $29.5 \%$ ) who were successful at singing STC series of tasks regardless of which tone was set. Also, the most successful task was the one in which the singing of the middle tone of a chord was required $(29.5 \%)$. 
Another reason for choosing tasks which resemble the musical idiom is the possibility of musically inexperienced respondents being confused by stepping out of their usual auditory experiential framework and being unable to fully demonstrate their abilities. The analysis of folk and children's songs included 153 songs, among which there were 75 traditional folk songs and dances of Slavonia and Baranja (regions in Croatia where the university is located) for children (Brdarić, 1986; Knežević, 1988, 1993), and the analysis included a selection of 78 children's songs to be performed in school practice (Nastavni plan i program za osnovnu školu, 2006; Riman 2008; Stanišić \& Jandrašek, 2011a, 2011b; Stanišić, Jandrašek \& Šimunov, 2011).

The constructive elements of music that are typical for maternal ${ }^{1}$ musical idiom and music culture adopted through education are the basis for the assessment of students' musical abilities. ${ }^{2}$ Musical experience that has been acquired over a long period of time through the accumulation of musical impressions into the so-called fund of musical assumptions (associative fund) is a kind of a database that one, mostly unconsciously, relies on when being exposed to the new musical content (Beočanin-Mijanović, 2008). Length of sequences is determined by the limits of short-term memory, therefore seven or less items to remember were given (Mildner, 2003) or in other words, melodic sequences of short musical units have been selected as a prerequisite for reproduction, to facilitate memorization.

Associative fund that relies on the maternal musical idiom of the region of Slavonia and Baranja, adopted at preschool and early school age, is based on the two-beat meter and rhythm. In respect to the meter and rhythm parameter, all 12 tasks of the SMV and SMP series are equally demanding. Since there is the sixth series of RM tasks which test the sense of rhythm and ability to memorize it, the above mentioned series of melody tasks are free of specific measures and rhythm to help participants focus on tonal relations within each task.

Melodic segment of the task, as the primary in these two series, relies on the distinctive features of typical melody of the regional musical idiom and the melodies of songs sung and listened to during general music education, which are characterized by major scale. Initial tones, compared to initial tones of the musical idiom, reveal the tasks that are going to be easier; in other words, the tasks having the same initial tones as the musical idiom, those being the fifth, first or second degree of the scale. On the contrary, the initial tones on other degrees of the scale will be more difficult. As far as the tasks in which tones should be sung, easier tasks are those with motives whose singing voice range is from $\mathrm{c}^{1}$ to $\mathrm{g}^{1}$, and the more difficult ones are those which are outside that range. Characteristics of the melodic movement show that, along with static melodies on one tone and a gradual movement upward and downward, the specific melodic leaps occur, usually a minor third, and to a lesser extent, major third and perfect fourth. Therefore, the motives that contain such leaps are estimated as easy for perception and singing.

\footnotetext{
${ }^{1}$ By the term maternal musical idiom, we mean specificity of musical idiom that child adopts in infancy without being affected by formal education.

2 The impact of music by way of being exposed to media will not be taken into account because it would require a very comprehensive analysis of music content, beyond the scope of this paper.
} 


\section{Perception and performing of rhythm}

Rhythm is important in music of every culture, but there are differences in how much importance is attached to it by a particular culture (Radoš, 2010). Thus, in tests of musicality rhythm is observed in different ways, depending on authors' opinions on the importance of rhythm in music and its connection with musicality (Radoš, 2010). TMA examines the ability to maintain a balanced pulse and ability of attack grouping in the context of the musical idiom of the sample to be examined.

An analysis of selected folk and children's songs has shown, as it was said earlier, that the musical idiom of Slavonia and Baranja is known for the two-beat measure dominant in songs. Three-beat and four-beat measures appear to be significantly less frequent, whereas complex and mixed measures occur in individual cases. The basic rhythmic characteristic of the selected songs is a two-part division of the counting unit. Dotted rhythm could not be found often, and syncope and reversed dotted rhythms occur in individual cases. The emergence of the upbeat is also modest and mostly tied to the three-beat measure.

Rhythmic motives in TMA were built from simple division into two or three parts of a counting unit, dotted rhythm figures on one or two counting units, syncopation on two counting units, and a combination of these within a four-beat measure. All rhythmic motives were derived from rhythmic structures represented in the analysed folk and children's songs. The difficulty of rhythmic tasks can be estimated in relation to the metric and rhythmic characteristics of the used musical idiom. All rhythmic tasks were in a four-beat measure. Those tasks that contain a two-part division of the unit of measure and tasks with dotted rhythm are considered to be easier. The tasks containing syncope and triplets are considered more difficult.

During the test on perception and performance of rhythm the examiner sang rhythmic motives in neutral style ('na'), while tapping the pulsation. This method of testing was chosen due to the fact that severe deficiencies in maintaining the tempo and synchronizing movement and sound are a great impediment to active engagement in music, even under the most professional guidance of a music specialist (Vasiljević, 2006).

The content analysis has shown that TMA tasks measure those aspects of musical abilities that are essential to students for the acquisition and development of musical skills within the curriculum of music education at teacher studies in Croatia.

\section{b. Task analysis - Factor analysis}

Due to the specific structure of musical abilities that are measured via TMA, any other standardized test that would measure the same properties in the target sample was not satisfactory. Therefore, the results in TMA cannot be compared with the results of similar tests to determine the validity of the test. "Construct validity must be investigated whenever no criterion or universe of content is accepted as entirely adequate to define the quality to be measured" (Cronbach \& Meehl, 1955, 282). One of the ways of proving construct validity is testing the homogeneity of the test (Bukvić, 2007). When a variable is composed of several components the homogeneity is not expected (Bukvić, 2007), but if homogeneity of TMA could be proved, the validity of the test could be confirmed. 
36 tasks of the TMA were subjected to principal components analysis (PCA). Prior to performing PCA, the suitability of data for factor analysis was assessed. By examining the correlation matrix, numerous coefficient values of 0.3 and more were revealed. Value of the Kaiser-Meyer-Olkin indicator was 0.86, which exceeds the recommended value of 0.6. Bartlett's test of sphericity reached statistical significance $\left(\chi^{2}=2195.345\right.$; $d f=630 ; p<0.000$ ), all of which points to factorability of the correlation matrix.

The analysis of the principal component revealed the presence of eight components with characteristic values over 1, explaining the variance from $3.17 \%$ to $34.39 \%$. By examining the diagram of the characteristic value for the criterion of a scree test, the existence of a clear breakpoint after the second point has been found. On the basis of Cattell criteria, it was decided to continue the research retaining two components, and such extraction was supported by the results of a parallel analysis whose characteristic values exceed the appropriate threshold value obtained using a matrix of numbers (36 variables $\mathrm{x} 105$ respondents). For the purpose of making a decision on the number of factors that will be kept, the Horn parallel analysis was conducted using the statistical program Monte Carlo PCA for parallel analysis. The results of 100 samples of random numbers indicated that only the first two extracted factors have eigenvalues (?) greater than the corresponding values obtained randomly via generated data, and that it would be most appropriate to keep them.

The solution with two components explained $41.81 \%$ of the variance, with the contribution of the first component of $34.39 \%$ and the other component of $7.41 \%$. For easier interpretation of these two components the oblimin rotation was conducted. Oblimin rotation with Kaiser normalization of selected components (values above 0.3) extracted the items of TMA which largely correspond to the individual factors (see Table 3).

Table 3. Pattern and structure matrix for PCA with oblimin rotation of two factor solution of TMA items

\begin{tabular}{|c|c|c|c|c|c|}
\hline \multirow{3}{*}{ ITEM } & \multirow{2}{*}{\multicolumn{2}{|c|}{$\begin{array}{c}\text { PATTERN COEFFICIENTS } \\
\text { COMPONENT }\end{array}$}} & \multirow{2}{*}{\multicolumn{2}{|c|}{$\begin{array}{c}\text { STRUCTURE COEFFICIENTS } \\
\text { COMPONENT }\end{array}$}} & \multirow{3}{*}{ COMMUNALITIES } \\
\hline & & & & & \\
\hline & 1 & 2 & 1 & 2 & \\
\hline SMV2 & ,803 &,- 029 & ,792 & ,274 & 628 \\
\hline STV3 & ,756 &,- 150 & ,700 & ,135 &, 509 \\
\hline STV2 & ,740 &,- 133 & ,690 & 146 & 492 \\
\hline SMV5 & ,736 & 067 & ,761 & ,344 & ,583 \\
\hline SMV3 & ,732 & 051 & ,751 & ,327 & ,566 \\
\hline STV6 & ,726 &,- 059 & ,704 & ,215 & ,499 \\
\hline STV4 & ,718 &,- 106 & 678 & ,165 & ,469 \\
\hline STV1 & ,700 &,- 196 & ,626 & 068 & ,425 \\
\hline SMP3 & ,652 & ,248 & ,745 & ,494 & 608 \\
\hline STV5 & 646, & -128 & ,598 & 116 & 372 \\
\hline SMP5 & ,582 & 321 & ,703 & ,541 & ,583 \\
\hline SMP2 &, 512 & ,362 & 649 &, 555 &, 533 \\
\hline STP3 &, 503 & ,289 & ,612 & ,479 & ,447 \\
\hline RM3 &, 502 & ,025 &, 512 & ,214 & ,262 \\
\hline STP2 & ,468 & 275 & ,571 &, 451 & ,391 \\
\hline
\end{tabular}




\begin{tabular}{|c|c|c|c|c|c|}
\hline SMV1 & 450 & 291 & ,559 & 461 & ,386 \\
\hline RM5 & 448 & -011, & ,444 & 158, & 201, \\
\hline STP1 & ,442 & 114, & 485 & 281, & 247, \\
\hline RM2 & ,442 & ,047, & ,460 & ,214 & 213, \\
\hline RM4 & ,376 & 140, & ,429 & 282, & 201, \\
\hline STC3 & ,064 & ,711 & 332 & 735 & ,544 \\
\hline STC2 & -,055 & 684 & 203 & 664 & 443 \\
\hline STC4 & 147 & 667, & 399 & 723 & ,541 \\
\hline STC6 & ,084 & 659, & ,333 & 691 & 483 \\
\hline STP5 &, 250 & 563, & ,462 & 657, & ,486 \\
\hline STP6 & ,325 & ,555 & ,534 & 678, & ,550 \\
\hline STP4 & ,360 & ,528 & ,559 & 663, & ,552 \\
\hline STC5 & -203 & 515, & -009 & ,439 & 228 \\
\hline SMV6 & ,432 & 483 & 614 & 646, & 577 \\
\hline SMV4 & ,404 & 429 & ,566 & ,581 & 477, \\
\hline SMP6 & ,412 & ,422 & ,571 & ,577 & 479 \\
\hline SMP4 & ,310 & 393, & 459, & 510, & 343, \\
\hline SMP1 & ,363 & 389, &, $\mathbf{5 1 0}$ & 526, & 390, \\
\hline STC1 & ,007 & 370, & 146 & 372, & 139, \\
\hline RM6 & 153 & 291 & 263 & 349, & 142, \\
\hline RM1 &,- 112 & 275 & -,008 & ,233 & 065 \\
\hline
\end{tabular}

Note: major loadings over 0,5 for each item are bolded.

There was a weak positive correlation between the two factors ( $r=0.38)$. The first factor corresponded with all tasks except the tasks of the STC series, then the two tasks of RM and one task of STP series. The first factor explained most of the variance (34.39\%) and its correspondence with the tasks of all series of tasks led to the conclusion that it can be characterized as a factor of general musical abilities in which SMV and STV series have the highest coefficients. The factor of general musical abilities is a complex concept consisting of many musical components. The second factor largely corresponded to the tasks of the STC series, but did not correspond to the tasks of the STV and RM series. As the STC series of tasks, in relation to the other series, showed the highest degree of auditory ability, and factor loadings of the second factor appeared with the very task of the STC series, this factor could be characterized as an auditory factor. As such, there is no correlation of the auditory factor to the task of the RM series, because rhythm is one of the most rudimentary abilities that can exist in the absence of a higher, more complex aspects of musical abilities (Wing, 1941, according to Mirković Radoš, 1998). STV series represents the elementary level of musical ability due to the imitation of the pitch set by singing and, as such, does not correspond with higher auditory abilities.

Correspondence of all items (except the first task of the RM series) with separated factors points to the complexity of each of the components and connection in the structural elements of the items, so Test of Musical Abilities, in the described form, can be used as a complete measurement instrument.

Factor analysis was used to statistically prove the homogeneity of $T M A$, which was proven by the results of the analysis. It can be confirmed that TMA has the constructive and content validity. 


\section{Reliability}

In order to establish the reliability of TMA, the results of individual parts of the test were compared (split-half technique), and the measure of reliability is shown by calculating the coefficient of correlation.

Using the split-half technique the test was divided into two equal halves of 18 tasks on the results of the whole sample. Tasks were alternately selected within series in order to equalize the ratio of difficult and easy tasks, and the principle of "odd and even“ separation was used to satisfy the 'parallelism' of the parts. For each student the results of one or the other half of the test were combined. The results of two groups of points were correlated (Pearson's linear correlation coefficient $r=0.92$; Guttman split-half coefficient $r=0.96$ ) and the coefficient of reliability of the entire test was calculated using Spearman-Brown formula (coefficient of reliability of the whole test $r=0.96$ ). It has been shown that the correlation is high, the coefficient of reliability is significant, and so the test has been estimated as reliable and relevant for the individual measurement and diagnosis. TMA, with its 36 tasks, has good internal consistency because the overall Cronbach's alpha coefficient is very high $(\alpha=0.94)$.

Factors affecting reliability of the test are many, and those that are most important for $T M A$ are the test length and the clarity and unambiguous instructions by the examiner.

Test length can be seen in the context of the duration of testing and the number of tasks. The excessive duration of testing can lead to monotony and fatigue and affect the reliability of the test. But a small number of tasks is not sufficient for examining elements of music abilities in a way that would make the test reliable. In order to reduce the impact of the length factor to a minimum, in relation to the criteria of testing of music abilities in the target population, it was decided to test the elemental indicators of musical abilities with a certain number of tasks. The great number of tasks, which is desirable for the test reliability and enables the use of split-half technique is limited in TMA to reduce monotony and fatigue to a minimum, particularly because tasks are sorted by difficulty and each subsequent task requires more attention of an examinee.

Clarity and unambiguous instruction on behalf of the examiner about solving the task was achieved by direct communication between examiner and examinee, in which the examiner had the opportunity to further clarify the task if the examinee seemed to be confused by or misunderstand the task, which might affect the reliability of results. Clarity of instruction is checked by a anonymous survey, which examinees completed immediately after the testing. The results showed that the instructions given by the examiner were clear $(M=1.13 ; S D=0.39 ; N=105$, Min. $=1 ; M a x .=3)$.

Compared to several significant psychological tests of the perceptive aspect of musical abilities (referred to in Law \& Zentner, 2012, 7) TMA, as a test of perceptual and reproductive musical abilities, has the same level of reliability. Given that the reliability indicators in relation to selected examples are relevant, TMA was accepted as a reliable test. It can be concluded that TMA meets the criteria of reliability, as much as possible, given the nature of testing of musical abilities.

\section{Objectivity}

Objectivity of the test is achieved by eliminating the possibility of subjective interpretation of test results by the evaluator (Rojko, 1981). Clear, unambiguous and 
careful formulation of tasks, as well as consistent evaluation, guaranteed the objectivity of the test. Test procedure and criteria for the recognition of correct answers have already been described earlier.

Objectivity of the TMA was achieved through the use of the same tasks with all respondents, as well as the same examiner and conditions of testing. The test contained the Evaluation sheet for TMA in which the examiner recorded respondents' achievement for each task of a particular series of the test. As the results depended on the assessment by the examiner, it must be emphasized that the examiner was a teacher of vocal and instrumental classes with 17-year teaching experience at teacher training college and a master's degree in music pedagogy, at that time a PhD student of music pedagogy, as well as the author of the TMA. Validation of TMA objectivity with more assessors was not performed, because the high interoperability of assessors does not imply a high consistency of respondents' performance from one task to another, given the fact that the internal consistency of evaluators and their interoperability are not a guarantee of high reliability of respondents' results (APA, AERA \& NCME, 1999).

\section{Discrimination}

Discrimination and sensitivity of the test may depend on number and quality of tasks and ways of assessing the test outcomes (Bukvić, 2007).

In addition to the quality of test items, which arises from the analysis of the test content shown earlier, discriminability of the TMA will attempt to be achieved by a sufficient number of variously difficult tasks. The number of tasks has resulted from the above mentioned analysis, standardized psychological tests of musical abilities and duration of the test per each candidate individually. A larger number of items leads to a greater number of different results, and this increases discriminability of the test. The duration of individual testing depends on how much time is needed to explain each of the series and what type of participant's reaction is desired, and, of course, on the duration of task setting and responding. The advantage of individual testing of musical abilities lies in the fact that the examiner may adjust the pace of testing to the situation, which means that the time required for such testing can vary from candidate to candidate. The ability of respondents to maintain focus varies from one participant to the other, so the number of tasks must not be as big as to become an aggravating factor to a greater number of respondents. It may take 4-12 minutes to respond to 36 TMA questions taking one or two attempts.

Difficulty of TMA tasks varies within each of the series, and tasks are arranged from easier toward more demanding, in order to encourage the subject and prevent the negative effect of a possible failure at one of the tasks at the beginning of the series. An assessment of the assignment difficulty has been done, based on the experience and previous research of the author. The correct answers range from the easy ones, for unselected population of students, to tasks which will be successfully addressed only by those students who have significant musical experience.

\section{Normativity}

TMA and other tests of musical abilities, do not measure the absolute amount of musical abilities, but one's relative individual level of musical ability compared to other subjects. In order to facilitate the interpretation of test results for each subject 
individually, it was necessary to transpose the results into units of an appropriate scale, in this case the percentile scale (see Table 4).

Table 4. Table for reading the norms of TMA

\begin{tabular}{lccccc}
\hline \multicolumn{1}{c}{ LEVEL } & $\begin{array}{c}\text { SIGNIFICANTLY } \\
\text { BELOW } \\
\text { AVERAGE }\end{array}$ & $\begin{array}{c}\text { BELOW } \\
\text { AVERAGE }\end{array}$ & AVERAGE & $\begin{array}{c}\text { ABOVE } \\
\text { EVERAGE }\end{array}$ & $\begin{array}{c}\text { SIGNIFICANTLY } \\
\text { ABOVE } \\
\text { AVERAGE }\end{array}$ \\
\hline $\begin{array}{l}\text { Percentiles } \\
\begin{array}{l}\text { Frequencies } \\
\text { \% of the }\end{array}\end{array}$ & 0 to 20 & 20 to 40 & 40 to 60 & 60 to 80 & 80 to 100 \\
sample & 18 & 21 & 23 & 22 & 21 \\
$\begin{array}{l}\text { Points in } \\
T M A\end{array}$ & 17.15 & 20 & 21.9 & 20.95 & 20 \\
\hline
\end{tabular}

The success of subjects may be observed at five levels, due to the division of the sample into five groups of 20 percentiles. This way, on the basis of points, it is possible to establish the level of musical abilities of each student in relation to their peers.

\section{Conclusions}

1. It has been shown that TMA has characteristics of a test - validity, reliability, objectivity, discriminability and normativity, which characterizes TMA as a good test with a potential ability to predict achievements in musical tasks. By identifying tasks and ways to test properties of musical abilities, and by determining metric characteristics of the TMA, the aim of test design and testing has been achieved. TMA is defined as an objective measuring instrument whose approach to testing of musical abilities is similar to the way music educators select candidates for teacher studies - the ones who will have adequate musical abilities enabling them to follow the higher education music lessons and to acquire and develop the necessary skills in music. Reliability and validity of the TMA make it a suitable measuring instrument for future research of issues in music education of students, future teachers in Croatia and the region with the same or similar musical idiom.

2. Limitations of the TMA are most obvious in the context of the examiner's personality, his/her musical, professional and educational competence, objectivity in assessing and, equally important, personal self-control, stability and responsibility. Criteria of deciding which answers are correct may become the weakest point of objectivity of the TMA if the examiner is not experienced in dealing with students of teacher studies. Therefore, when a new examiner is introduced, in order to adapt to work with musically non-selected population, they should be introduced to the process of vocal and instrumental teaching and the testing process itself, through training under the guidance of an examiner with extensive experience in teaching and testing of music abilities. 


\section{References}

American Educational Research Association, American Psychological Association \& National Council on Measurement in Education (1999). Standards for Educational and Psychological Testing. Washington, DC: American Psychological Association.

Antović, M. (2004). Muzika i jezik u ljudskom umu [Music and Language in the Human Mind]. Niš: Kulturni centar (in Serbian).

Beočanin-Mijanović, J. (2008). Između greške i inercije sluha u solfeđu [Between Faults and Inertia of Hearing in Solfeggio]. Kragujevac: Filološko-umetnički fakultet Univerziteta $u$ Kragujevcu (in Serbian).

Bogunović, B. (2010). Muzički talenat i uspešnost [Musical Talent and Successfulness]. Beograd: Fakultet muzičke umetnosti i Institut za pedagoška istraživanja (in Serbian).

Brdarić, R. (1986). Brojalice i pjesme Slavonije i Baranje [Traditional Children Songs of Slavonia and Baranja]. Osijek: Zavod za prosvjetno-pedagošku službu za područje općina Osijek (in Croatian).

Bukvić, A. (2007). Načela izrade psiholoških testova [Principles of Making Psychological Tests]. Beograd: Zavod za udžbenike (in Serbian).

Cronbach, L. J. \& Meehl, P. E. (1955). Construct validity in psychological tests. Psychological Bulletin, 52(4), 281-300.

Gordon, E. E. (1989). Manual for the Advanced Measures of Music Audiation. Chicago: G. I. A. Publications, Inc.

Knežević, G. (1988). Šečem, šečem, drotičko [A Game of Pottery Fixers]. Zagreb: Kulturnoprosvjetni sabor Hrvatske (in Croatian).

Knežević, G. (1993). Naše kolo veliko: hrvatski dječji folklor, gradivo iz 19. i 20. stoljeća [Our Dance in the Big Circle: Croatian children's folklore, 19th and 20th century art]. Zagreb: Ethno (in Croatian).

Law, L. N. C. \& Zentner, M. (2012). Assessing musical abilities objectively: Construction and validation of the Profile of Music Perception Skills. PLoS One. 7(12): e52508. doi: 10.1371 /journal. pone.0052508

Lundin, R. W. (1967). An Objective Psychology of Music. New York: The Ronald Press Company.

Mildner, V. (2003). Govor između lijeve i desne hemisfere [Speech Between the Left and the Right Hemisphere]. Zagreb: IPC grupa (in Croatian).

Mirković Radoš, K. (1998). Psihologija muzičkih sposobnosti [The Psychology of Musical Abilities]. Beograd: Zavod za udžbenike i nastavna sredstva (in Serbian).

Nastavni plan i program za osnovnu školu (2006). [Elementary School Curriculum]. Zagreb: Ministarstvo znanosti, obrazovanja i športa Republike Hrvatske (in Croatian).

Nikolić, L. \& Ercegovac-Jagnjić, G. (2010). Uloga glazbenih sposobnosti u glazbenom obrazovanju učitelja primarnog obrazovanja [The role of music abilities in music education of primary education teachers]. Metodika, 11(20), 23-33 (in Croatian).

Radoš, K. (2010). Psihologija muzike [Psychology of Music]. Beograd: Zavod za udžbenike (in Serbian).

Riman, M. (2008). Dijete pjeva: pjevanje u prvom, drugom i trećem razredu osnovne škole [The Child Sings: Singing in the first, second and third grade of elementary school]. Rijeka: Sveučilište u Rijeci, Učiteljski fakultet (in Croatian). 
Rojko, P. (1981). Testiranje u muzici [Testing in Music]. Zagreb: Muzikološki zavod Muzičke akademije (in Croatian).

Sergeant, D. (1973). Measurement of pitch discrimination. Journal of Research in Music Education, 21(1), 3-19.

Stanišić, A. \& Jandrašek, V. (2011a). Razigrani zvuci 2, priručnik iz glazbene kulture za učitelje u 2. razredu osnovne škole [Playful Sounds 2, A manual for teaching music for teachers in the 2nd grade of elementary school]. Zagreb: Školska knjiga (in Croatian).

Stanišić, A. \& Jandrašek, V. (2011b). Razigrani zvuci 3, priručnik iz glazbene kulture za učitelje u 3. razredu osnovne škole [Playful Sounds 3, A manual for teaching music for teachers in the 3rd grade of elementary school]. Zagreb: Školska knjiga (in Croatian).

Stanišić, A., Jandrašek, V. \& Šimunov, J. (2011). Razigrani zvuci 1, priručnik iz glazbene kulture za učitelje u 1. razredu osnovne škole [Playful Sounds 1, A manual for teaching music for teachers in the 1st grade of elementary school]. Zagreb: Školska knjiga (in Croatian).

Vasiljević, Z. M. (2006). Metodika muzičke pismenosti [Methodology of Musical Literacy]. Beograd: Zavod za udžbenike i nastavna sredstva (in Serbian).

Vurma, A., Raju, M. \& Kuuda, A. (2011). Does timbre affect pitch? Estimations by musicians and non-musicians. Psychology of Music, 39(3), 291-306.

Received 17.05.2017

Accepted 06.07.2017 
Lidija NIKOLIĆ

Appendix

Tasks in the Test of Music Abilities

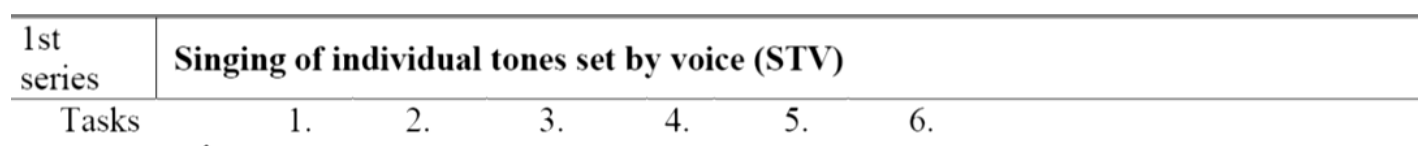
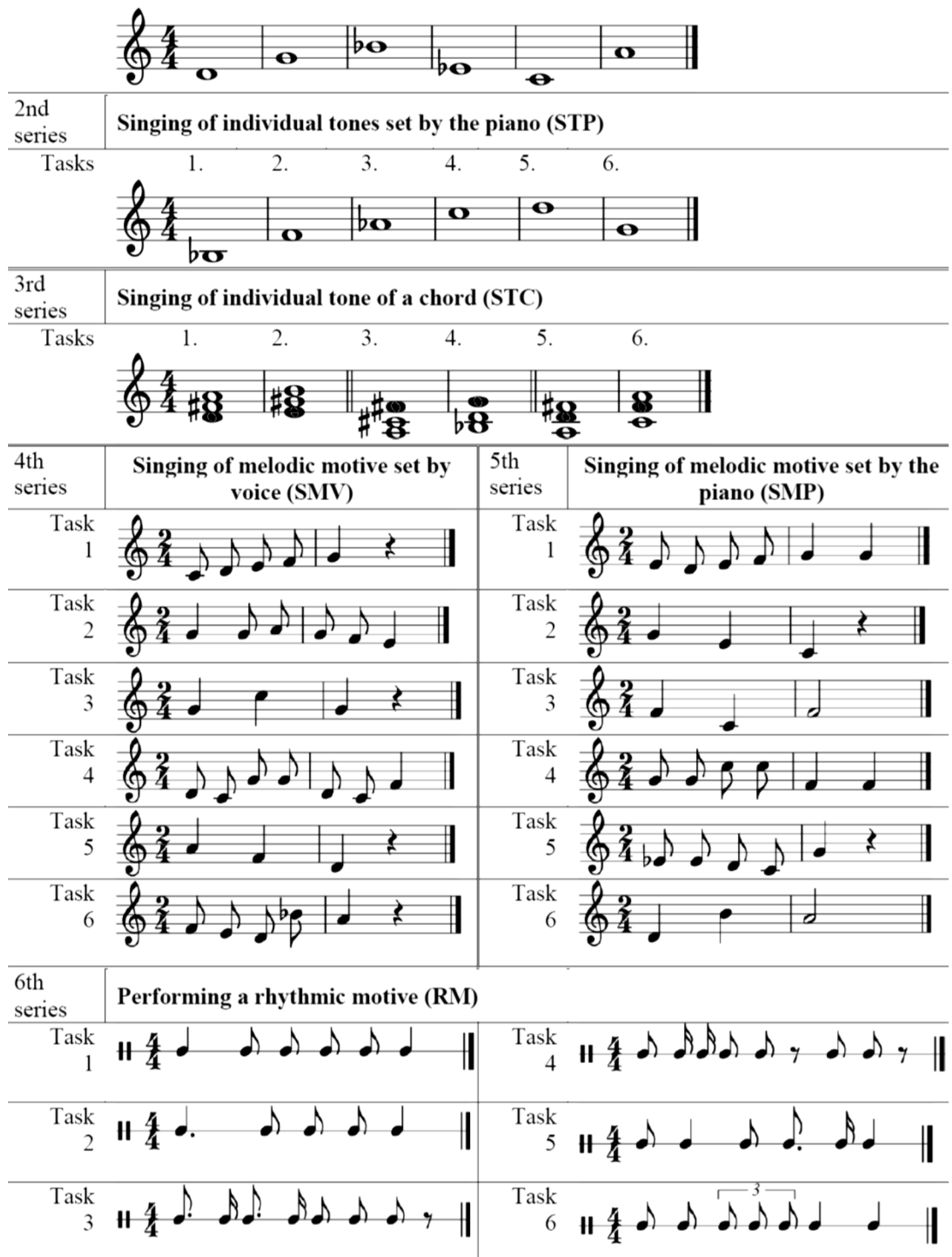

24 


\title{
MODELS AND SCIENTIFIC MODELLING IN MUSIC CONTEXT
}

\section{Gerhard LOCK}

Estonian Academy of Music and Theatre, Tallinn University, Estonia

email: gerhard.lock@tlu.ee

\begin{abstract}
The object of modelling in this article music can be understood as natural environment (Reybrouck, 2015) and as dynamical system (Burrows, 1997). Scientific models have diverse functions (aims, purposes), but also constraints, they work with different methods. They derive from implicit and explicit knowledge, appear between cognitive experience and implicit and explicit data within the paradox of knowledge as 'world first' vs 'mind first', manifested in two extremes: existence and technique (Varto, 2009).

In the theoretical part, the author introduced his multi-dimensional scheme of modelling and models incorporating models from music theory (analysis) and music psychology (perception and cognition) including the creative approach (musical composition/improvisation). Its aim is to position modelling used in (and for understanding of) music within the context of modelling in science in general. Also, the relation of models to theory, as well as computational and cognitive models in music are discussed briefly.

In the main contribution, the author introduced his Twelve Strategic Steps for modeling/analysis of models (partly inspired by Purwins et al., 2008), presented his enlargement of Justi and Gilbert's (2002) "Model of Modelling" and compared it with the Twelve Strategic Steps. In the implications and conclusion, the author proposed that modelling in science results if an idea can become explained with a concept, which can then be approached systematically, further developed as a method, includes connections/backups to one or more theories, and is consistent (a whole), either representing or exploring a known (but less systematically explained) phenomenon including cross-domain mappings. The author hopes that this article enhances the understanding of modelling and assists in creating models in sciences in the field of music and music education.
\end{abstract}

Keywords: models in sciences, representation, music analysis and cognition, computation, education 


\section{Introduction}

In science, the arts, and in education we often use the term 'model'. A common belief is that a scientific model represents something observable in the world (a 'phenomenon') or that a model is a theoretical/mental construct. The word 'model' in education, has come to represent or serve as an example of achievement, or something to replicate. In the arts, a model is a scheme or a description which is used to create a new artwork; also in music outstanding performances can become models informing further interpretations. Models and modelling play a crucial role in science and science education as well. 'Scientific modeling' is defined in the Encyclopaedia Britannica as "generating a physical, conceptual, or mathematical representation of a real phenomenon that is difficult to observe directly. Scientific models are used to explain and predict the behavior of real objects or systems [...]" (Rogers, 2017). In all these fields mentioned above, a model's purpose, form, and way of application differ. Models and modelling underlie a highly controversial discussion concerning their nature, function, relation to reality and theory, and their ability for scientific explanation, etc. (see more in Frigg \& Hartmann, 2012). Interestingly, in the Stanford Encyclopedia of Philosophy, Frigg and Hartmann (2012) conclude their article "Models in Science" admitting that "despite the fact that [models] have generated considerable interest among philosophers, there remain significant lacunas in our understanding of what models are and of how they work". In practice, however, models are both disbelieved and highly accepted as technical and pedagogical tools to gain knowledge and understand the world around us.

Approaches using models and modelling have been used for a long time in music creation (musical composition/improvisation) and music analysis (music theory) for both - pedagogical and academic - purposes (see Burkholder, 2017), a cross-domain approach (see Zbikowski, 1997, 2002). Since the rise and change of the empiricism paradigm (see Kuhn, 1962/1970; Bhattacherjee, 2012) during the 20th century models and modelling play a major role also in music psychology and cognition research (see Purwins et al., 2008). With the development of powerful computers (since the end of the $20^{\text {th }}$ century) models and modelling are an undoubted part of computational approaches to comprehend music, its perception and creation (see e.g. Giomi \& Ligabue, 1995; Marsden, 1995; Tiits, 1995; Vercoe, 1997; Wang, 2007). In education, particularly in the social sciences and science education, models and modelling have been researched (e.g. Lahti, 2013), as well as developed didactically (e.g. Cartier, Rudolph \& Stewart, 2001; Justi \& Gilbert, 2002; Gilbert, 2010). Here should also be mentioned publications dealing with modelling theory in science in general (e.g. Coll \& Lajium 2011; Börner et al., 2012a, 2012b).

The main goal of this article is to present the Twelve Strategic Steps, which I posed as questions, which I have developed to create/analyse scientific models of 
phenomena or data based on their function and the method of how they work. ${ }^{1}$ The additional goal is to enlarge Justi and Gilbert's (2002) "Model of Modelling" based on the Twelve Strategic Steps including 'input' and 'output' data, as well as cross-domain mapping aspects into their model. The pedagogical purpose of this article is to enable the reader to better understand modelling in science providing a practical tool to enhance this understanding. However, questions also appear concerning when or why an idea, concept, systematic approach, a method or a theory may turn into a model and when or why not. The Twelve Strategic Steps to create/analyse a model attempt to assist to answer these questions.

For a faster overview I have subdivided the Twelve Strategic Steps into eight stages/phases (these terms I have defined as follows: stage - rather spatial term, kind of plateau where something is gained, rather stable state or a kind of 'extended' arrival point; a phase - rather temporal term, something which lasts for a certain time, rather dynamic, developmental process or transition towards a certain stage, taking place in gradual stages, 'carrying out' something (Lock, 2016)):

a) definition of the phenomenon and the problem/aim;

b) prospective outcome (with or without hypothesis);

c) discussing 'input' data and retrieval of this data for the model;

d) ability of these data to model/research the phenomenon or its observer, or both;

e) in which stage/phase of the research process (and why) it is possible/necessary to apply modelling and what type of model makes sense to apply;

f) discussing 'output' data of the model;

g) how to treat these data further;

h) comparison achieved with data from other methods (or models), which opens the approach towards cross-domain understanding.

I hereby claim that modeling itself is already a cross-domain approach (see also Zbikowski, 1997, 2002), because of the use of different kinds of analogies (see Duit, 1991; Coll \& Lajium, 2011), as well as techniques to visualize data and connections between the data and the phenomena.

1 This article is part of my doctoral dissertation in progress forming a theoretical background for the Cognitive Octagonal Slice Model (COSM) developed to analyze contemporary orchestral music using music theory/analysis as well as empirical and cognitive methods - „Tension design. Methodological principles and analytical examples“ (Estonian Academy of Music and Theatre). My acknowledgment for valuable content advice, terminological suggestions and language editing during writing this article goes to my supervisor music theorist, composer and educator prof. dr. Kerri Kotta (EAMT); music theorist, composer and online learning specialist dr. Paul Beaudoin (Brandeis University, USA); my colleague associate prof. of musics didactics dr. Tiina Selke (TLU BFM); the data analyst of Tallinn University School of Digital Technologies Ilkka Kosunen (MSc and PhD candidate at University of Helsinki); and my brother, musicologist, composer and music programming specialist Hans-Gunter Lock (MA, PhD candidate in composition at EAMT), lecturer at EAMT electronic music studio and Head of New Media Lab of the Estonian Academy of Arts (EKA). 


\section{Theoretical background}

A. Music and models between natural environment and dynamical systems, experience and data, existence, and technique

The main object of this theoretical article on models and modelling is music as a temporal, social and cognitive phenomenon being created and perceived through a variety of human sensory organs. It can be understood and studied as natural (ecological) environment (Reybrouck, 2015), and as dynamical system (Burrows, 1997). The first approach leads us to 'music as a phenomenon', therefore to (representational) 'models of phenomena' (phenomenon as "umbrella term covering all relatively stable and general features of the world that are interesting from a scientific point of view" (Frigg \& Hartmann, 2012)). The second approach describes the musical 'piece as a whole' that is "projected from instant to instant throughout the course of a performance by a process of cognitive contextualization" (Burrows, 1997, 530), which takes place in analogy to dynamical systems that are "coherent processes constituted of the interaction of two or more components" (Burrows, 1997, 530). To understand the complexity of such a dynamical system we may use (representational) 'models of data' (see Frigg \& Hartmann, 2012).

As a general definition, I propose that models are a way to express systematic thinking and understanding in science, arts, and education. They are basic tools to be used to interpret implicit and explicit knowledge (see Dienes \& Perner, 1999) gained from experiences, and from implicit and explicit data, to relate them to themselves and among each other, the research object, the social context (to both the individual and the research object) and the natural environment (lifeworld, Lebenswelt). The terms 'explicit data' and 'implicit data' can be found also in the computer science in the meaning of data conversion (see e.g. Byham, Hamilton \& Guyer, 2017) and the distinguishing meaning in marketing (e.g. Bailey, 2017). The TechTarget website provides the following definition: "Implicit data is information that is not provided intentionally but gathered from available data streams, either directly or through analysis of explicit data. Explicit data is information that is provided intentionally, for example through surveys and membership registration forms" (Wigmore, 2017). Implicit data can be retrieved from the context in which explicit data is collected (e.g. as so called metadata in telecommunication or internet traffic). I agree with Hans-Gunter Lock that the generation of implicit data using the context (analyzing explicit data) and statistics works as a model itself.

How problematic knowledge and the understanding of modelling can be in the education field, has been found by Lahti (2013) in a study on cognitive development and students understanding of scientific models, underlining that there is "a large gap existing between students' initial conceptions about models and science and full scientific conception, it may be ambitious to expect students to move completely to an expert conception in a short period of time such as a one-semester class" (Lahti, 2013, 178). As to my knowledge, there is no comparable empirical study yet on the application of scientific modelling in music and music education.

For the creation, as well as the perception and understanding processes and conceptualizing of the environment or a dynamical system (constituting of components on different complexity levels), one uses cognitive models, which are not manifestations in themselves but vehicles to imagine, verbalize, visualize, comprehend and communicate 
ideas or concepts about the world (and music in the case of this article). Mental constructs can be part of these modeling processes (see Justi \& Gilbert, 2002; Gilbert, 2010). Theoretical models can be built either as independent constructs based on logic (see Frigg \& Hartmann, 2012), or they are the basis for musical composition (creation), or music theoretical systems of different musical styles (as detected by musical analysis). The latter means that a theory or a model (no matter which was first) as a product of the activity of the human mind may be the basis for a creation (musical composition) or its understanding (listening, analysis) and interpretation (performance). Purwins et al. (2008) points out that "traditional music theory can be used as a guide, but not as a normative reference that dictates the kind of processes and structures that operate in the mind of the listener" (p. 152). They underline, that traditional music theory searches for universal (and normative) laws of music, but these attempts face limitations in the plurality of styles - style-intern rules of one style may not fit rules in another style. For instance, style specific harmony rules in tonal music do not apply in post-tonal music, even if the basic perceptual mechanisms of simultaneously sounding pitches are the same. This means, we may find (and empirically test the perceiving of), for instance, consonant harmonies in atonal (or other post-tonal) music, but this do not fit to the music theoretical explanation of this style. Further, series (12-tone rows) in Schoenberg's (and others') dodecaphonic music, are almost impossible to perceptually trace correctly (as the composer has used them in the music), empirical tests should reveal rather other aspects of this musical style. According to Cross (1998), music analysis and the psychology of music are "fundamentally incompatible" (p. 4); Cross discusses here also Cook's (1994) criticism of 'theorism', underlining that "an a priori reliance on music-theoretic concepts as constituting or corresponding directly to cognitive categories and concepts [...] maybe levelled at specific studies of music cognition, it is not a charge that can be levelled against all studies of music cognition denatura" (Cross, 1998, 4). Cross calls this understanding of an 'analytical idea' of perception in music analysis also 'folk psychology' referring here to Brunner (1990): “... a set of more-or-less normative descriptions about how human beings 'tick', what our own and other minds are like" (p. 35). "The act of perception is subject to purposive volitional intervention, and categories of experience - qualia - may in the light of the analyst's enquiries be consciously shaped and re-made (for the analyst, at least)" (Cross, 1998, 4-5).

Because a performed (sounding) musical composition becomes part of our life world (natural environment), even constituting a sounding environment itself or is understood as dynamical system, providing information (experiences turned into knowledge) through perception, a general epistemological question in science/philosophy and the arts (appearing also in education) can be posed: „Which comes first in knowledge, the mind or the world, and what is their relative significance?" (Varto, 2009, 8). What follows are, according to Varto (2009: 11), two extremes: existence and technique (or, in the view of Varto, the ontic and the epistemological). Varto claims that ,it is the technique that makes the ontic ontological: provides an event with order from some selected point of view" (Varto, 2009, 11).

This epistemological question appears also in the different understandings of music: either as natural environment - the focus is on its existence (including its function), or as dynamical system - the focus is on the technique (including the method of how it works). It is mirrored in Cartier, Rudolph and Stewart's (2001) discussion of the explanatory roll of scientific models. They point out that "models are constituted by 
empirical or theoretical objects and the processes in which they participate" and "models are consistently assessed on the basis of empirical and conceptual criteria" (pp. 4-6).

This is visualized in their figure 3 (Cartier, Rudolph \& Stewart, 2001, 6), which I have redrawn and extended based on their claims here in Figure 1. The authors specify the arrows of their scheme as follows: Generally, explanatory models are assessed based upon whether they can (1) explain patterns in data; (2) correctly predict the results of new experiments or observations; and (3) are consistent with other ideas (models, beliefs, and metaphysical commitments).

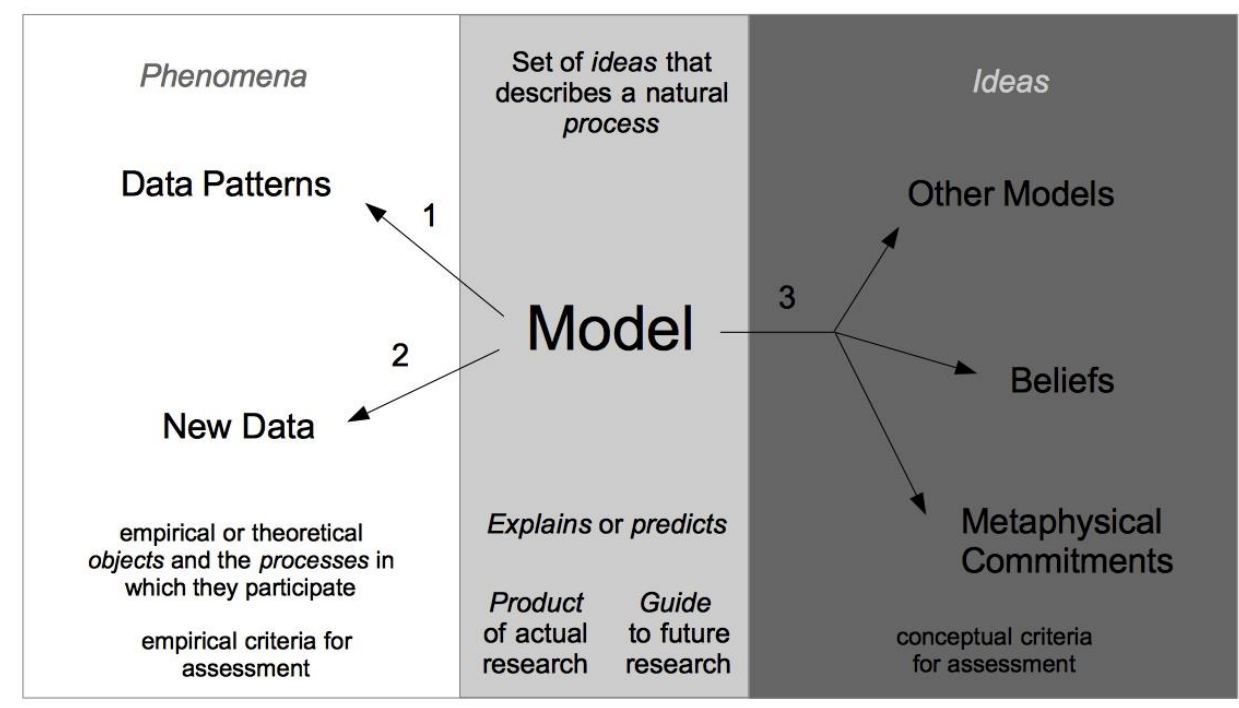

Figure 1. The nature, structure and assessment of explanatory models

To summarize my previous points, I suggest that music can be seen twofold: As empirical object - treated as natural environment, based on its existence how it is experienced and what is its function - Varto's "world-first" view; or as a theoretical object - treated as dynamical system, based on the technique and the method how it is created and/or perceived/cognized/understood - Varto's "mind first" view. But, according to Varto $(2009,8-9)$, both assumptions remain problematic: the "world first" supposition causes the question Why is so much fallacy and fantasy in the world? The "mind first" supposition poses the question How does the mind come about, and how can it be valid in the world and create intersubjective science? But, in both cases - especially expressed in modelling - the processes in which the music, the music maker, the listener and the analyst/model user or creator are involved, are crucial.

\section{B. Functions and methods of scientific models}

Coll and Lajium (2011) point out that models have a key role in scientific enquiry offering four distinct functions (aims, purposes): discovery, development, evaluation and exposition. Discovery means the formation/generation of new knowledge or the formulation of a hypothesis - using the model to further develop a hypothesis or discovery - either theoretical or experimental. A model also needs to be tested to evaluate a hypothesis (pro or con). Exposition means to explain hypotheses or theories through a model. Coll and Lajium (2011) describe that models based on analogies are useful in concept generation, a "personal mental process", "a vital stage of a scientists" 
thinking", "mapping of attributes from the known to the unknown", as well as "generative models are dynamic tools rather than static representations used for understanding" "individuals seek to find ways of making it easier to explain observed phenomena and so develop their own models to advance their understanding" (pp. 8-9).

For this article, I have developed a multi-dimensional scheme of modelling and models in music incorporating chosen types of models from music theory (analysis) and music psychology (perception and cognition) including also the creative approach (musical composition/improvisation) as well as the educational functionality (at different school levels), and the way(s) in which each of these types in dependence on the purpose of the model is used or developed for and with learners. These models deal with the phenomena of music and sound (their understanding and perception/cognition) directly, not with sociological opinions, beliefs or paradigms about music and sound. However, models in (developmental) psychology, sociology, identity, personality, motivation, creativity etc. may also fall into the function and method categories introduced below, but their structure, purpose and way of application may differ.

Before I show and explain my multi-dimensional scheme in Figure 2 (see below), I would like to present the basic categories' terms the scheme is developed with. The first category (vertical axis in Figure 2) labels the function (aim, purpose) (I-V) - what a model does: predicting, explaining, exploring, creating, giving strategies. The second category (horizontal axis in Figure 2) defines the method (a-e) models in music creation, analysis and perception/cognition are using to express the function defined before and showing, how and on what level of abstraction the model works. The function category can be generalized as expressing the existence (ontic) aspect, the second category shows the technique (epistemological aspect) which makes the ontic ontological (see Varto, 2009).

The function (aim, purpose) category includes the following types of models: I prediction/expectation models and II - explanation models, e.g. models on phenomena like musical and tonal tension, and expectation in music (e.g. Margulis, 2005; Huron, 2007; Lerdahl \& Krumhansl, 2007; Farbood, 2012).

Type I and II include also computational models of music perception and cognition: auditory expectation in information dynamics of music, Computational Auditory Scene Analysis (CASA) (see Wang, 2007), computational classification, search and retrieval of audio or content-based retrieval of music and audio. Such models try to understand well known phenomena or music (cognition) in general using cognitive, empirical, mathematical, and computational tools. III - exploratory models (including cognitive models, mental models, analogy models, metaphorical models) try to understand not yet formalized phenomena or phenomena from a yet unexplored angle. IV - models in composition/analysis of music (see more in Burkholder, 2017) can be separated into sub-categories IVa (composition) and IVb (analysis). V - teaching/learning models (e.g. strategies (developmental) psychology, sociology, identity, personality, motivation, creativity; individual vs group teaching and learning; e- and online learning) can be divided into $\mathrm{Va}$ (teaching) and $\mathrm{Vb}$ (learning) models.

The method category shows the modeling technique: a) mathematical models (statistics, algorithms, equations, also graphically expressed, including computation), b) representation models (including computational models, also cross-domain models, 
also graphically expressed), c) cognitive models (including analogy, cross-domain, and rule-based models, computational models, graphical models), d) theoretical models (including rule-based models, graphical models), e) conceptual models (including symbolic and iconic models, graphical models).

The following multi-dimensional scheme of modeling and models in music (Figure 2) considers also creativity aspects as well as how much the field of meaning of the phenomenon (to be observed and represented) and that of the model are in concordance. These aspects are explained below the figure. This rather generalizing overview can be understood as a ground plane scheme (viewer perspective from above), which means that both $\mathrm{x}$ and $\mathrm{y}$ axis are located on the horizontal plane, the dashed diagonal axes may then go even diagonally upwards to turn this scheme mentally into a 3D scheme.

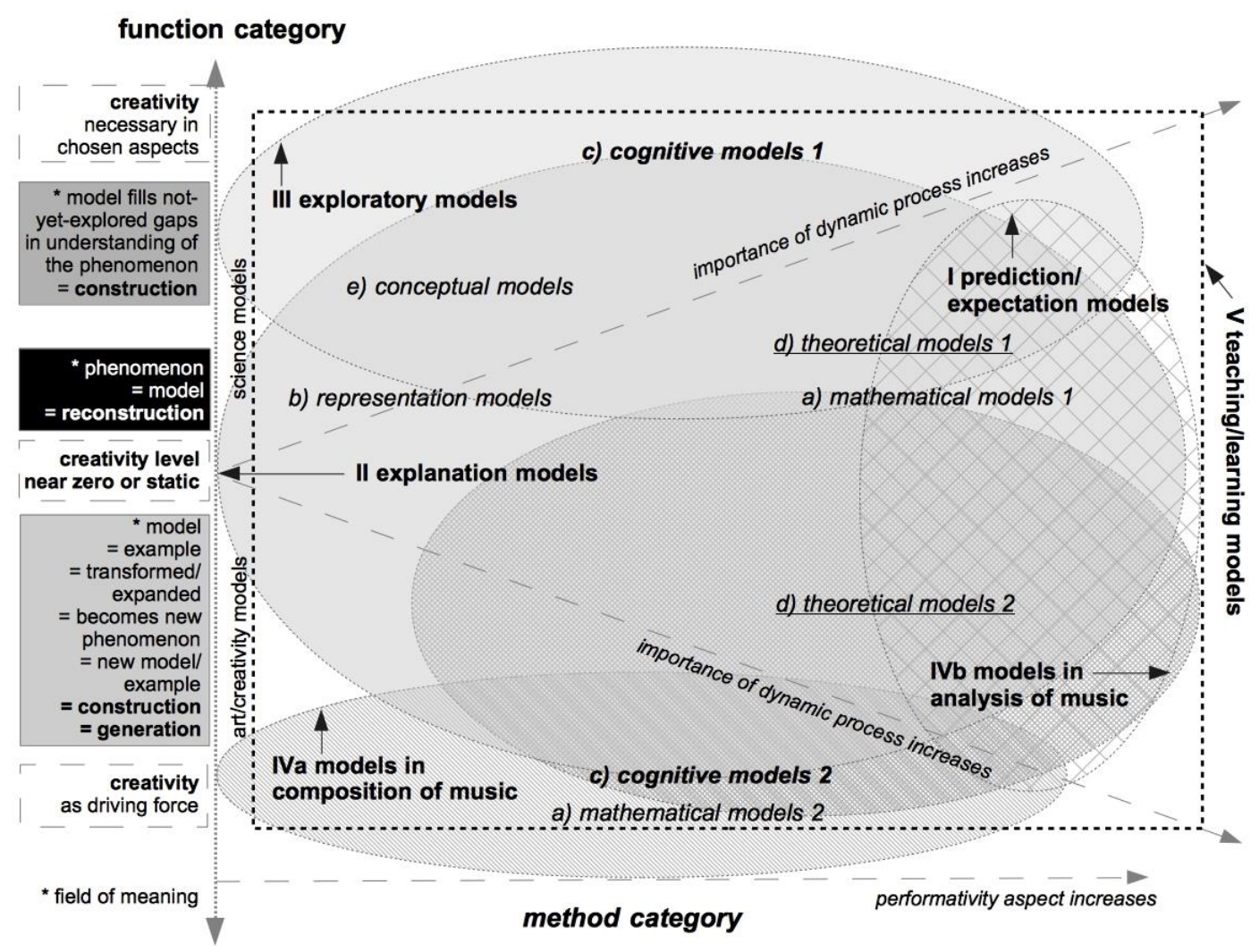

Figure 2. Multi-dimensional scheme of modelling and models incorporating models from music theory (analysis) and music psychology (perception and cognition) including the creative approach (musical composition/improvisation)

To understand Figure 2, one should start on the vertical axis' (left side) central point "creativity level near zero or static" which means that such types of models do not convey much creativity (of course, they may have been created also using creative thinking, but they don't express or perform creativity as such), they either represent or explain something (a phenomenon, source) directly, the analogy between the phenomenon and the model is high. From this central point, models develop in two directions: upwards one will find rather science models, downwards rather art/creativity models. In science models, creativity is necessary in chosen aspects 
(especially in exploratory models), in art/creativity models like composition (and improvisation) of music creativity is the driving force both in the generation and the use of models. On the left side of the scheme also field-of-meaning aspects of models are shown: in science models the model may either be in analogy with the phenomenon (means reconstruction) or, in exploratory models, not-yet-explored gaps in understanding of the phenomenon are filled (means construction) and need to be verified with experiments. In art/creativity models, the model becomes the example for similar achievements which is transformed and expanded, it becomes a new phenomenon, as such it can become a new model and example etc. (means construction and generation at the same time). The dashed diagonally axes express that the importance of the dynamic process (changing in time) included into the function and method of the models increases. This is in accordance with the dashed horizontal axis that shows the increase of the performativity aspect making models work only in the act of performance in real-time. Both express that models on the left side of the scheme use rather static principles (representing just one single state or situation), models on the right side of the scheme apply more dynamic principles (representing more than one single state, including the flow and development analyzed retrospectively as well as showing their prediction and expectation).

For each of the function category models (with roman numbers I-V) a 'bubble' like shape symbolizes the field of influence they approximately may embrace, and, more important here, how much their fields/bubbles overlap with each other. The 'bubble' of the II explanation models (grey area) is located most centrally and shows the largest extend, most of the models, indeed, explain something. The "bubble" of the III exploratory models (light grey area) is somehow narrower but overlaps to a large amount with that of the explanation models. They, too, explain phenomena, but their real aim is to deal with modeling something not-yet-explored. The 'bubble' of the IVa models in composition of music (tightly hatched diagonally from-left-to-right area), located below the explanation models' 'bubble', is smaller and overlaps both with the explanation models' and the IVb models in analysis of music (tightly cross-hatched area) 'bubble', located rather in the middle of the scheme, showing overlapping with all other model types' 'bubbles'. The I prediction/expectation models' (loosely crossed area) 'bubble' is located on the right side of the scheme, it shows overlapping with most of the other model types 'bubbles', showing the littlest amount with the IVa models in composition of music, because (not mentioning pieces written in a certain style/style copy pieces) creative contemporary musical composing plays with violating rules, models and expectations. I prediction/expectation models, in turn, show developments according to a clear predictability - of course they may show different possibilities and become performed dynamic models. IVb models in analysis of music, on the other hand, may or may not depart from composition models, they explain something already created as well as deal with predictions and expectations. The dotted square framing the scheme symbolizes that most of the previously introduced types of models can be used as V teaching/learning models.

The method category types of modeling (a-e) are put at those places in the scheme where they are most expected (however, different types of function category models use different methods in the same time) or where they can be localized in cross areas between different function types. In addition, c) cognitive models and d) theoretical models are positioned separately in the scheme, because their theoretical background differs: cognitive models 1 include music psychological cognitive approaches, cognitive 
models 2 include approaches in music theory/analysis (and composition) realms, e.g. treated as individual and folk psychology (see Cross, 1998). Theoretical models 1 are often mathematical or computational approaches. Theoretical models 2 refer to methods used in music theory/analysis which are based on musical scales, intervals, chords and voice leading principles and theories. Sometimes they use also mathematical means, see the position of a) mathematical models 1 , in the cross section between I, II, III and IVb. Also in the IVa models in composition of music 'bubble' a) mathematical models 2 can be found, using different computational algorithmic and synthesis type of methods. The e) conceptional models are put in this scheme near the exploratory models, but as cross domain mental models they can be the starting point of several other types of models, too. The b) representation model is mostly a method used for explanation models and exploratory models, using also mathematical and theoretical means.

\section{Constraints of scientific models}

In this context it is necessary to point out two kinds of constraints scientific models can show (after Frigg \& Hartmann, 2012): (1) 'Aristotelian idealization' through reduction (a kind of imaginary 'stripping away') of aspects and features (properties) not necessarily important to the problem observed in order to concentrate on only those chosen and isolated properties (also called 'abstraction'). This means, in my opinion, pruning the object of observation. This kind of idealization can be found also in models of musical composition. Also, we should consider a constraint called (2) 'Galilean idealization' involving deliberate distortions, because in reality, there are no idealized situations (ideal limits), a distorted (or even false model) can offer useful information for improvements of both the model and the understanding of the object of observation (and the research method). It was characteristic of Galileo's approach to science to use simplifications of this sort whenever a situation was too complicated to tackle (Frigg \& Hartmann, 2012). This means, in my opinion, pruning the structures and relations between objects of observation in order to focus on specific aspects or achieve greater generalization. This kind of idealization can be found also in models of music analysis the most common example for this in traditional music theory is the reduction of the music under observation to its primary parameters, pitch and rhythm, excluding secondary, but (especially perceptually and emotionally) also influential parameters like dynamics (loudness), articulation, or even instrumentation (timbre) etc.

Simplifications and distortions are useful both in science and (science) education, but these can become problematic - in education the question appears who (the teacher, the curriculum, political agenda) decides how and for what (pedagogical, developmental) reason which parts are simplified and distorted. In science it depends on the purpose of the research and the ability and sensitivity as well as the knowledge and experience of the researcher.

\section{Models vs theory}

A distinction between models and theory is complicated and can depend on the attitude towards science. One may say that this is 'just a model' or already awarded as 'theory' (Frigg \& Hartmann, 2012) or vice versa as I think: a theory can have a pejorative meaning (because it may be speculative, incomplete, too complex), but a model (as both an example and consistent part of science) may be regarded as more valid than a theory. Frigg and Hartmann (2012) propose two extremes: a syntactic (logical positivistic) and 
a semantic view of theories (a theory is a family of models, models are seen as central units of scientific theorizing (see also Zbikowski, 1997)). They additionally point out that models can be independent of theories as 'autonomous agents' using two aspects: construction and functioning. Models can complement theories or so to speak stepping in when theories are too complex to handle (Frigg \& Hartmann, 2012), or they can function as preliminary theories, or even as 'study models' or 'toy models' (without representational function, giving information just about itself, to test theoretical tools for later building of representational models).

Zbikowski (1997) explains that conceptual models are based on image schemata (which are not necessarily visual but mental images), specialized to a specific domain, but "not in the cognitive processes that it involves" (Zbikowski, 1997, 195). Conceptual models work also in cross-domain mappings: "The conceptual models fundamental to theories of music are most typically borrowed from concrete domains and brought to bear on the domain of music through the process of cross-domain mapping. This process relies on establishing correspondences between the image-schematic structure of the source domain and the image-schematic structure of the target domain. Each such mapping will preserve only a portion of the structure of the target domain, and import only as much of the structure of the source domain as is appropriate" (Zbikowski, 1997, 217).

According to Bhattacherjee (2012), in social science there are (among others like mathematical, network, path models) normative models used "to guide our activities along commonly accepted norms or practices" (p. 14). The author further divides models into static (represent the situation of a system at a chosen time point) and dynamic models (represent an evolution of a system over a certain time). An important aspect in models and modeling is the trajectory - deductive $v s$ inductive - it is developed or unfolds, the first starting from theory (theoretical or logical reasons and an initial set of premises), the second from facts and observed (empirical) evidence (Bhattacherjee, 2012).

Lahti (2013) proposes four subdivisions explaining how students relate to scientific theory and modeling: a) student's understanding of theories (through analogy with models), b) the tentative nature of these theories (revision and modification), with possible c) understanding of the role of creativity in science (which variables to include), or d) the scientific method (construction of models, although not a typical experiment, is an appropriate scientific method of investigation, particularly for phenomena that may not be observed directly).

Schwarz et al. (2009) from the MoDeLS (Modeling Designs for Learning Science) project define scientific modeling as "including the elements of the practice (constructing, using, evaluating and revising scientific models) and the meta-knowledge that guides and motivates the practice (e.g., understanding the nature and purpose of models)" (p. 632). Their learning progression for scientific modelling includes two dimensions that combine meta-knowledge and elements of practice - scientific models as tools for predicting and explaining, and models change as understanding improves.

\section{E. Computational and cognitive models in music}

The computational understanding of modelling is based on the ability to express phenomena, processes (assumptions and consequences) that can be formulated in algorithms and computational representations, also in the neurological domain. In 1997, 
Vercoe (1997) was convinced that "acoustic input can be the stimulus for computational models of an entire range of processes involved in the perception and cognition of music" ( $\mathrm{p}$. 325). He continues that the goal should be "to find how complex musical data is represented and processed by the human auditory-cognitive system. Only then will we understand why music that exploits this capacity has the structure it does" (p. 325).

Earlier, Marsden (1995) revealed technical problems arising from computer modeling (which are still relevant also today) while categorizing the use of computers as tools in research as follows: (1) computers require strictly formal representations of theory; (2) they make possible the testing of theory through the implementation of models embodying that theory. He explains what has been so far (even today) the main approach: "A computer program or sets of programs is written embodying some music theory, incurring developments in codification and (hopefully) clarification, because of (1) above; then the output of this program is tested by some criterion, e.g. comparison with human musical products, following (2) above, and, on the basis of any deficiencies, further developments of theory are proposed which can be codified and tested in anew cycle and so on" (Marsden, 1995, 335).

Purwins et al. (2008) ask What is a valuable cognitive model using computational implementation based on findings from several disciplines like neuroscience, psychology, cognitive science, artificial intelligence, and musicology? (p. 154). They summarize the so far known methodology as "localization of musical processes in the brain, and the flow of cognitive operations involved in turning physical signals into musical symbols, going from the transducers to the memory systems of the brain" (Purwins et al., 2008,151), They point out four aspects: a) predictive power, b) generalizing power, c) simplicity, and d) relation to existing theories. Also, they underline that the predicted outcome of the model should be later tested in experiments and without the model this kind of outcome would be unexpected. Furthermore, a model should explain data (from experimental results) "that have not been taken into consideration in building the model" (Purwins et al., 2008, 154). Importantly, referring to the fourth aspect (relation to existing theories), a model may have the ability to unify existing theories: "This may help understanding a phenomenon instead of just reproducing input-output relation inherent in the data" (p. 154). Purwins et al. (2008) underline that "assumptions and consequences must be clearly defined and distinguished" (p. 154). Their questions and claims have inspired me in the first place to develop my own twelve steps of a modelling approach.

\section{Main contribution}

\section{A. Twelve Strategic Steps for modelling/analysis of models}

In this section, I introduce my Twelve Strategic Steps (posed as questions) developed as a guide to create/analyze models in science (see Figure 3 below). The steps appear as one or more questions and sub-questions in eight developing stages/phases:
A) Initial situation (problem) stage,
B) Prospective outcome (hypothesis) stage,
C) Data developing stage 1 ,
D) Object of the model/research in relation to the data,
E) Model(ing) application phase,
F) Data developing stage 2, 
G) Data analysis phase,

H) Data comparison phase (cross-domain mappings).

The questions presented in Figure 3 inquire necessary aspects of some of these "selected point [s] of view" proposed by Varto $(2009,11)$ in relation to the 'event with order' (making the ontic ontological by the technique). The event is the phenomenon observed/represented by the model (e.g. music), the order is the chosen method of approach to the phenomenon with the help of the model (technique). These stages and phases should not be worked through linearly. They should be used in a rather spiraltype of modelling process. Answers to these questions may require their testing (including refinements and modifications) as well as going back and forth between necessary questions, steps, stages and phases depending on their answers and resulting in next follow-up steps. My steps and questions have been partly inspired also by Purwins et al. (2008) four basic questions and other requirements for building cognitive models on the following way: to a lesser amount its predictive power, to a greater amount its generalizing power, to a great amount its simplicity, and, as a basic requirement, its relation to existing theories (if possible, unifying of several theories) as well as experimental testing of its 'input' and 'output' data.

Initial situation (problem) stage

Q 1. What kind of phenomenon one observes/investigates/explores?

A See typologies of models.

Q 2. What is the problem/aim to be researched/explored?

Prospective outcome (hypothesis) stage

Q 3. What may be the postulated outcome to be reached?

B Q 3a. What kind of theory/theories relate/s to/explains the phenomenon/problem/aim?

$Q 3 b$. Is a hypothesis necessary?

Quantitative approach: yes

Qualitative approach/Artist research: no

Data developing phase 1 - "input" data for the model (IDV - independent variables)

Q 4. What kind of data does the phenomenon provides?

C Q 5. How to retrieve/record appropriate data, portions of data (e.g. feature analysis)?

$Q 5 a$. Is computation of data retrieval possible?

Q6. To what requirements need the data be restricted, portioned, segmented?

Object of the model/research in relation to the data

Q7. Does the data enable to model/research the phenomenon or its observer, or both?

Model(ing) application phase

E Q. In which stage of the research process (and why) is it possible/necessary to apply modeling?

Q 9. What type (function/method) of model makes sense to apply?

See typologies of models.

Data developing phase 2 - "output" data of the model (DV - dependent variables)

$Q 10$. What kind of data are the output of this model?

F $Q 10 a$. Does it represent the phenomenon well?

$Q$ 10b. How generalizable are the results?

Data analysis phase

Q 11. What is the concrete aim of the "output" data?

G Q 11a. How to treat (deduce, reduce, transpose, analyze) this "output" data further? Q 11b. How to use computational tools for data analysis?

Data comparison phase (cross-domain mappings)

H Q 12. How able are the data to be compared with output from other research methods applied on the same phenomenon?

Q 12a. How to use computational tools for data comparison?

Figure 3. Twelve Strategic Steps (grouped in eight stages/phases) for modelling/analysis of models 
Answers to these questions will lead to a versatile network of information that opens up a growing understanding of the phenomenon the model aims to describe the theory (theories) and scientific paradigm(s) behind the phenomenon, its research field and the model applied or to be developed. Several aspects will be needed to be answered in more than one questions recurrently, but from different perspectives. These mirror the selected points of view and give a multi-faceted insight into the model's function and/or the modelling process. As a useful pedagogical aspect, it may happen that one must correct or change opinions, understandings, functions or the method during the process of modelling or analysis of a model.

After having developed a model using these Twelve Strategic Steps it needs to be tested technically (if it has a computational realization), this also may reveal additional problems or aspects connected with its development, requiring maybe modifications (see also in Justi and Gilbert's "Model of Modelling"). If the model works technically well, the next phase is its real application (empirical tests) and the interpretation of the data as well as drawing conclusion in relation to the phenomenon observed or how it explains the mental construction the model represents. If the model goes too far from the observed phenomenon or revolves only around the data retrieved and computationally further developed it should be critically questioned and if needed revised and modified again.

\section{B. Justi and Gilbert's enlarged "Model of Modelling"}

Although Justi and Gilbert's (2002) "Model of Modelling" includes on the mental and the empirical level (of the research design) the requirement of tests/experiments, they say nothing about the method, how to do this, they do not go into the data topic (explicit vs implicit, 'input' vs 'output' data). Therefore, I have re-visualized and enlarged their "Model of Modelling" in Figure 4. Interestingly, and different from the distinctive definition shown in the beginning of this article, the authors integrate mental modelling (thought experiments) with the empirical testing requirement, the representation stage of their modelling is located between these both phases. Their first step is to decide on the purpose for a model (1). The second step is selecting the source for the model (2a) and including own experiences (2b). The third step is to produce a mental model (3), the forth step to express this mental model in different forms of representations (4). The fifth step is to conduct thought experiments (5) including modifying in case of fails $(5 x)$, the sixth step is to design and perform empirical tests (6) including modifying in case of fails (5x). The fifth and sixth steps may also lead (in case of extreme fails) into rejecting the mental model (6x). If the mode of representation of step four needs data development (a step added by me), one can proceed to (4a). If this results in a certain mode (visualization, verbalization, equation) (6b) which satisfies the modeler, then the purpose of modelling is already fulfilled (6z). Also step six (6) may involve data development (6a) (added by me). In case of successful passing all previous steps, the model has fulfilled its purpose (6z). As a last seventh step, one should consider the scope and limitation of the model (7). I have added step eight, the concept of crossdomain mapping (8) which opens interdisciplinary possibilities to decide on a next purpose (1) to continue the modeling process on a next level. These steps don't include more specific aspects like structure of the source, no mentioning of the target or type of data and originally no data development aspects. The steps are enlarged with an additional data development step (4a) and (6a) as well as step eight cross-domain 
mappings (8), which opens interdisciplinary possibilities to continue the modelling process on a next level (see Figure 4).

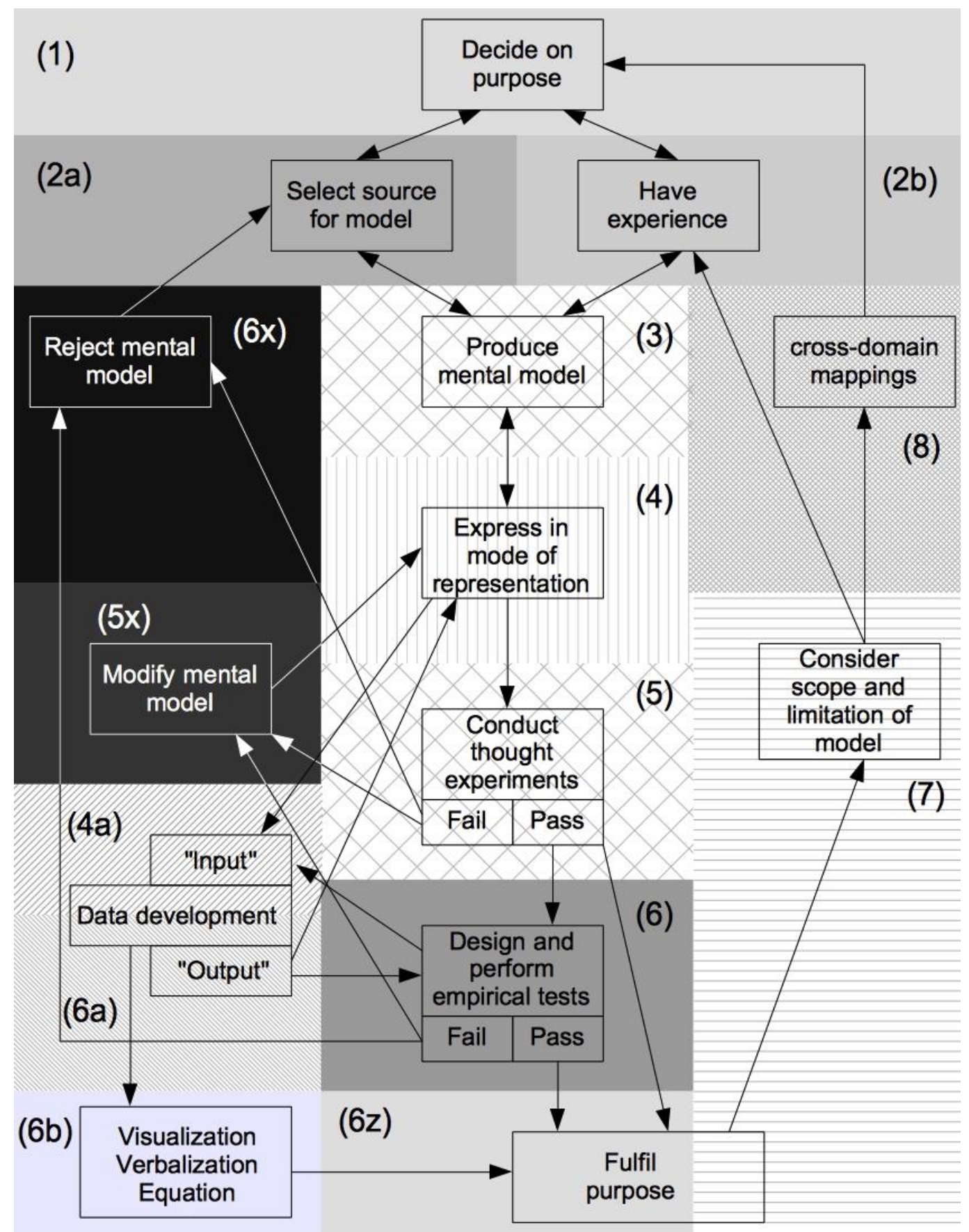

Figure 4. Enlargement of Justi and Gilbert's (2002), Gilbert's (2010) "Model of Modelling" by G. Lock

C. Comparison of Justi and Gilbert's "Model of Modelling" and the Twelve Strategic Steps

Justi and Gilbert's (2002) "Model of Modelling" step (1) (decide on purpose) can be compared with stage/phase A (initial situation) and B (prospective outcome) of my Twelve Strategic Steps. Step (2a) (select source for model) is connected to A and E 
(modeling application phase). Step (2b) (have experience) means the experience with A (the phenomenon one observes/ investigates/ explores) and one comes back after the modelling process including step 7 (consider scope and limitation of the model) which means to having gone through all stages/phases from A to G. Step (3) (produce mental model) is not directly addressed in my strategic steps as separate stage/phase, but it can be part of B (prospective outcome, if mentally run). Step (4) (express in mode of representation) means to visualize step (3) which I have separated info C and F (data development stage 2, data may become an own 'reality'). Having enlarged Justi and Gilbert with a step (4a) the aspect of data, which allows representation, is brought in. Step (5) (conduct thought experiments) also does not have a direct equivalent in my steps, because I operate from beginning on with 'input' and 'output' data which enables also mental aspects to be graspable and visualize-able $(6 a, 6 b)$ before they can be empirically tested (6). If either the visualization/verbalization/equation derived from steps (3) and (4) or the empirical tests (6) are successful, then the model can be treated as ready (6z) (fulfills purpose), but these steps are in my approach part of other stages/phases during data development ( $\mathrm{C}$ and F) and data analysis phases (G). Stage/phase H (data comparison/cross-domain mappings) is somehow separated in my approach, I have added it also to Justi and Gilbert's scheme as step (8) (cross-domain mappings) in order to lifting their scheme to a next level of developing a possible new model.

Both approaches are in some aspects, close to each other dealing with purpose, source, experience, experiments, but they are not identical. Justi and Gilbert's (2002) approach can, indeed, be called a "Model of Modelling" because in its enlarged version it fulfills most of the theoretical implications I propose below in the implication section (of course, theory is not mentioned, but it could be found in the mental model production step), and it forms a whole: from the starting point through modelling steps back to the same starting point (on a next level). In contrast, I underline that my Twelve Strategic Steps establish not a model, they remain a kind of algorithm to follow, steps from one starting point (initial situation) through different stages/phases until 'output' data analysis (G). Their aim is to develop a basis to compare its outcome with other methods (models). Also, my Twelve Strategic Steps enable the analysis of existing models, their questions can trigger answers concerning when or why an idea, concept, systematic approach, a method or a theory may turn into a model (see also conclusion below). Both approaches should be applied in parallel considering the purpose of the modelling aim and necessity during the research process.

\section{Implications}

The implications drawn from the developing of the Twelve Strategic Steps for modelling/analysis of models are the following: a scientific model should be built based on a theory or multiple theories even if the relation between models and theory is 'perplexing' (Frigg \& Hartmann, 2012). Models can be also the basis for theories (for general science see Frigg \& Hartmann, 2012, for conceptual models and cross-domain mappings in the music field see Zbikowski, 1997, 2002), but in this article, I favor the theory-first approach, because an unexplainable or non-theory-grounded approach goes against the pedagogical purpose of this article. Further, a scientific model must be tested against the phenomenon or theoretical/mental construct it represents, the elements of a model must be always consistent and not functionally empty (providing 
justified answers to why-questions). A theory, in contrast, may remain incomplete (Frigg \& Hartmann, 2012). Scientific models, like creative outputs and comprehensions, derive from explicit and implicit knowledge of the modelling person which is gained either intuitively, systematically, system-based or automatically (see Lock, 2006, 2014), "models are vehicles for learning about the world" (Frigg \& Hartmann, 2012). A scientific model should gather and synthesize rather well-known, proven or justified elements (see theory requirement in the first implication). The innovations of new models lie often in the surprising way these elements are combined, one can also learn about the model through experiments, thought experiments and simulation (Frigg \& Hartmann, 2012). To achieve testability of a scientific model, it itself (and its representation) should operate with explicit or implicit data, which can be expressed as numbers and even computer algorithms to a) enable greater validity and generalizability, b) be applicable in further comparative research (including cross-domain mappings). These data may appear in numerical form (explicit) or may be hidden behind narrative or visual (or nonverbal), rather ambiguous, forms of expression, but it is still existent implicitly as basis for the models' shape, technique and method as both 'input' data (data gained from the phenomenon under observation or the theoretical/mental construct) and 'output' data (data derived from the model itself). To test a theoretical/mental model or a model built and analyzed based on 'non-explicit' (hidden) data, its implicit data need to be made accessible: turned into a logical structure that can be expressed in numerical data. To be clear: the approach I present does not treat commonly called 'data models' in the meaning of mathematical equations or algorithmic procedures, also not 'data models' derived from empirical research using standard procedures of descriptive statistics etc. It therefore does not restrict modelling to an abstract quantitative 'game with numbers' and should not detach it form the phenomenon under observation.

As I showed in the theoretical background section, music can be understood and studied both as (open) natural environment in the sense of world/reality or as dynamical system treated as (closed) theoretical system. But, music evolves only through creation (either technically via composing/performance or mentally interpreting sounds as music), to conceptualize (understand) sounds as music, one uses different kinds of models (either being aware of them or not). Hence, the perception/cognition process is explainable for human beings also through different kinds of models, which are not the phenomenon itself but a vehicle to verbalize, visualize, comprehend and communicate it as idea and concept of a 'real-world reality'. Models therefore, based on Varto's (2009) philosophical background, offer a systematic, visualized and reasonably simplified 'selected point of view' to an 'event' the observer has given an 'order'. The intriguing question concerning knowledge gaining - 'mind first' or 'world first' (Varto 2009) - should be answered as an intertwining dependence of both from each other.

A model, which is theory and data-based, but does not exclude the world in which the phenomenon exists, can have the ability to enhance the awareness, conceptualization, and simplify this intertwining dependence between the world and the mind as well as the existence and the technique having concrete functions (aims, purposes) and using reasonable methods in this model. In other words, the successful functioning of a model depends on the proper method it uses. I also agree with the even more concluding twofold-categorization of models and modelling proposed by Hans-Gunter Lock which merges function and method: 1) analytical or descriptive models - describe a 
phenomenon of the world; 2) generative models - allow to generate new understanding (explanations) of a phenomenon of the world: a) compare the new explanation with the phenomenon itself (e.g. Chomsky's Generative Grammar, String Theory in physics, b) apply generative models in creative activities (counterpoint rules, algorithmic composition, etc.).

\section{Conclusions}

1. To summarize, it makes sense to develop and apply a model under the following conditions and concluding the basic implications proposed in this article:

a) A scientific model needs to have one or more accepted/proven theories as backbone(s);

b) The phenomenon observed/modeled must be able to be interpreted, translated and expressed into explicit or implicit 'input' data, the latter should be able to be made explicit, turned into numbers; the explicit 'output' data must be analyzed and interpreted reasonably and simply without losing touch with the phenomenon to be modeled;

c) The model must be consistent, a whole in itself. Gaps or inconsistencies must be minimized or turned off (eliminated);

d) As an exploratory or new model, it should explain something generally known, but not yet explained in a similar systematic way from the same angle, from a new viewpoint based on accepted/proven theories, but offering also new or even unexpected aspects using e.g. cross-domain mapping approaches between different fields.

2. Answers to the questions concerning when or why an idea, concept, systematic approach, a method or a theory may turn into a model can be found in my Twelve Strategic Steps introduced above. The A "Initial situation (problem) stage", Q1 inquiring the kind of the phenomenon to be observed/investigated/explored requires in parallel to become familiar with already known typologies of models, Q2 asks about the problem/aim to be researched. The B "Prospective outcome (hypothesis) stage" Q3a reveals what kind of theories can be found behind the phenomenon to be observed/researched. The C "Data developing stage 1" Q4 on the kind of "input" data the phenomenon provides as well as Q5 and Q5a on retrieval/recording and computation possibility reveal explanations towards the applicability of a data-based model. In D "Object of the model/research in relation to the data" Q7 gives insight whom the data actually represents, the phenomenon and/or the observer. The question of whom to model/research seems to be late here and may be taken into account already in earlier stages (A and B). But in my opinion one should first do some kind of data development ('input' data) to understand better what this data may model (an early and to strict determination may lock up/limit the further development of the model as well as the understanding of the phenomenon to be modeled. The answers in E "Model(ing) application phase" to Q8 (In which stage of the research process (and why) is it possible/necessary to apply modeling?) and Q9 (What type (function/method) of model makes sense to apply?) are the most direct questions to detect the usefulness of developing/applying a model. Also the $\mathrm{F}$ "Data developing stage 2" enables to find answers to the quality and independence of the "output" data, which with Q10a (Does it represent the 
phenomenon well?) Further the G "Data analysis phase" with Q11 (What is the concrete aim of the "output" data?) and Q11a on "output" data treatment and analysis possibilities gives hints together with the final $\mathrm{H}$ "Data comparison phase (cross-domain mappings)" Q12 towards detection of the reasonableness of developing an idea, concept, systematic approach, a method or a theory into a model.

3. In short, modelling in science is fruitful, if an idea can become explained with a concept, which can be approached systematically, further developed as a method, includes connections/backups to one or more theories, and is consistent (a whole), either representing or exploring a known (but less systematically explained) phenomenon based on its explicit and implicit knowledge and data including cross-domain mappings.

I hope that my Twelve Strategic Steps for creation/analysis of models and the enlarged Justi and Gilbert "Models of Modelling" will enhance the understanding of modelling and will assist creating models in sciences in the field of music and music education.

\section{References}

Bailey, M. (2017). Implicit \& Explicit Data. MarketMotive (simplilearn). Retrieved 07.10.2017 from http://www.marketmotive.com/training/home/tutorials/email-techniques/implicitexplicit-data

Bhattacherjee, A. (2012). Social Science Research: Principles, methods, and practices. Tampa (USA): University of South Florida. Retrieved 07.07.2017 from http://scholarcommons.usf.edu/oa_textbooks/3

Börner, K., Boyack, K. W., Milojević, S. \& Morris, S. (2012a). An introduction to modeling science: Basic model types, key definitions, and a general framework for the comparison of process models. In A. Scharnhorst, K. Börner, \& P. van den Besselaar (Eds.), Models of Science Dynamics Encounters Between Complexity Theory and Information Sciences. Retrieved 07.10.2017 from http://cns.iu.edu/images/pub/2012-borner-modsci-springer.pdf

Börner, K., Boyack, K. W., Milojević, S. \& Morris, S. (2012b). An introduction to modeling science: Basic model types, key definitions, and a general framework for the comparison of process models. In A. Scharnhorst, K. Börner, \& P. van den Besselaar (Eds.), Models of Science Dynamics Encounters Between Complexity Theory and Information Sciences (pp. 3-22). Berlin, Heidelberg: Springer.

Bruner, J. (1990). Acts of Meaning. London: Harvard University Press.

Burkholder, J. P. (2017). Modelling. In Oxford Music Online/Grove Music Online. Retrieved 07.07.2017 from http://www.oxfordmusiconline.com.ezproxy.tlu.ee/subscriber/article/grove/music/53082

Burrows, D. (1997). A dynamical systems perspective on music. The Journal of Musicology, 15(4), 529-545.

Byham, R., Hamilton, B. \& Guyer, C. (2017). Data type conversion (Database Engine). Microsoft Docs article (23.07.2017). Retrieved 07.10.2017 from https://docs.microsoft.com/en-us/sql/tsql/data-types/data-type-conversion-database-engine

Cartier, J., Rudolph, J. \& Stewart, J. (2001). The Nature and Structure of Scientific Models. Madison (USA): The National Center for Improving Student Learning and Achievement in Mathematics and Science (NCISLA) of Wisconsin Center for Education Research, School of Education, 
$\begin{array}{lllll}\text { University of } & \text { Wisconsin-Madison. } & \text { Retrieved } & \text { 07.07.2017 }\end{array}$ https://eric.ed.gov/?id=ED461513

Coll, R. K. \& Lajium, D. (2011). Modeling and the future of science learning. In M. S. Khine, \& I. M. Saleh (Eds.), Models and Modeling: Cognitive Tools for Scientific Enquiry (pp. 3-21). Dordrecht: Springer Netherlands.

Cook, N. (1994). Perception: A perspective from music theory. In R. Aiello, \& J. Sloboda (Eds.), Musical Perceptions. Oxford: Oxford University Press.

Cross, I. (1998). Music analysis and music perception. Music Analysis, 17(1), 3-20.

Duit, R. (1991). On the role of analogies and metaphors in learning science. Science Education, 75(6), 649-672.

Dienes, Z. \& Perner, J. (1999). A theory of implicit and explicit knowledge. Behavioral and Brain Sciences, 22, 735-808.

Farbood, M. M. (2012). A parametric, temporal model of musical tension. Music Perception, $29(4), 387-428$.

Frigg, R. \& Hartmann, S. (2012). Models in science. Stanford Encyclopedia of Philosophy. Retrieved 07.07.2017 from http://plato.stanford.edu/entries/models-science/

Gilbert, J. K. (2010). The role of visual representations in the learning and teaching of science: An introduction. Asia-Pacific Forum on Science Learning and Teaching, Volume 11, Issue 1, Foreword (Jun., 2010). $\quad$ Retrieved 07.10 .2017 from https://www.researchgate.net/publication/45459005

Giomi, F. \& Ligabue, M. (1995). Semiotic bases and computer assisted composition: Towards a cognitive model. In E. Tarasti (Ed.), Musical Signification. Essays in the semiotic theory and analysis of music (pp. 355-360). Berlin, New York: Mouton de Gruyter.

Huron, D. (2007). Sweet Anticipation: Music and the psychology of expectation. Cambridge MA, London: MIT Press.

Justi, R. \& Gilbert, J. K. (2002). Modelling: Teachers' view on the nature of modelling, and implications for the education of modelers. International Journal of Science Education, 24(4), 369-387.

Kuhn, T. J. (1962/1970). The Structure of Scientific Revolutions (Second Edition, enlarged). Chicago: University of Chicago Press.

Lahti, R. D. (2013). Does Attainment of Piaget's Formal Operational Level of Cognitive Development Predict Student Understanding of Scientific Models? (Doctoral dissertation). Missoula: University of Montana.

Lerdahl, F. \& Krumhansl, C. L. (2007). Modeling tonal tension. Music Perception, 24(4), 329-366.

Lock, G. (2016). Stages and phases of the creative process of novice composers (paper presentation). Paper presented at the Pedagogical Forum Performing Arts Belgrade "Building Experience and Meaning in Music Education". Belgrade: University of Arts.

Lock, G. (2014). Visualisierende Analyse. In F. Diergarten (Hrsg.), Musikalische Analyse. Begriffe, Geschichten, Methoden (ss. 287-319). Laaber: Laaber.

Lock, G. (2004). Aspekte der Visualisierung und graphischen Analyse von Musik. Die Fünfte Sinfonie von Lepo Sumera. Musical Work: Boundaries and Interpretations (38th Baltic Musicological Conference), hrsg. von A. Žiuraityte (pp. 243-269). Vilnius.

Margulis, E. H. (2005). A model of melodic expectation. Music Perception, 22(4), 663-714. 
Marsden, A. (1995). Musical pragmatics and computer modelling. In E. Tarasti (Ed.), Musical Signification: Essays in the semiotic theory and analysis of music (pp. 335-348). Berlin, New York: Mouton de Gruyter.

Purwins, H., Herrera, P., Grachten, M., Hazan, A., Marxer, R. \& Serra, X. (2008). Computational models of music perception and cognition I: The perceptual and cognitive processing chain. Physics of Life Reviews, 5, 151-168.

Reybrouck, M. (2015). Music as environment: An ecological and biosemiotic approach. Behavioral Science, 5, 1-26.

Rogers, K. (2017). Scientific modeling. Encyclopaedia Britannica. Retrieved 07.17.2017 from https://www.britannica.com/science/scientific-modeling

Schwarz, C. V., Reiser, B. J., Davis, E. A., Kenyon, L., Acher, A., Fortus, D., Shwartz, Y., Hug, B. \& Krajcik, J. (2009). Developing a learning progression for scientific modeling: Making scientific modeling accessible and meaningful for learners. Journal of Research in Science Teaching, 46(6), 63-654.

Tiits, K. (1995). Experiments on grammar-based analysis of music. In E. Tarasti (Ed.), Musical Signification: Essays in the semiotic theory and analysis of music (pp. 361-369). Berlin, New York: Mouton de Gruyter,

Varto, J. (2009). Basics of Artistic Research: Ontological, epistemological and historical justifications. Helsinki: University of Art and Design Helsinki.

Vercoe, B. (1997). Computational auditory pathways to music understanding. In I. Deliège, \& J. Sloboda (Eds.), Perception and Cognition of Music (pp. 307-326). Hove (UK), New York: Psychology Press.

Wang, D. (2007). Computational scene analysis. In W. Duch, \& J. Mandziuk (Eds.), Challenges for Computational Intelligence (pp.163-191). Berlin: Springer.

Wigmore, I. (2017). Implicit data (definition). WhatIs.com /TechTarget. Retrieved 07.10.2017 from http://whatis.techtarget.com/definition/implicit-data

Zbikowski, L. M. (2002). Conceptualizing Music: Cognitive structure, theory, and analysis. Oxford: Oxford University Press.

Zbikowski, L. M. (1997). Conceptual models and cross-domain mapping: New perspectives on theories of music and hierarchy. Journal of Music Theory, 41(2), 193-225. 



\title{
THEORETICAL FUNDAMENTALS OF THE PROCESS OF ACQUIRING THE DIDACTIC MODEL FOR STYLE MODELLING IN MUSICAL IMPROVISATION
}

\section{Jurijs SPIGINS}

Latvia

e-mail: jurijs.spigins@gmail.com

\begin{abstract}
The study is concerned with the analysis of the theoretical fundamentals of the process of acquiring the didactic model for style modelling in musical improvisations. In improviser's creations, the author's method of style modelling is the starting position in the process of acquiring musical improvisation. Modelling has its own typical devices of describing and representing the taught subject. When students explore and learn improvisation, notation-graphical and musical-sound structures are used as supplementary aids. Students may identify them with both ideal and material models.

Author 1) characterizes five sides of the existence of student's improvisation: a) metaimprovisation, b) improvisation 'de-facto', c) immanent improvisation, d) prepared improvisation, and e) spontaneous improvisation, as well as 2) explains some theoretical fundamentals of Didactic Model for Style Modelling in Musical Improvisation and its pragmatic, prognostic and heuristic functions.

Keywords: musical improvisation, modelling of styles, didactic model, content-analysis of improviser's activity
\end{abstract}

\section{Introduction}

Musical modelling is extensively used at analyzing various scientific and practical problems in the field of teaching the fundamentals of improvisation. Basically, modelling is done by employing musical, verbal, graphical and mathematical means. A number of studies describe opportunities for modelling and structural analysis of creative processes at the lessons (for instance, Pressing, 2000; Ward, 2004; KertzWelzel, 2004; Zarinšs, 2005; McPherson \& McCormick, 2006; Dairianathan \& Stead, 2010; Kingscott \& Durrant, 2010; Davidova \& Znutiňš, 2011; Spigins, 2013). Modelling is used at studying the potential ways of developing learners' creativity, intuition and self-efficacy (for instance, Green \& Gallwey, 1987; Burnard, 2000; Burnard \& Younker, 2004; Thompson \& Lehmann, 2004; Barrett, 2005; Koutsoupidou, 2005; Webster, 2005; Goncy \& Waehler, 2006; Hickey, 2009). The methods of optimizing creative 
processes are also explored by focusing on musical modelling (for instance, Reimer, 1989; Elliott, 1995; Hamilton, 2002; Martin, 2005; Hallam, 2006; Спигин, 2008; Shaughnessy, 2012). Through musical, verbal, graphic, and mathematical devices modelling is extensively used in literature on musicology as well (for instance, Mehegan, 1962; Конен, 1965; Stearns, 1970; Berendt, 1975; Asriel, 1977; Панасье, 1978; Назайкинский, 1982; Коллиер, 1984; Сарджент, 1987; Coker, 1987, 1989, 1990; Baerman, 2006; Alldis, 2003; Cion, 2005; Chung \& Thurmond, 2007). In his monograph, at creating the didactic model the author relies on style modelling (Spigins, 2013).

When students learn musical improvisation they also have to deal with musical modelling. The case study revealed a number of simplifications in the creative tasks fulfilled by students when they modelled style in their improvisations. However, only they themselves can control the dynamics of their creative processes to a full extent and find ways for their optimization. During the process of acquiring style modelling in improvisation, it was established that students mechanically transfer the seminal ideas of author's didactic model to practice (Spigins, 2013). To identify the causes of this phenomenon, and to obtain data about the correctness of perception and selfassessment of musical events at tests and examinations, a questionnaire survey was conducted. The results obtained from the survey showed that

- students do not have a clear understanding about the very nature of theoretical fundamentals of style modelling and their functions;

- students do not adequately understand the content of criteria, parameters, levels and indicators of acquiring the techniques of improvisation formulated in the questionnaire survey;

- students lack skills of exploring the content of theoretical fundamentals of modelling style in improvisations based on the results of the empiric studies of these improvisations;

- there is no transition from the empiric level of knowledge (observation, measurement, experiment) to the theoretical level of knowledge (concepts, judgment, deduction).

In order to resolve this problem the theoretical fundamentals of author's didactic model of style modelling were explained. Three most essential functions of theoretical fundamentals of style modelling were described: a) pragmatic, b) prognostic and c) heuristic function.

Research object: the acquisition of theoretical fundamentals of musical improvisation in the process of modelling its style.

Research aim: to describe the nature of theoretical fundamentals of style modelling and their functions.

Methods: a) the analysis of literature on philosophy, music psychology and music pedagogy; b) style modelling. 


\section{The nature of theoretical fundamentals of Didactic Model of Style Modelling in Musical Improvisation}

Style modelling is a method for a scientific exploration of one object by means of another, through applying all necessary techniques of a special research conducted for this purpose. Different authors have their individual methods of research, and these methods are determined by the tasks of modeling. During the process of modelling students fulfill numerous creative tasks. The key tasks are three:

- modelling of improvisation and the structural analysis of one's own creative process;

- the development of one's creativity, intuition and self-efficacy;

- search for methods of optimizing and rationalizing one's creative process.

Only students themselves, by optimizing and analyzing the structure of their own creative process, are able to develop their creativity, intuition, self-efficacy and find methods for optimizing and rationalizing their creative process. Self-development has a crucial role in the formation of a future professional. To organize the fulfillment of these tasks, students have to divide their activity into several stages. Each stage involves comprehending a definite type of improvisation. They can be relatively subdivided into five types (Спигин, 2008). These types of improvisation have to be always in the focus of students' attention. These are five sides of the existence of student's improvisation: a) meta-improvisation, b) improvisation 'de-facto', c) immanent improvisation, d) prepared improvisation, and e) spontaneous improvisation.

A. Meta-improvisation is an open system of changeable and developing theoretical knowledge which is used for the analysis of structures, features of improvisations 'de-facto' and methods of modelling immanent improvisations. This open system of knowledge is characterized by the interaction with the environment outside it. The system is constantly supplemented with new information from outside of it. By borrowing the ideas, they have liked, students model these or other solutions involving the organization of musical matter of their improvisation.

B. Improvisation 'de-facto' is the improvisation implemented during its analysis by means of meta-improvisation.

C. Immanent improvisation is a potential, aim-setting model of improvisation, which is built by means of meta-improvisation and is accumulating improviser's creative potential. When students are getting ready for a concert, they, relying on their experience, model and test in practice a lot of different strategies for improvising on a specific theme, as well as work on a great number of mobile elements of the prospective musical form. In the concert performance, the basic data mass of mobile elements will remain outside the framework of the specific improvisation 'de-facto'. Elements of a musical form, which are its content, become stable elements. The great amount of mobile elements left outside the framework of a form provide the improviser with the opportunity to produce also other versions of improvisation 'de-facto' on this specific theme.

D. Prepared improvisation is an improvisation in which a creative process develops according to the logic of connections and relationships of formbuilding devices, which has been comprehended in advance during modelling 
the immanent improvisation. Before a concert, from a great number of elements of a prospective musical form, students, on the basis of some framework, or plan, make a selection, a grouping of elements of the prospective form. When improvisation is performed, the model is thought of as a guiding principle, allowing for correcting the connections and relationships of form-building devices of music established in the model. The results of the correction, when needed, are integrated into the creative process of developing musical improvisation. In ensemble improvisation, the degree of demonstrating individual spontaneity in improvisation depends on norms of style.

E. Spontaneous improvisation is an improvisation in which the creative process does not develop by following strict rules, the driving force of the creative process in this improvisation is not the logic, here some other aspects of human's spiritual life come to the foreground: emotions, intuition, imagination, instinct. Spontaneous improvisation, too, requires a thorough pre-concert work on the elements of a prospective improvisation form. But a detailed planning and a preliminary selection of elements of form for a specific improvisation are not made. In this type of improvisation, rules are always made and eliminated by the musician himself/herself. At describing such creative processes students cannot trace cause-effect connections that have stimulated them to perform these or other creative acts. They control only the basic specific and non-specific factors of improvisation. Improvisers of this trend play the way they feel it in the given specific moment (Спигин, 2008).

It is important for students to understand that improvisation is a variational musical piece. In author's opinion, the concept of variational (variable) musical composition reveals improviser's creative method (Спигин, 2008). By improvising one and the same composition in different ways, he/she, actually, only regulates connections and relations between some constant body of stable and mobile elements in accordance with the specificity of the moment. They assume the character of stable and mobile elements directly in the process of improvisation. Outside the framework of improvisation, they are included in some body of individual means of expression of one or another improviser and do not have the properties of stability or mobility.

Learners' imagination, creative processes and their optimization, development of creativity, intuition and self-efficacy are based on notation-graphical (analysis of visual perception) and musical-sound (auditory analysis) structures. It is necessary to read music much and listen to various kind of music (Reimer, 1989; Elliott, 1995; Hamilton, 2002; Martin, 2005; Hallam, 2006; Спигин, 2008; Shaughnessy, 2012). Students use notation-graphical and musical-sound structures as supplementary aids during the process of exploring and acquiring theoretical fundamentals of musical improvisation. These structures are needed for generating ideal-spiritual (intoning) and materialsound (variation) models. At some definite stage, students start understanding the logic of musical form structure, subtleties of different styles and begin hearing music with inner ear (Назайкинский, 1982). The development of improvisation's musical form occurs on the basis of musical-sound perceptions in musical hearing. Students develop the ability of modelling ideal-spiritual and material-sound models. Modelling of swing in jazz-music appeared to be especially complicated for students.

Problems of swing are complicated and have not been studied almost at all on a theoretical level. The testimony to this is the fact that there is no undivided position on 
swing among the explorers and practitioners of jazz improvisation as yet. Approaches to resolving this problem and conclusions made happen to be extremely different. Russian musicologist Konen (Конен, 1965) writes that the American researchers of jazz have frequently tried to identify the fundamental psychological regularities inherent in the rhythmic schemes of jazz, however their observations are unable to help a performer, not feeling the rhythm of jazz, to grasp this new sensation. The German critic of jazz Berendt (Berendt, 1975) also asserts that swing defies defining. The American musicologist Collier (Коллиер, 1984) takes a more constructive position and emphasizes that though it has always been assumed that the most mysterious thing in jazz is a specific metric pulsation, usually called 'swing', jazz music, however, is a physical reality and therefore we can have a precise notion about it. As Collier stresses, the most important thing is to realize that for a jazz musician vital are not the notes and chords he is playing, but rather the way he/she is playing them. However, the overwhelming majority of musicologists assign swing phenomenon to metro-rhythmic side of jazz music. For instance, French music critic Panassie (Панасье, 1978) writes that swing is a steady rhythmic pulsation, however not a mechanical pulsation, and a musical phrase is a swing only potentially, everything depends on the manner of performing it. The American musicologist and critic Sargeant (Сарджент, 1987) has adequately shown the metro-rhythmic nature of swing by describing rhythmical conflicts, 'pre-emptive' and 'belated' syncopations, and a poly-rhythmic character of swing.

We would like to note that the attempts to find the definition of swing exclusively in the area of technical and metro-rhythmic specificities of jazz and completely ignoring musical-psychological aspects are the cause of numerous failures. One can create rhythmic conflicts, syncopate, and form poly-rhythmic structures without swing as well. The well-known American musicologist Stearns has drawn attention also to the unusual nature of spontaneous, intuitive, irrational factors in jazz. He has carried out a comparative analysis of boogie-woogie performances by two musicians: Iturbi, a wellknown Spanish pianist, with a perfect academic training and Afro-American jazz pianist Smith. Having compared the performances of these musicians, Stearns arrives at a conclusion that rhythms made by Iturbi seem awkward, while the rhythm in Smith's performance is stable, uninterrupted, flowing easily and freely. Stearns draws a conclusion: the infectious and irresistible rhythms made by Smith are too complicated to be precisely reflected by our system of notation (Stearns, 1970).

The next opinion, which the author of this article strongly agrees with, is expressed by Berendt (1975), who concludes that swing is simultaneously related to the measurable, objective time expressed in jazz by the pulsation of a rhythmic section; and to the psychological, experienced time of individual rhythms of the soloists' improvisation applied over this pulse. At times, these rhythms reject the main pulse, and at times recreate it again. The author of this article finds it necessary to define Berendt's idea more precisely: the measurable, objective time is experienced psychologically too, and swing is possible even if the improviser plays alone.

Swing enables to trace the history of jazz improvisation. It unfolds as a change and enrichment of musical languages of jazz. Swing is universal, but it sets the norms, traditions of a specific style trend or the style of one or another improviser. After all, musicians of different style swing differently. The author describes these types of swing in detail in his monograph (Спигин, 2008). 
In jazz improvisation five types of swing are distinguished: a) intra-note-value swing, b) intra-time swing, c) intonation-syntactic swing, d) mono-structural swing and e) poly-structural swing. A musical intonation-style experience is of special importance for learning and understanding swing, but it requires constant improvement of musicalauditory perceptions and musical hearing in general on the basis of intonation. For example, without a thorough training, it is equally complicated to play stylistically correctly Chopin's mazurkas, waltzes, polonaises as well as to play stylistically correctly any jazz composition with swing. From the aspect of music psychology, swing is one of the numerous musical-psychological phenomena of the jazz style which a contemporary musician has to be competent in.

\section{Functions of the theoretical fundamentals of the model}

The three key functions of theoretical fundamentals based on the systematization offered by Littlejohn (Littlejohn, 1994) are described: a) pragmatic, b) prognostic and c) heuristic.

A. The pragmatic (practical) function of theoretical fundamentals involves:

- scientific substantiation of a creative activity on studying and embodying a specific improvisation at the given moment;

- identifying the principles and methods for a rational organization of a creative activity.

Theoretical fundamentals produce real results, and through their conceptions stimulate the development of students' creativity, intuition and self-efficacy aimed at satisfying the changeable needs of the learning process as completely and qualitatively as possible. Consequently, theoretical fundamentals not only formulate problems, but also indicate concrete directions and methods for resolving them.

B. The prognostic function of theoretical fundamentals involves

- defining the prospects of the preparation made for acquiring musical improvisations whose learning is only being planned;

- studying and systematization of facts provided by students' selfobservations (introspection) and pedagogical observations;

- revealing the content of statistic regularities and methods for a rational organization of a creative activity.

Theoretical fundamentals allow prognosticating students' successfulness in acquiring the style modelling of improvisations, which gives the opportunity to better address the needs of the learning process and to use the learning time more rationally. Thus, the prognostic function is related to designing future strategies for acquiring style modeling.

C. The heuristic function of theoretical fundamentals involves

- application of logical research methods and rules for discovering the regularities of acquiring musical modelling;

- creation of prerequisites for the growth of scientific knowledge by method of trial and mistake about the rationalization of creative activity at studying and embodying students' improvisations;

- organization of the process of a productive creative thinking; 
- studying the mechanisms characteristic of musical modelling, with the help of which the procedures oriented towards fulfilling creative tasks are generated;

- acquiring the art of musical composition and improvisation;

- supervising the process of finding new ways of acquiring musical modelling in a methodological way.

The heuristic function of theoretical fundamentals demonstrates itself in

- tackling tasks related to the models of taking decisions;

- seeking for what is new in acquiring musical modelling;

- structuring the descriptions on acquiring the art of musical improvisation.

\section{Conclusion}

The research results open new opportunities for a theoretical activity of pedagogues and students on studying and acquiring the nature of theoretical fundamentals of author's Didactic Model of Style Modelling in Musical Improvisation. Theoretical fundamentals are a starting scientific material, they form a framework of concepts for studying style modelling, set out research strategies for the process of acquiring the fundamentals of style modelling.

\section{References}

Alldis, D. (2003). A Classical Approach to Jazz Piano Improvisation. USA: Hal Leonard Corp.

Asriel, A. (1977). Jazz: Analysen und Aspekte. Berlin: Lied der Zeit.

Baerman, N. (2006). Big Book of Jazz Piano Improvisation. USA: Alfred Publishing

Barrett, M. (2005). A Systems view of musical creativity. In D.J. Elliott (Ed.), Praxial Music Education: Reflections and dialogues (pp.177-195). New York: Oxford University Press.

Berendt J. E. (1976). Das Jazzbuch: Von Rag bis Rock. Frankfurt am Main: Fischer-TaschenbuchVerlag.

Burnard, P. (2000). How children ascribe meaning to improvisation and composition: rethinking pedagogy in music education. Music Education Research, 2(1), 7-23.

Burnard, P. \& Younker, B. (2004). Problem-solving and creativity: Insights from students' individual composing pathways. International Journal of Music Education, 22, 59-77.

Chung, B. \& Thurmond, D. (2007). Improvisation at the Piano (A Systematic Approach for the Classically Trained Pianist). USA: Alfred Publishing.

Cion, S. J. (2005). Modern Jazz Piano: An intermediate guide to jazz concepts, improvisation, technique and theory. USA: Hal Leonard Corporation.

Coker, J. (1987). Improvising Jazz. New-York: A Fireside Book, Published by Simon and Shuster.

Coker, J. (1989). The Teaching of Jazz. West Germany: Advance Music.

Coker, J. (1990). How To Listen To Jazz. West Germany: Jamey Aebersold

Collier, J. (1983). Louis Armstrong: An American genius. USA: Oxford University Press. 
Collier, J. (1987). Duke Ellington. New York: Oxford University Press.

Crook, H. (1991). How to Improvise. Boston: Advance Music.

Dairianathan, E. \& Stead, E. P. (2010). Improvisation as inventive space. In W. Sims (Ed.), Proceedings of the 29th ISME World Conference (pp. 52-55). Sage.

Davidova, E. \& Znutiňš, E. (2011). Practically oriented approach to writing a professional master's thesis in the field of music pedagogy. In S. Vaitekūnas (Ed.), Changing Education in a Changing Society (pp. 150-160). Klaipeda: Klaipedos universitetas.

Elliott, D. (1995). Music Matters: A new philosophy of music education. New York: Oxford University Press.

Goncy, E. \& Waehler, C. (2006). An empirical investigation of creativity and musical experience Psychology of Music, 34(3), 307-321.

Green, B. \& Gallwey, T. (1987). The Inner Game of Music. London: Pan Books.

Hallam, S. (2006). Music Psychology in Education. London: Institute of Education.

Hamilton, A. (2002). The art of improvisation and the aesthetics of imperfection. In G. Spruce (Ed.), Teaching Music in Secondary Schools (pp. 209-225). New York: Routledge Falmer.

Hickey, M. (2009). Can improvisation be 'taught'? A call for free improvisation in our schools. International Journal of Music Education, 27(4), 285-299.

Kertz-Welzel, A. (2004). Didaktik of music: A German concept and its comparison to American music pedagogy. International Journal of Music Education, 22(3), 277-286.

Kingscott, J. \& Durrant, C. (2010). Keyboard improvisation: a phenomenological study. International Journal of Music Educati, 28(2), 127-144.

Koutsoupidou, T. (2005). Improvisation in the English primary music classroom: Teachers' perceptions and practices. Music Education Research, 7(3), 363-381.

Littlejohn, S.W. (1994). Theories of Human Communication. Belmont, California: Wudsworth Publishing Company.

Martin, J. (2005). Composing and improvising. In D.J. Elliott (Ed.), Praxial Music Education: Reflections and dialogues (pp. 165-176). New York: Oxford University Press.

McPherson, G. \& McCormick, J. (2006). Self-efficacy and music performance. Psychology of Music, 34(3), 323-336.

Mehegan, J. (1962). Jazz Improvisation 2: Jazz rhythm and the improvised line. New York: Amsco Publications.

Pressing, J. (2000). Improvisation: Methods and models. In J.A. Sloboda (Ed.), Generative Processes in Music (pp. 129-178). Oxford: Clarendon Press.

Reimer, B. (1989). A Philosophy Of Music Education. New Jersey: Prentice Hall.

Shaughnessy, M. (2012). An interview with Mark Dal Porto: The composer, composition and the craft. Problems in Music Pedagogy, 10, 82-86.

Spigins, J. (2013). Improvizācijas pamatu apguve topošo mūzikas skolotāju studiju procesā [The Acquisition of Improvisation Fundamentals during the Study Process of Prospective Music Teachers]. Rīga: SIA Jumi (in Latvian).

Stearns, M. W. (1970). The Story of Jazz. USA: Oxford University Press Inc.

Thompson, S. \& Lehmann, A. (2004). Strategies for sight-reading and improvising music. In A. Williamon (Ed.), Musical Excellence (pp. 143-159). London: Oxford University Press.

Ward, V. (2004). The performance teacher as music analyst: A case study. International Journal of Music Education, 22 (3), 248-265. 
Webster, P. (2005). Creativity as creative thinking. In G. Spruce (Ed.), Teaching Music in Secondary Schools (pp. 87-97). London: Routledge.

Zarinšs, D. (2005). Radoša pieeja klavierspēlē [Creative Approach to Piano Playing]. Rīga: RaKa (in Latvian).

Конен, В. (1965). Пути американской музыки [Ways of American Music]. Москва: Музыка (in Russian).

Назайкинский, Е. (1982). Логика музыкальной композиции [Logic of Musical Composition]. Москва: Музыка (in Russian).

Панасье, Ю. (1978). История подлинного джаза [History of the Authentic Jazz]. Ленинград: Музыка (in Russian).

Сарджент, У. (1987). Джаз: Генезис. Музыкальный язык. Эстетика [ Jazz: Genesis. Musical Language]. Москва: Музыка (in Russian).

Спигин, Ю. (2008). Импровизация в контексте теории и истории музыки и её проявление в джазе: Монография [Improvisation in the Context of Theory and Music History and it's Display in Jazz]. Rīga: JUMI (in Russian).

Received 09.07.2017

Accepted 24.09.2017 



\title{
TEACHING ARRANGING TO CLASSICAL AND CONTEMPORARY MUSIC STUDENTS IN HIGHER EDUCATION
}

\author{
Annie K. MITCHELL \\ Southern Cross University, Australia \\ e-mail: annie.mitchell@scu.edu.au
}

\begin{abstract}
This article's author discusses new teaching and learning approaches to develop arranging skills in pre-service teachers and musicians entering the contemporary music industry, the challenges non-classically trained musicians encounter in understanding classical composition techniques and structures, and how these problems can be overcome through the application of traditional compositional techniques to contemporary repertoire. The paper also explores how classically-trained musicians and educators can expand their traditional knowledge to arrange contemporary repertoire using contemporary harmony, chord voicings, chord substitution and reharmonisation techniques.

Examples of contemporary arranging are presented: using a popular song as the thematic material to teach four-part fugue composition, an SATB choral arrangement with rhythm section accompaniment, a big band arrangement of a jazz standard, an orchestral arrangement of film music from a piano score, and the reharmonisation of contemporary repertoire using jazz harmonic vocabulary and chord voicings.

Teaching arranging has diverse applications for music education and pedagogy:

- teaching pre-service teachers vocational arranging skills required for secondary school music teaching;

- $\quad$ providing professional development for music teachers needing to improve their composition skills;

- assisting music educators to transfer classical composition skills to contemporary music styles and genres;

- scaffolding contemporary music arranging with traditional classical composition techniques;

- motivating music teachers to compose original educational resources;

- applying arranging skills in professional music practice to create repertoire for professional ensembles.

The approaches discussed are increasingly valid given the increase of contemporary music content in music higher education and the growth of creative work/exegesis projects in higher research degrees globally.
\end{abstract}


Keywords: arranging, music pedagogy, contemporary music, teaching strategies, harmonisation

\section{Introduction}

\section{Background}

Music composition skills of arranging and orchestration are valuable professional attributes for contemporary and classical musicians. These vocational skills are essential a) in specialised music industry careers such as composing/arranging, film score writing and songwriting; b) in school teaching professions; c) in performance and recording where the application of theoretical knowledge to creative practice enhances the arrangements of live and studio performance, and also d) in portfolio careers (typical of today's music industry professional) encompassing these diverse activities.

As a Senior Lecturer in Southern Cross University's (SCU) Bachelor of Contemporary Music (BCM) Program, author teaches a range of units (subjects) that develop advanced music theory and aural musicianship, arranging, composition and orchestration skills: Contemporary Music Theory II (CMTII) and Advanced Musicianship (AM) in second year, Studies in Western Art Music (WAM), Advanced Studies in Western Art and Contemporary Music (ASWAM), and Ensemble Direction and Arranging (EDA) in third year. Author's pedagogical practice is based on a learning-centred teaching style that prepares for successful employment in the music industry and teaching profession, as performing musicians, composers and arrangers, music teachers, or through a portfolio of these creative activities.

In this article author discusses new teaching and learning approaches to develop arranging skills in pre-service teachers and musicians entering the contemporary music industry, the challenges non-classically trained musicians encounter in understanding classical composition techniques and structures, and how these problems can be overcome through the application of traditional compositional techniques to contemporary repertoire. Author also explores how classically-trained musicians and educators can expand their traditional knowledge to arrange contemporary repertoire using contemporary harmony, chord voicings, chord substitution and reharmonisation techniques, and contemporary rhythms and grooves.

Four assessment items in arranging will be presented, interrogating the pedagogical strategies used to teach these skills, providing examples of students' creative work and evidence of student learning, and reporting responses by students undertaking each task. Two educational resources that author had developed to underpin student learning in this field are also explained.

\section{Aim of the research}

This research aims to examine the teaching strategies and assessment instruments author uses to teach contemporary music arranging at undergraduate and postgraduate university levels, in order to establish best practice in compositional pedagogy and to develop these skills in young musicians and pre-service teachers. Specific objectives include educating music students to compose and arrange music in classical 
structures such as sonatas and fugues, compose for contemporary ensembles of SATB choir plus rhythm sections, arrange jazz repertoire for big bands, orchestrate piano scores and film pieces for small orchestras, and apply these creative skills to their original compositions.

The broader aim of author's pedagogy is to educate university music students in advanced-level music theory, aural musicianship and compositional practice through sequential, scaffolded learning experiences within an innovative curriculum. This curriculum should challenge students to expand their own potential and contribute creatively to the development of original music repertoire and music teaching resources, in preparation for successful, sustainable and rewarding careers in the music industry and music teaching profession.

\section{Object of the research}

Over the second and third year of Southern Cross University's Bachelor of Contemporary Music degree, mentioned curricula aims to develop knowledge and practical skills in advanced harmony, sectional writing, repertoire analysis and orchestration in undergraduate music students. Specific objectives of the second year Contemporary Music Theory II curriculum include composing short theoretical exercises such as correctly voicing chord progressions, creating rhythm section grooves in a variety of contemporary genres, arranging and harmonising short fills for horn sections, arranging four-part vocal harmonies and harmonising bass lines for four instruments in various styles (jazz, rhythm and blues, ballads, Latin). In Advanced Musicianship, the object is to develop advanced aural skills in students, then the ability to apply this aural perception and the music theory they have learned, to notate musical scores and charts. Thus, the major assessment item is the transcription, notated in conductor's score, of a contemporary ensemble piece, usually for voice, backing vocals, guitar, bass, drum kit, piano and/or keyboard, with horn and/or saxophone lines.

Third year students are required to compose a fugue or sonata based on given themes/subjects, arrange a contemporary, jazz or Latin song for SATB choir plus instrumental accompaniment, and to create a big band arrangement of a jazz standard. Their final task is to orchestrate and arrange the piano score of a piece (usually a film theme) for a small orchestra. The purpose of the curricula is to develop advanced-level contemporary music theory knowledge in students, facilitate their ability to apply this knowledge to compositional tasks and performance practice, and to gain expertise in arranging; tasks enabling graduates to work in the music industry or to teach these skills to school students. An emphasis on creativity is particularly fostered in students applying this expertise to their original compositions. What pedagogical practices and assessment instruments work to realise these objectives are the focus of this article.

\section{Methodology}

Multiple qualitative methods have been employed to undertake this research. Interrogation of author's own pedagogy has occurred over several years through participant observation, peer review, formal and informal student feedback, student focus groups, reflective practice and auto ethnography. Study of my own pedagogy and 
curriculum design has been triangulated against pedagogical models such as the spiral curriculum models of Bruner (1960, 1996), Harden \& Stamper (1999) and Efland (1995).

\section{Pedagogical method}

Author created the curriculum design, which was originally based on Bruner's Spiral Curriculum $(1960,1996)$. A foundation of musical literacy is embedded in first year, then built upon through recurrent and deeper engagement with more advanced levels of the subject matter in second year. In third year, this literacy is applied to various musical styles and periods, such as classical and contemporary, and refined by composition and practical activities in a range of genres. Such application develops versatility of learning and flexibility in the application of knowledge and skills to different learning and creative contexts. Self-directed learning occurs when students undertake independent Honours and Doctoral research and creative work/exegesis projects. On graduation, students are equipped to practice these skills of performance, composition and arranging at professional levels and educate new learners in this domain through secondary or private teaching. This curriculum model is illustrated in Figure 1.

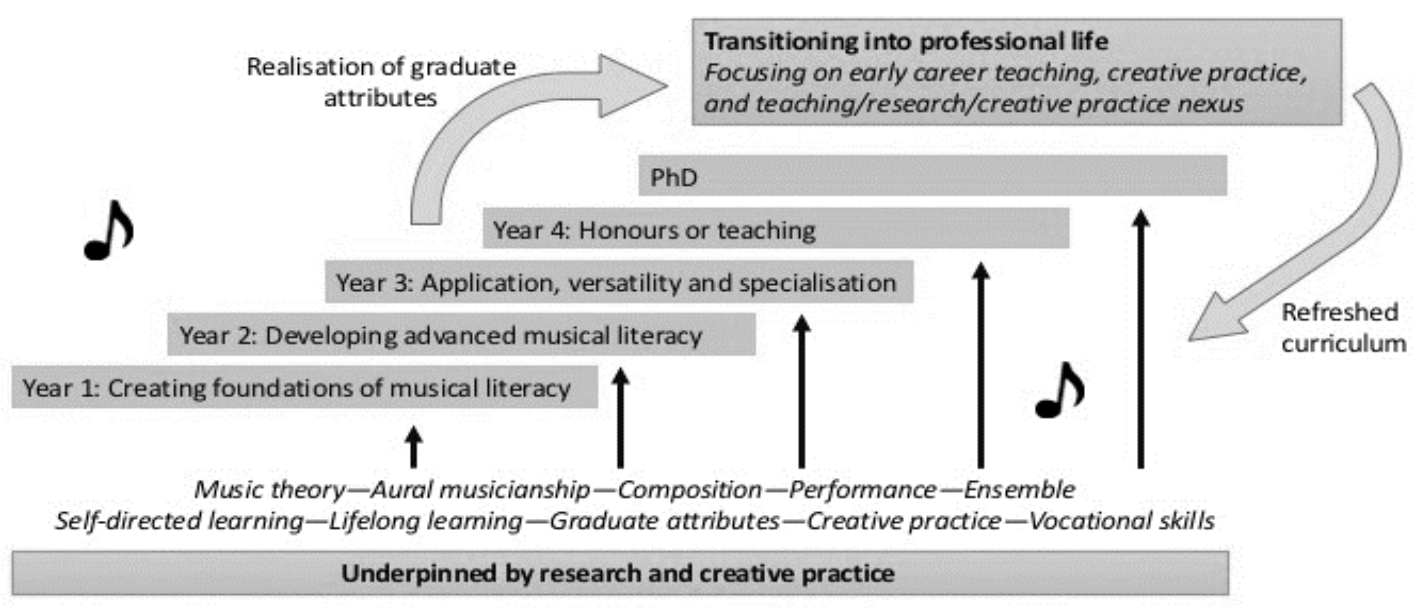

Figure 1. A spiral curriculum in contemporary music

While this approach aligns with the hierarchical and developmental learning theories of Bruner (1960), author's current curriculum design includes elements of Efland's Lattice curriculum (1995), which demands more advanced knowledge of the subject matter, "expertise within specific domains of knowledge" (Efland, 1995, 134), a diversity of pathways to learning, and the transfer of prior knowledge to problem-solving in new areas and different contexts (Efland, 1995, 139). This newer model is vertically and horizontally integrated, with constant musical concepts linking up through each educational level and applied across each year of study, built on a foundation of advanced musical literacy, and presented through a comprehensible structure and sequence of content (Curzon \& Tummons, 2013). The musical constants include musicianship, practice, creativity, employment, expression and fulfilment; core skills and learning objectives in every level of this curriculum. 


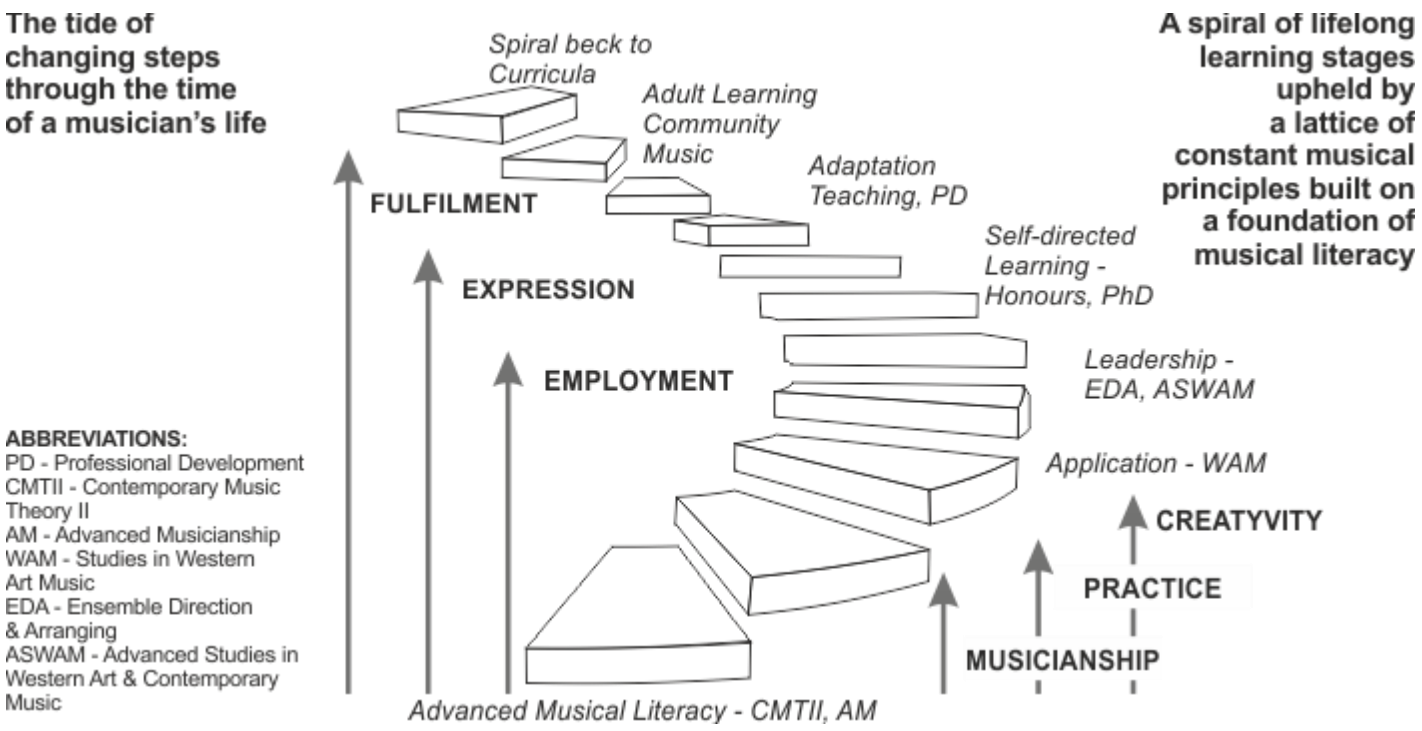

Figure 2. A new curriculum model for contemporary music higher education

\section{Practice-led research}

Practice-led research has been undertaken to investigate author's teaching of composition and arranging and students' compositional processes and outputs. This methodology, described by Candy (2006) is "concerned with the nature of practice and lead[ing] to new knowledge that has operational significance for that practice" (Candy, $2006,1)$. Author's investigation of teaching composition and arranging informs knowledge about compositional practice and skill development, and how to pass on this knowledge and these skills to student musicians and teachers. Compositions are assessed according to musical criteria, moderated by a panel of experts, demonstrated and workshopped by the class cohort, then publically performed and evaluated. This varied scrutiny of the data (creative works) triangulates the analysis of this creative practice and informs the research results.

\section{Results of the research}

Four examples of contemporary arranging are presented in this article: 1) using a popular song as the thematic material to teach four-part fugue composition, 2) an SATB choral arrangement with rhythm section accompaniment, 3) a big band arrangement of a jazz standard, and an orchestral arrangement of film music from a piano score, and 4) an example of reharmonisation of contemporary repertoire using jazz harmonic vocabulary, voicings and rhythms is included. These activities are assessment items in the undergraduate music degree. The research results offer strategies to ensure successful creative outcomes, provide evidence of student learning and report student responses to these tasks.

To prepare students for these assessments, Contemporary Music Theory II curriculum content covers extended harmonic vocabulary, chord voicings, voice leading, key analysis, scale-to-harmony application, rhythmic groove construction, sectional 
writing, four-part vocal harmonisation, quartal and So What chords, and block chord harmony. In an associated unit (Advanced Musicianship) students practise aural recognition and dictation exercises in melody, rhythm and harmony; embedding a functional musical literacy in the learner. This is a scaffolded process where students learn jazz chord vocabulary based on the chords at beginning of The Real Books (Sher, 1995), build chord extensions, play and sing simple and lush piano voicings. Embedding this harmonic foundation is supported by a Piano Chord Voicing Resource. An excerpt from this resource is seen in Figure 3 (numbers indicate notes of each chord).

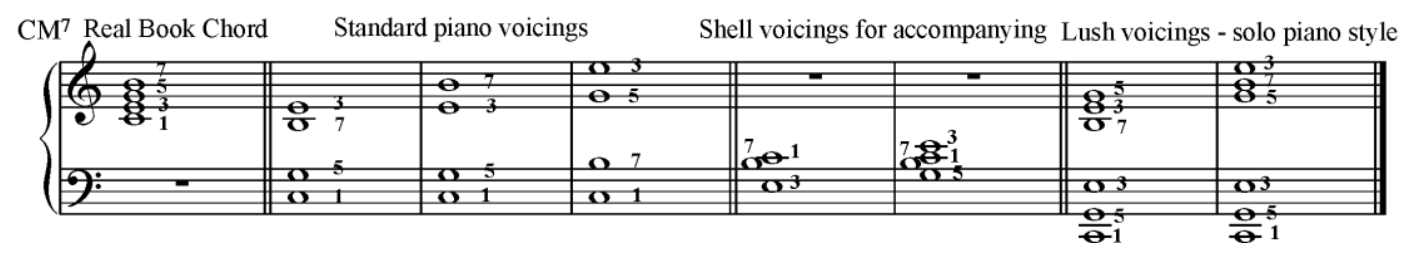

Figure 3. Excerpt from Piano Chord Voicing Resource

All chords and voicings are transposable to different keys. Students practise simple application of these voicings through arranging standard chord progressions for select small ensembles. Playing chord progression using these voicings assists students in aural recognition of chord qualities and progressions. The resource is valuable in helping non-pianists to voice chords in a pianistic manner, nuanced to different contemporary genres and also to the function the keyboard is playing within a piece. These voicings can be used to create keyboard parts for rhythm section groove writing, in a variety of contemporary styles including jazz, rock, blues, RnB, funk and Latin. Extensions of this learning include the development of simple improvisation skills by the application of scales and modes over keys and chord progressions.

Another core learning outcome in CMTII is sectional harmonisation. After learning the spelling (note construction) and voicing (vertical placement) of chords, students must also consider the horizontal texture that the moving layers of notes in a chord progression create (voice leading). This skill is valuable for writing harmony parts for choirs, backing vocals, horn sectional parts and string lines; common elements in classical and contemporary ensembles. One activity in teaching this skill is four-part vocal harmonisation of a popular song, e.g. After the Love Has Gone (Foster, Graydon \& Champlin, 1979). Students firstly spell each chord, select the four most important chord notes according to their harmonic function and tone colour, prioritising $3^{\text {rd }}$, ${ }^{\text {th }}$, extension, then root notes of chords. Notes are assigned to alto, tenor and bass voices, within their appropriate ranges; soprano sings the melody. Figure 4 demonstrates a harmonisation of this melody, featuring well-spaced chord voicings, smooth voice leading, imitative harmonisation of falling melodic sequences, and inclusion of the most harmonically functional and colorful tones in each chord. 
NFTE THE LOVE HAS GONE - EARTH. WWNO \& FRE
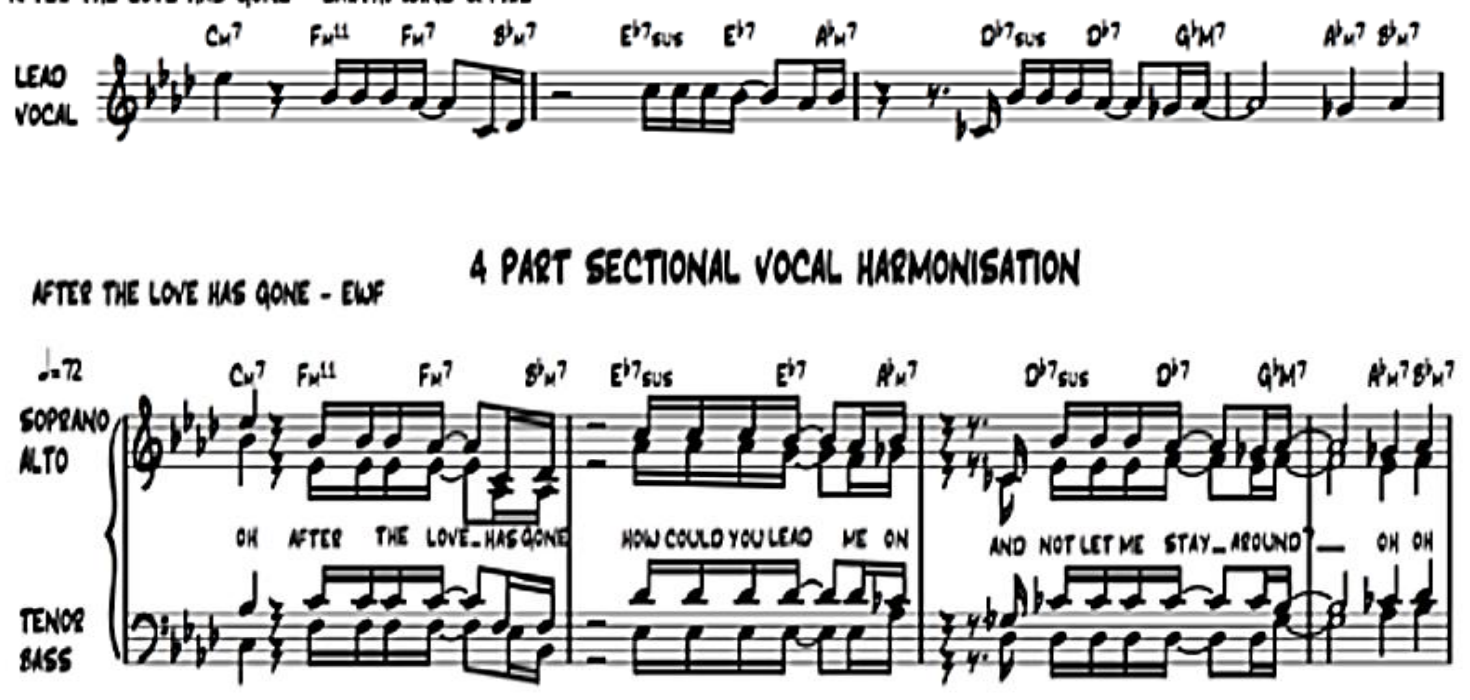

Figure 4. After the Love Has Gone-Lead vocal line then four-part vocal harmonisation

This foundational harmonisation skill is established in second year, then in third year, students apply these techniques to larger pieces; vocal arrangements, big band then arranging for small orchestra. Author uses her own arrangements of repertoire as models, each accompanied by a comprehensive analysis of compositional techniques. Learning is reinforced through student performance of these arrangements and demonstration and analysis of previous students' work.

\section{Example 1: Creating a four-part fugue}

Students in SCU's Music Education major train for careers as secondary school teachers, and therefore need knowledge of classical music repertoire, important composition structures and compositional techniques. Third year students of the unit Studies in Western Art Music compose a fugue or sonata based on given subjects (themes). Templates are provided to assist students in navigating the architecture of each form. To facilitate this learning, author composed a four-part fugue based on The Beatles' pop song Eleanor Rigby (McCartney \& Lennon, 1966). Eleanor Rigby was chosen for thematic material as the song has highly identifiable and memorable melodies, simple harmony adaptable to canonic overlaying, and malleable melodies suitable for development and reharmonisation. The opening "Eleanor Rigby" melody forms the fugal subject, "All the lonely people" and "Ah, look at all the lonely people" form the melodies for the first and second episodes respectively. Common fugue compositional techniques include modulation, addition of a countersubject, canonic imitation, cycle of fifths modulation, Alberti bass, pedal points and stretto. Contemporary nuances are a chromatic secondary diminished chord progression, a descending chord stream and a half-diminished scale that leads into the final episode. Figure 5 (concert pitch) presents a new melody in G\# minor, derivative of the main fugal subject, played by flutes (soprano part); a pedal point is sustained by the Cor Anglais (alto part), clarinets play a syncopated descending moving line (tenor part), while the bassoon outlines root note counterpoint. This four-bar section passes through a cycle of fifths, going from G\# minor 
to $\mathrm{C} \#$ minor, then $\mathrm{F} \#$ minor and $\mathrm{B}$ minor. The voices (soprano, alto, tenor and bass parts) swap roles between playing the melody, moving line, pedal point or root notes, whilst instrumentation changes through different sections of the orchestra.

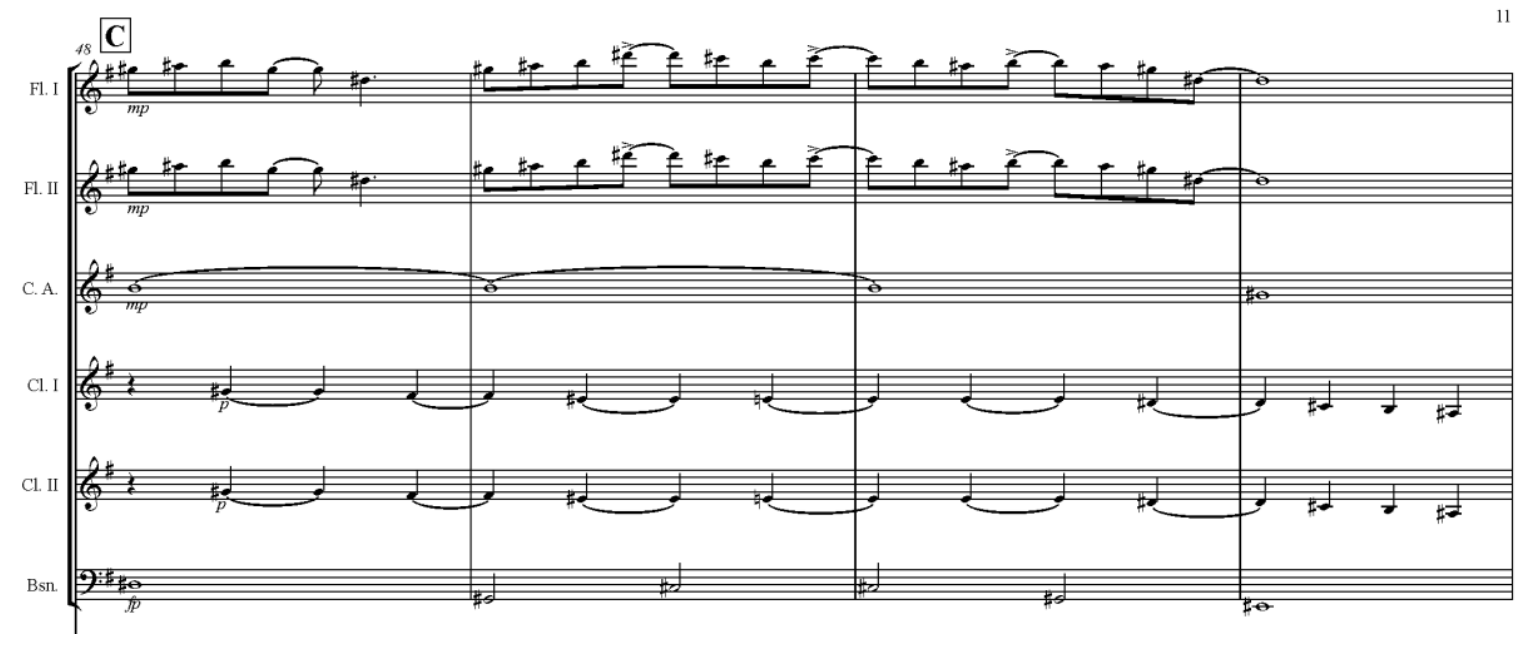

Figure 5. Eleanor Rigby Fugue for Orchestra excerpt

Figure 6 is an example of student work, an excerpt from a four-part fugue created for string quartet. Students were given a subject, which appears here in Violin II transposed from its original $\mathrm{Bb}$ major key. The student composed a countersubject in Violin I, with cello outlining the harmonic progression. Further variation continues from bar 25 in the viola part.

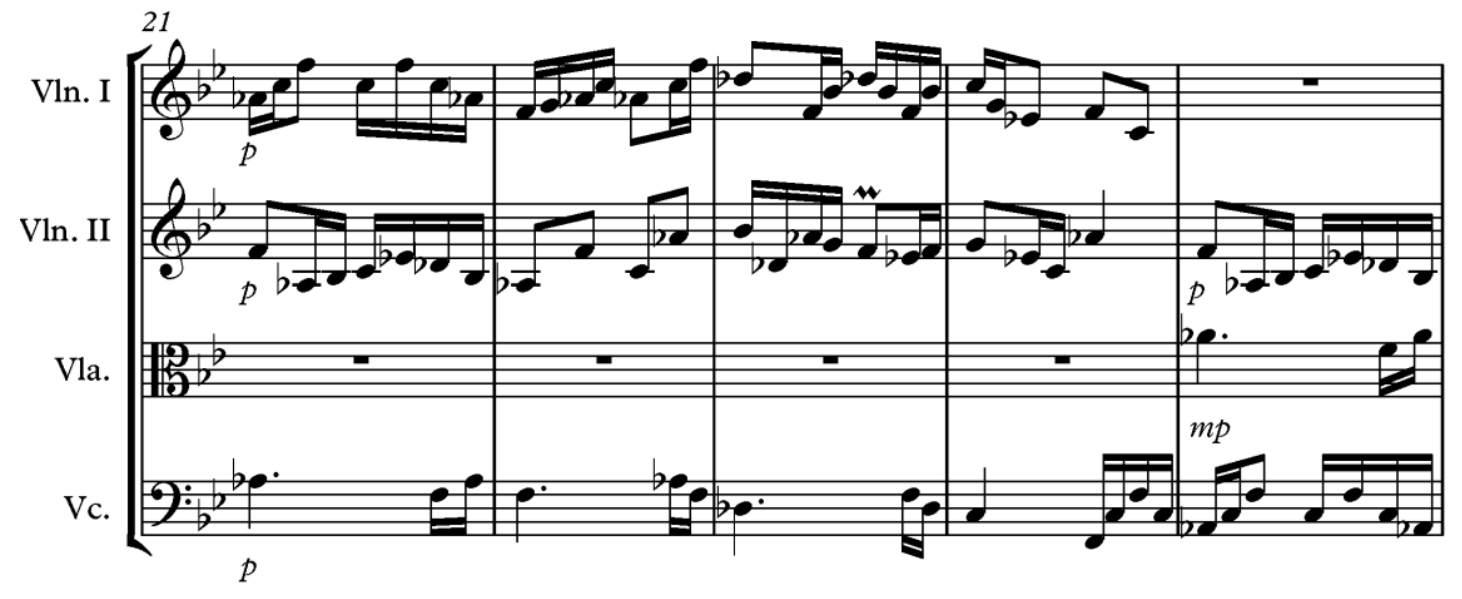

Figure 6. Student assignment excerpt - Fugue for String Quartet

\section{Example 2: SATB Choral Arranging}

Example 2, an excerpt from my harmonisation of the ballad Wolfcry (Porter, 2013) for SATB choir exemplifies the strategy of using original arrangements as resources to prepare students for assessment tasks. Author's arrangement blends classical four-part vocal harmonisation techniques with jazz nuances in a modern song that crosses genres of interest to contemporary music students: jazz, vocal ballad and blues. This repertoire choice is current, relevant and significant, coming from Gregory Porter's 2013 album 
Liquid Spirit, which won the 2014 Grammy Award for Best Jazz Vocal Album (National Academy of Recording Arts and Sciences, USA).

Techniques featured in this arrangement include dividing the lyrics between female and male voices, establishing the narrative style of the piece by relating the song's love story characters through the choral vocal groups. Harmonisation of the melody is staggered, commencing with one added voice, then another. Some parts are created by moving line progressions and contrary motion of lines. The Coda (see Figure 7) displays a mixture of classical four-part vocal harmonisation, triads and extended jazz chords, bass pedal notes creating slash chords, and bIIM9 substitution of chord V7 (G7) in the final cadence.Voice leading features converging inward contrary motion (bars 57-59), minimal pitch movement in parts with voice leading going to the nearest note in next chord, then expanding outward contrary motion (bars 60-62) to expand vocal ranges. Block chord homophony suggests resolution not only of the harmonic progression but also of the narrated love story.
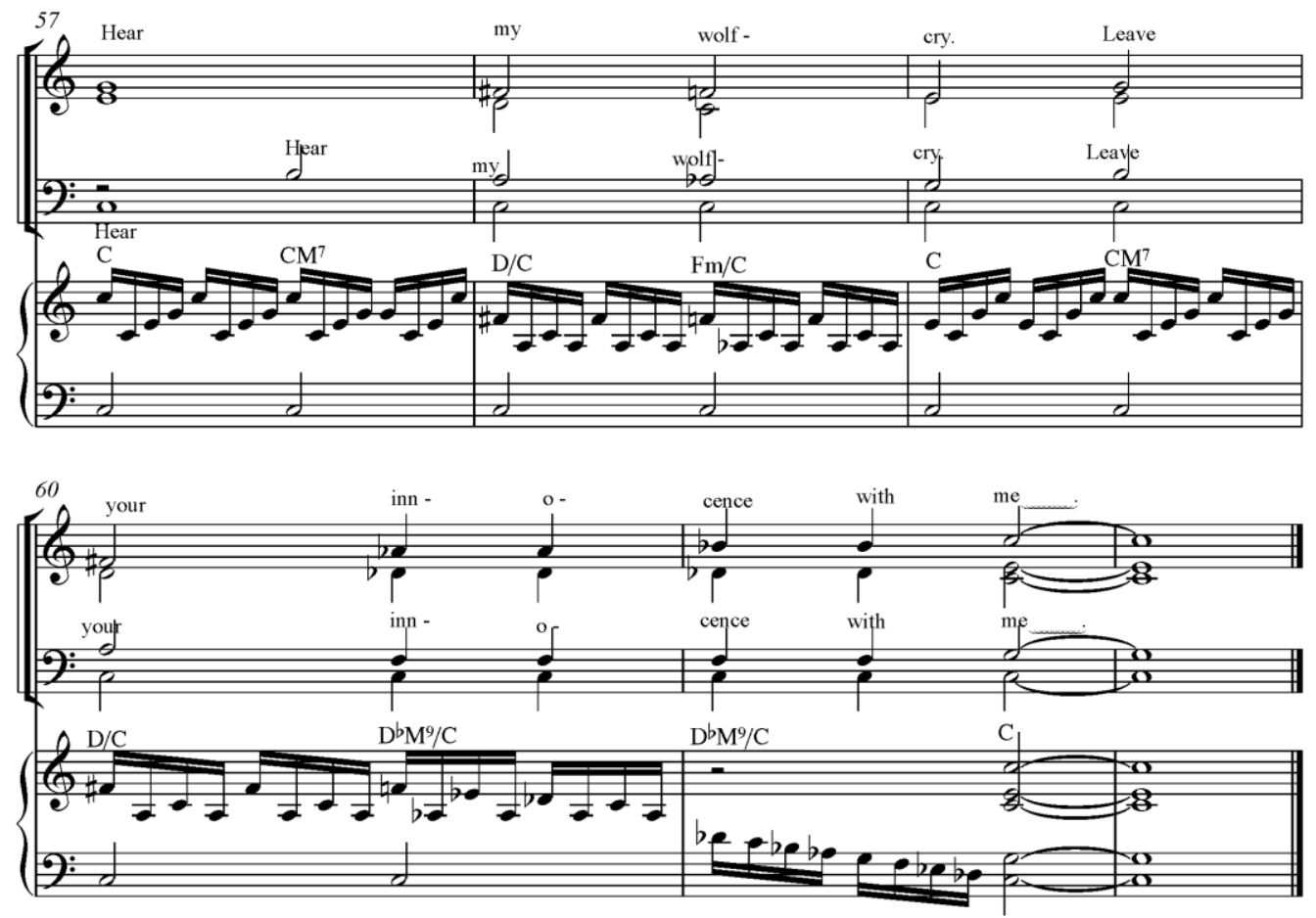

Figure 7. Wolfcry Coda - excerpt from SATB choral arrangement

Students apply similar composing techniques in an assessment task for the third year unit Advanced Studies in Western Art and Contemporary Music, creating a choral arrangement with rhythm section accompaniment of a contemporary song. The following example demonstrates a student arrangement of the jazz-funk song In the Winelight (Eaton, Elling \& Galdston, 2003). This assessment develops skills of sectional harmonisation, countermelodic writing, moving line progressions, voice leading, word setting, groove creation, writing stylistically authentic rhythm section accompaniment, and scale harmony application to create solos. Students particularly liked the choice of repertoire and being introduced to new artists. This arrangement now forms part of the SCU Choir's repertoire. 


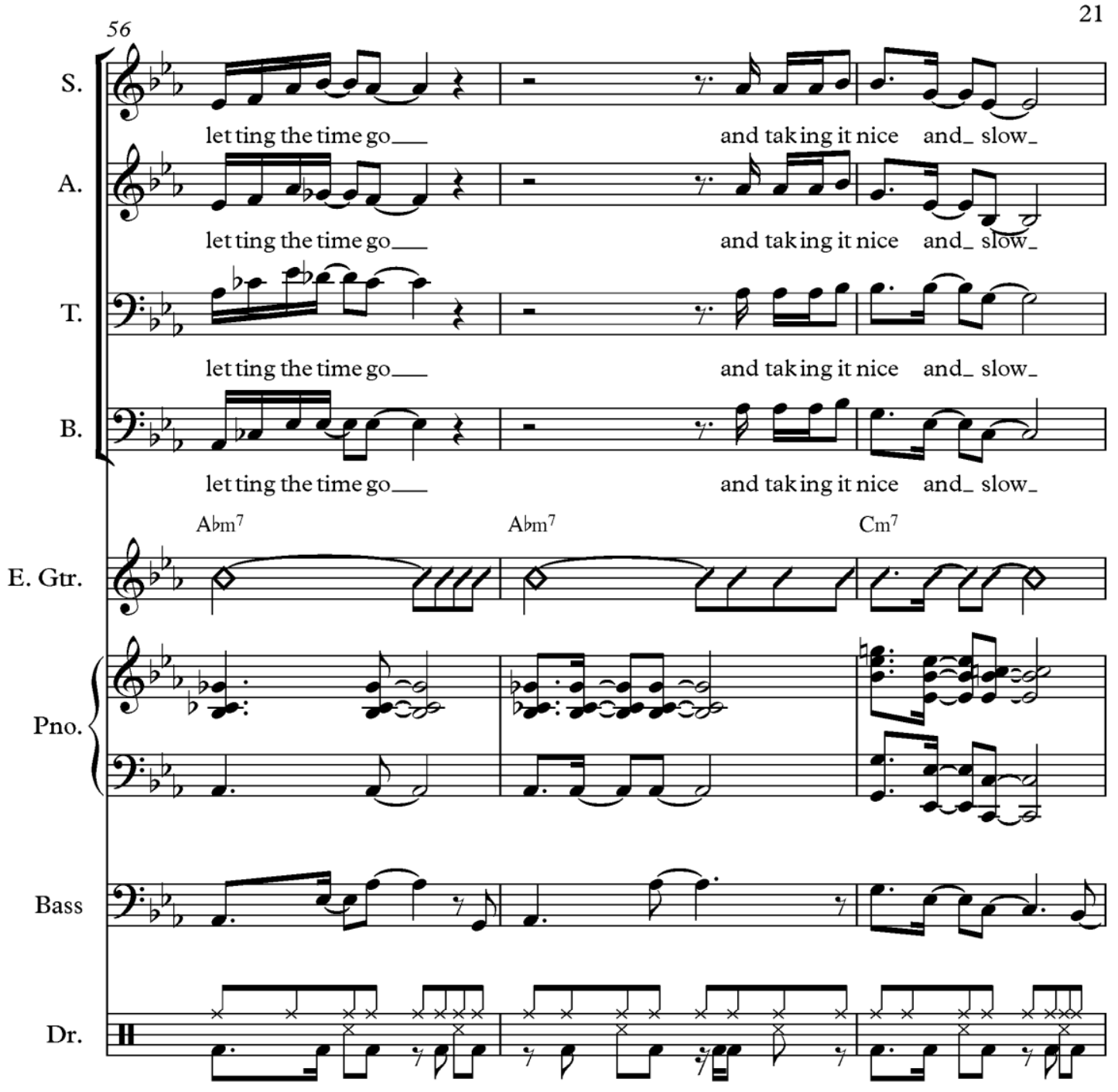

Figure 8. Student assignment excerpt - In the Winelight

\section{Example 3: Big Band Arranging}

Example 3 reflects the eclecticism of much contemporary music, with foundations in the past (jazz), borrowings from non-Western music traditions (Latin American) and embracing contemporary genres. To teach students contemporary big band arranging, author arranged An Olive Tree (Robinson, Trzetrzelewska \& White, 1994) merging standard big band jazz arranging techniques with modern Latin nuances. Other features of this arrangement are sectional harmonisation in saxes and brass, countermelodic writing, moving line progressions, quartal and 'Drop 2' voicings spreading out chords from close to open voicings. The piece commences with a bossa nova feel, then goes into a double-time samba with a multi-metric chorus. The final section changes into 6/4 with Cuban influences and many cross-rhythms and polyrhythms. Figure 9 exemplifies the tumbao bass line, then the piano montuno pattern over $6 / 4$ bass figure. 

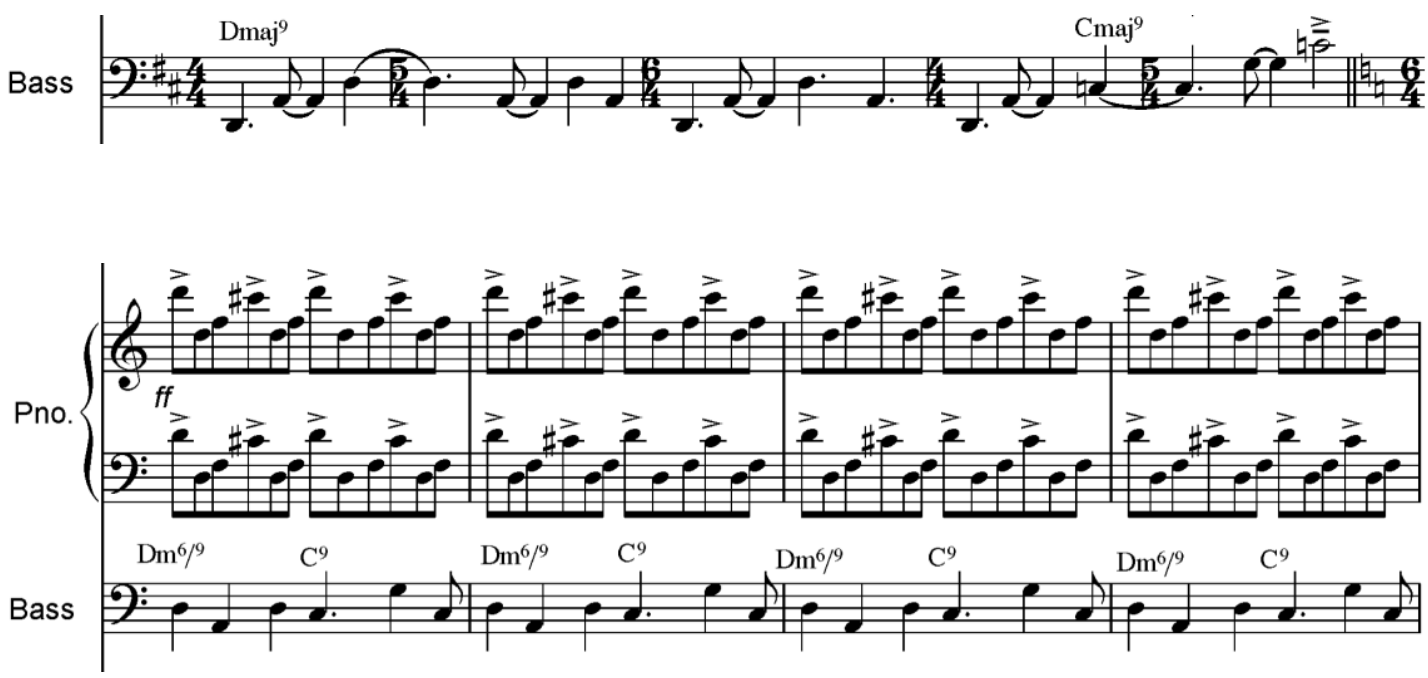

Figure 9. An Olive Tree big band arrangement excerpt - tumbao bass line, piano montuno

These compositional techniques have been introduced in second year. Preliminary exercises scaffold the following assessment task, in which third year ASWAM students are given a Real Book chart of a jazz standard to arrange for 16-piece big band comprising saxophone, brass and rhythm sections. An example of rhythm section writing with Latin influences, syncopated bass lines and piano chordal vamp is seen in Figure 10, an excerpt from a student big band arrangement of the Herbie Hancock composition, Tell Me A Bedtime Story (1980).

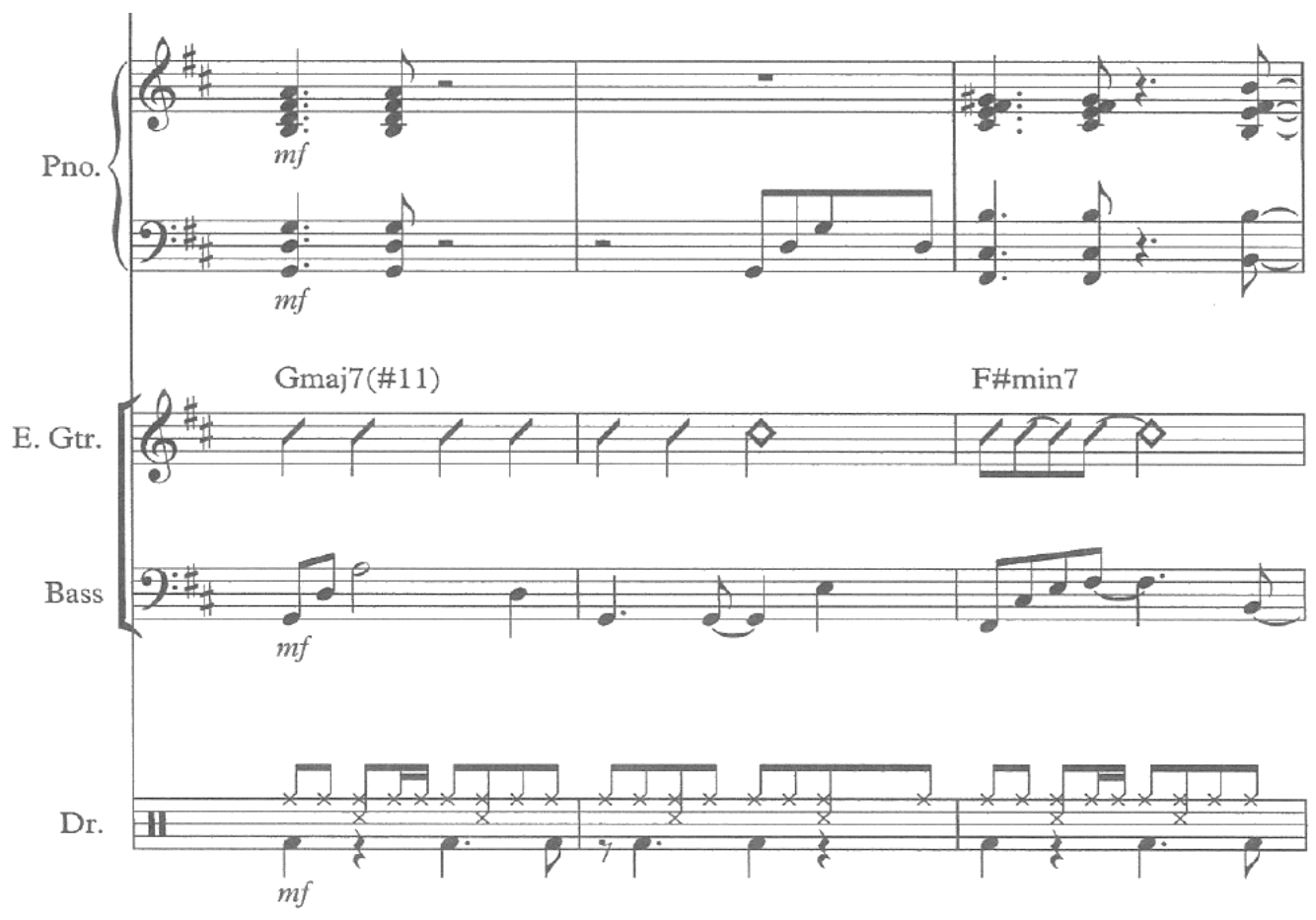

Figure 10. Student assignment excerpt - Tell Me A Bedtime Story, rhythm section 


\section{Example 4: Film Score Orchestration}

The capstone arranging task is the orchestration of a movie theme, arranged for small orchestra from a piano score. The suite of classical and contemporary composition and arranging skills that students have developed throughout the BCM degree culminate in this assessment task. Significant aspects of this task include writing for orchestral

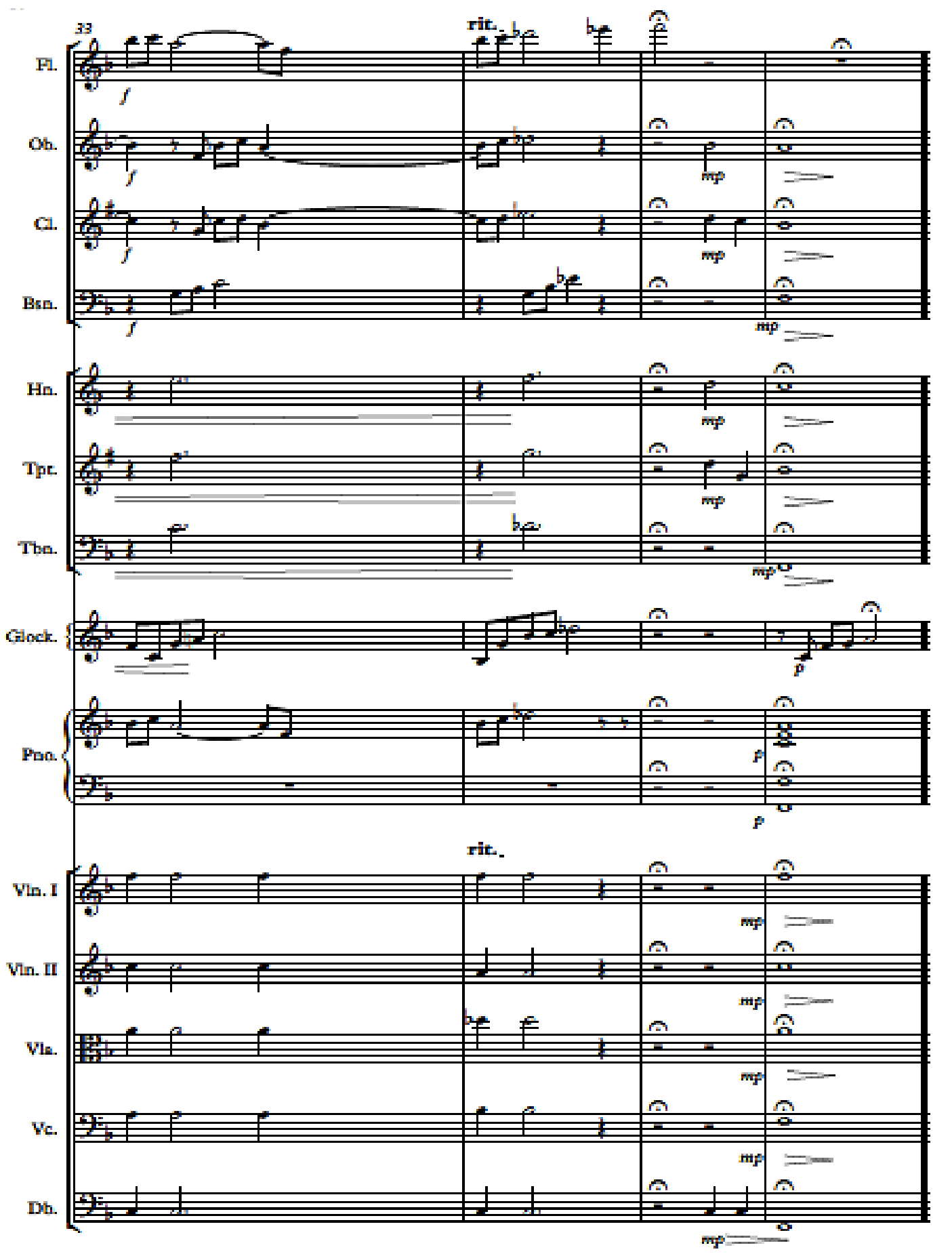

Figure 11. Student assignment excerpt - The Summer Knows orchestration, final bars 
families, using a palette of tonal colours to showcase individual timbral qualities of each instrument and creating unique timbral blends when combining instruments. Technical capabilities of instruments must also be considered, plus stylistic nuances appropriate to the piece's setting. Figure 11 is an example of a student orchestration of The Summer Knows (Legrand, Bergman \& Bergman, 1971), theme song from the movie The Summer of 42. This excerpt from the final bars features the closing melodic motif in flute and piano, with dialogue in other woodwinds. The crystalline timbre of the glockenspiel contrasts to sustained, syncopated brass chords. This palette is underpinned by repeated chords slowly pulsating in the strings. Effective use of rhythmic delay is created in bar 35, where the flute reaches the climax, playing the resolution note solo before the orchestra chimes in to harmonise the final chord.

\section{Example 5: Reharmonisation}

An effective composing technique for adding a contemporary flavor to the harmonic character of music is reharmonisation, i.e. changing the harmony of the original song. This can be done by extending existing chords, adding notes to chords, altering notes in chords (especially the $5^{\text {th }}$ and/or $9^{\text {th }}$ degree) and substituting original chords with different chords, either diatonic or outside the key. An excellent example is the reharmonisation of Stevie Wonder's popular song, I Just Called to Say I Love You (1984), found on Herbie Hancock's album Possibilities (2005). The harmonic vocabulary firmly places this arrangement in jazz, fusion and funk idioms. Chord extensions include major 9ths, added 9ths, \#11ths, 11ths, minor 6ths, minor 7ths, minor 9ths, minor 11ths. Alterations to chords include \#9ths, \#5ths, flat 9 ths, flat 5 ths, and various combinations of these. Chords over non-tonic root notes are frequent; a nuance commonly found in fusion and funk. Frequently an ascending, scalic bass line is formed from using slash chords and chord inversions in this arrangement. This rich harmonic vocabulary not only extends the chords used in the original version, but adds extra chords, substitutes chords and modulates in verse 2 into a rather 'outside' interpretation of the verse. Figure 12 shows an excerpt from a transcribed chord chart of this version, with the original chords placed in the centre of each bar and the chord reharmonisation stated above.

\section{JUST CALLED TO SAY I LOVE YOU}

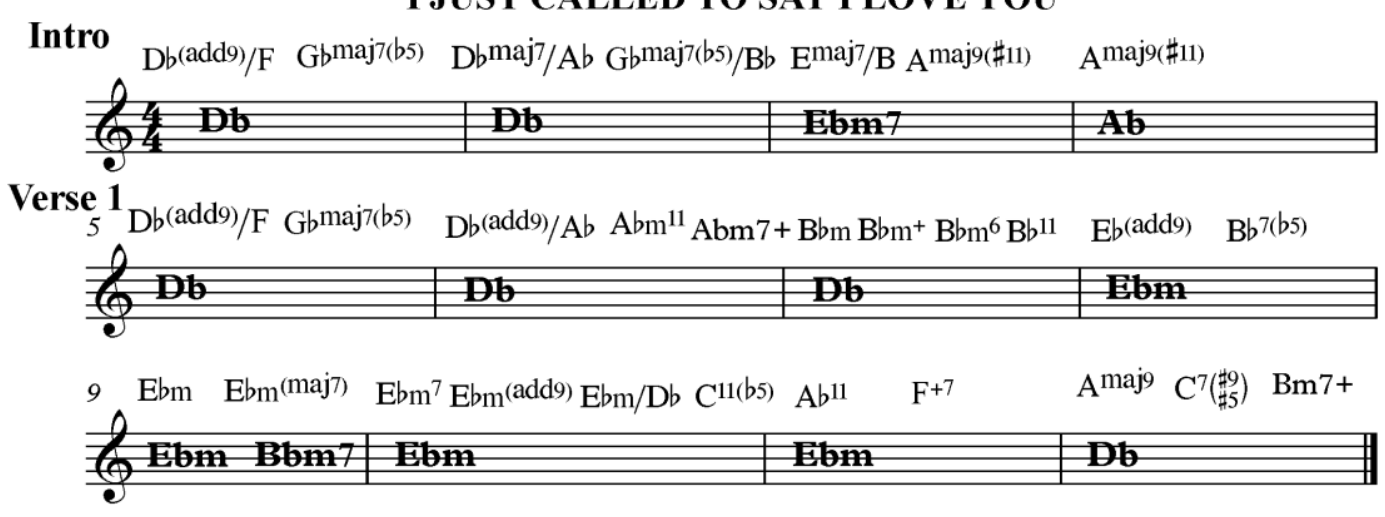

Figure 12. Chord chart of Herbie Hancock's arrangement of I Just Called to Say I Love You 
The jazz flavour of this arrangement is further reinforced by the scale and modal choices that are used for embellishing the accompaniment and for improvisation. In the introduction the keyboard plays an A Lydian mode over the chord A major 9 (\#11); appropriately including the altered 'modal' note of this chord in the scale choice. The outside extension used in this chord and the application of a mode that includes this outside note affirm, from the beginning of the piece, the strong influence of jazz.

Similar chord substitution techniques can be seen in Figure 13, which demonstrates an outside (less closely related and more dissonant) reharmonsisation of the Burt Bacharach standard, Alfie. Original chords from The Real Book (1980) are written below the staves, my reharmonisation is stated above. This example features non-diatonic chord substitution, added chords, chord extensions, the displacement of a cadence by firstly stating it one semitone above, altered $5^{\text {th }}$ and $9^{\text {th }}$ degrees, pedal points, slash chords, a moving line progression, secondary dominant chords and tritone substitution.

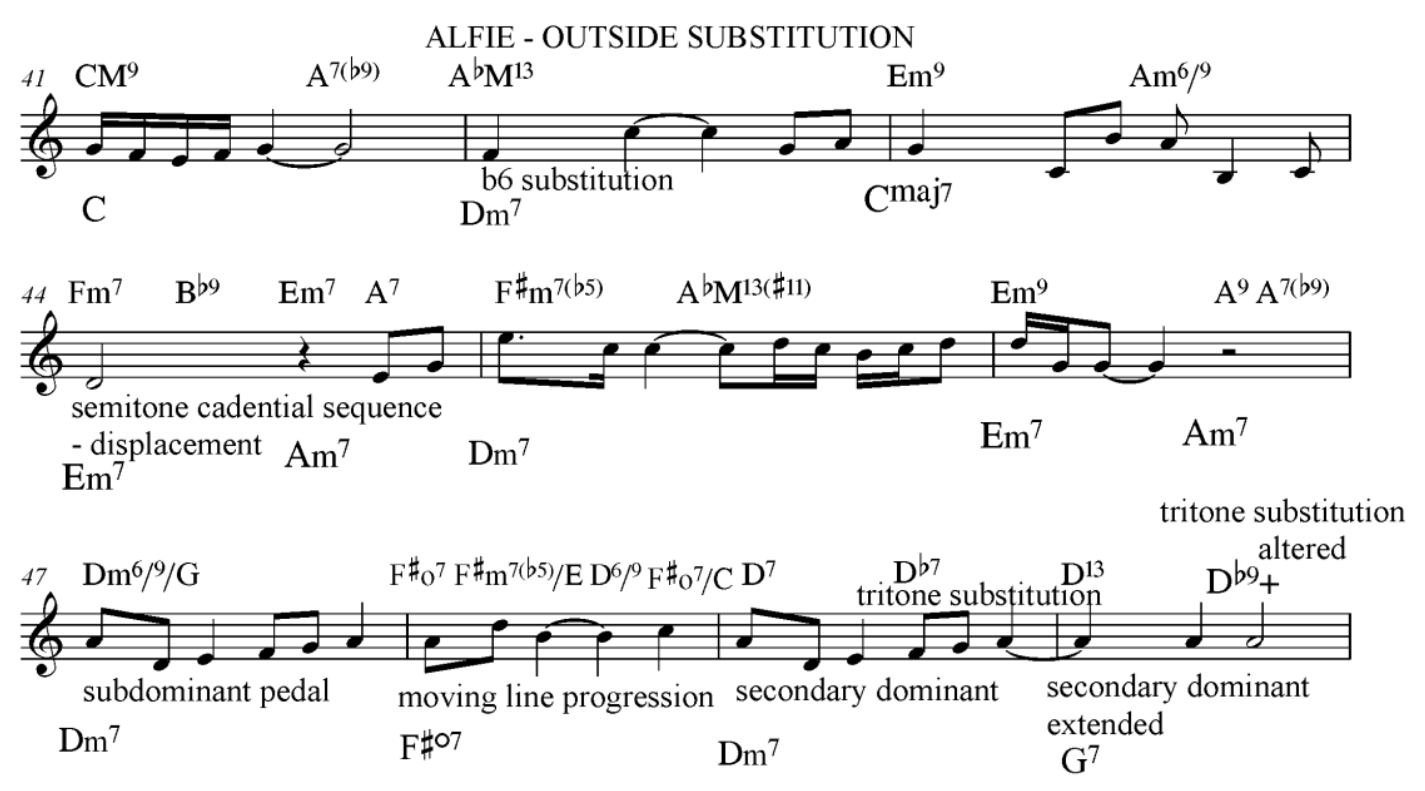

Figure 13. Reharmonisation of Alfie verse

\section{Pedagogical problems, evaluation and conclusion}

A major educational objective of the curricula discussed in this article is to facilitate innovative teaching and learning approaches to develop arranging skills in university music students, pre-service teachers and musicians entering the contemporary music industry. Problems in music pedagogy encountered in this learning process include the challenges non-classically trained musicians encounter in understanding classical composition techniques and structures. This challenge is exacerbated when students have poor music notation skills and little knowledge of classical repertoire and composition structures. Many students express an incomprehension of classical music, fearful and daunted by its complexity and reputation. To simplify and demystify the repertoire and to teach composing in classical structures, author uses templates as building blocks that guide students in the architecture of each composition and provides themes upon which to build the compositions. Students retain significant creative input by arranging pieces such as fugues, sonatas, string quartets, and adding 
countersubjects. This creative task is reinforced firstly by aural and score analysis of traditional repertoire, relating examples to the provided formal template, then modelling examples of student work and performing my arrangements while discussing an associated analysis.

Conversely, classically-trained music students, educators and musicians express a similar lack of understanding of contemporary music nuances, such as jazz harmonies, extended chords, jazz and contemporary rhythms, unfamiliar scales and modes and the application of these for improvisation, and arranging and playing contemporary repertoire in stylistically authentic ways. These problems can be overcome through the application of traditional compositional techniques to contemporary repertoire. Crossing the divide between classical and contemporary music genres can be facilitated by leveraging on the knowledge base that students already possess. Contemporary composition and arranging can be approached through contrasting, yet complementary strategies. Harmonisation can be learned from traditional four-part vocal harmony, including cadence writing and correct voicing and voice leading. The compositional procedure can be applied to extended chord vocabulary as the basic musical principles are the same. Similar arranging techniques and concepts exist in all styles of music, e.g. a ground bass is one type of moving line progression, quartal chord voicings are evident in compositions by Debussy as well as in jazz, extended harmonies occur in romantic piano and orchestral music; cross rhythms and multi-metres abound in twentieth century classical music as well as in contemporary genres.

Identifying similarities between various musical styles, then adapting compositional techniques to a range of genres develops cognitive flexibility and transferability of skills in learners. The composing and arranging assessments presented in this article follow a scaffolded pathway from building a foundation of musical literacy, applying this knowledge through small exercises, then presenting increasingly challenging arranging tasks that extend the skills already learned and transfer the compositional craft to new musical contexts and different styles. This process also develops skills in students to compose for a range of instruments, expanding their understanding of the ranges, capabilities and roles of many instruments. Such expertise is particularly useful for musicians composing out of their instrumental specialisation, e.g. drummers writing for piano, vocalists writing from an instrumental rather than vocal perspective, composers understanding the different functions of instruments (melodic, harmonic and rhythmic) plus the changing roles of instruments within a piece (melody, accompaniment, counterpoint).

The learning pathway is constantly reinforced by aural musicianship training, developing in students an advanced capacity to hear, recognise and transcribe melodies, chords, voicings, progressions, rhythms and instrumental timbral effects. Class performances of student compositions and showcasing outstanding examples in the SCU Concert series also reinforces student learning and motivates their efforts to competently complete composition assignments. Evidence of student learning is apparent in the quality and originality of arrangements that BCM students create each year, as the excerpts above attest. Student performances of these works develop their ability to play parts in polyphonic or complex arrangements, to sing parts in choral arrangements and to recognise the function and textural importance of each musical part. Students also demonstrate independent musical literacy to analyse their own arrangements and justify how each compositional part works. Performing pieces 
reinforces their understanding of structures and assists in composing. Using a variety of teaching strategies accommodates different learning styles (visual, aural, kinaesthetic) and results in cumulative learning.

Formal students' evaluations from 2011-2017 of author's teaching and the units discussed in this article testify to the success of the teaching strategies employed and student's satisfaction with the units. Ratings are consistently above $4 / 5$ and also consistently above the SCU and School average.
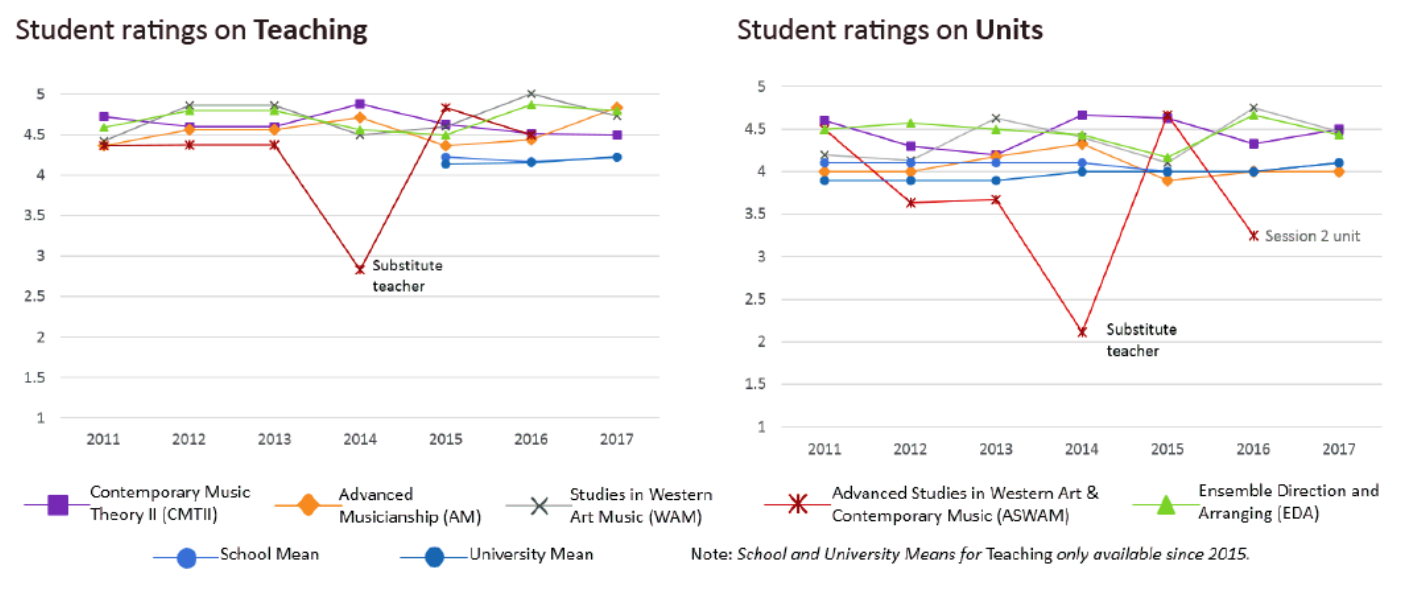

Figure 14. Formal student evaluation of Teaching and Units 2011-2017

This paragraph reports some student responses on completion of these units and includes feedback from an international academic colleague:

"Formerly I was dull in the knowledge of theory but now I have a deep understanding of what has been taught in this unit which will now lead me to further advancement in subsequent units. The content was complex and vast. I have learned a great deal and greatly enjoyed it" (Student Feedback (SF) CMT II, 2014).

"I enjoyed learning in depth about Western Art Music, it helped me gain appreciation and I enjoyed knowing the theory behind the compositions. I have a better understanding of its significance in the musical world and its relationship to education" (SF, WAM, 2009).

"The basic structures that were used so that we get the chance to compose our own classical composition and teach people in future these very same rules and techniques" (SF, WAM, 2010).

"A fantastic learning experience - I was forced to understand vertical harmony as opposed to just writing with intuitive horizontal ideas"

(SF, EDA, 2017).

"I have really enjoyed writing this arrangement and look forward to putting some of these skills into practice on prac" (SF, ASWAM, 2013). 


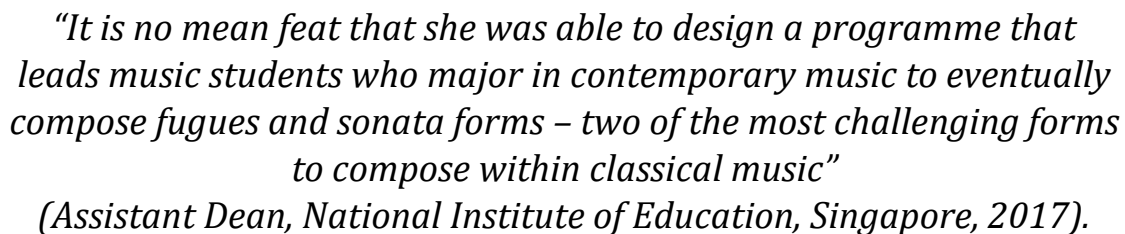

Formal and informal feedback and student focus group discussion are regularly analysed and used to inform and refresh curricula and pedagogical strategies.

\section{Applications}

The skills and knowledge in contemporary music theory, aural musicianship, classical and contemporary composition and arranging learned by students through the contemporary music curricula analysed in this article have extensive applications in music teaching, professional practice and the music industry. The assessment tasks prepare pre-service teachers for many practical aspects of secondary school teaching, such as arranging music for choirs, school ensembles, big bands and small orchestras. Pre-service teachers refine these vocational skills on practicum and report how useful these skills are and how they can be applied. The ability to arrange and orchestrate music is a valuable vocational craft allowing musicians to create new versions of standard repertoire, stylistically situate pieces in different musical genres, add musical complexity and rigour to simple compositions, and embrace a variety of musical traditions and nuances that can be expressed aesthetically in a cohesive whole arrangement. Established teachers also benefit from upskilling in composing and arranging in genres with which they are unfamiliar, by developing the ability to transfer compositional skills from one genre to another, such as classical to contemporary or vice versa. This benefits educators who have to teach composition in secondary school music curricula or changing university music programs.

Strategies that ensure successful learning include designing a spiral curriculum where engagement with the theory and compositional concepts is encountered repeatedly and at increasingly higher levels of difficulty and complexity. These encounters are underpinned by a foundation of musical literacy, supported by aural musicianship training and applied practical performance. The purpose and application of the skills and knowledge learned through these curricula are constantly identified and practised in diverse vocational contexts, therefore reinforcing the relevance of this compositional craft. Ideally the expertise music students, teachers and practitioners gain from this education motivates them to create original educational resources and original creative works throughout their professional life. Sharing author's pedagogy, teaching strategies, assessments and the resources that enable its success contributes to international scholarship, research and teaching in the music discipline.

\section{References}

Bacharach, B. (1980). Alfie. In The Real Book (Rev. ed.). Syosset, NY: The Real Book Press, 1.

Bruner, J. (1960). The Process of Education. Cambridge, MA: Harvard University Press.

Bruner, J. (1996). The Culture of Education. Cambridge, MA: Harvard University Press. 
Candy, L. Practice based research: A guide. Retrieved 26.09.2017 from https://www.creativityandcognition.com/resources/PBR\%20Guide-1.1-2006.pdf

Curzon, L. B. \& Tummons, J. (2013). Teaching in Further Education: An outline of principles and practice ( $7^{\text {th }}$ ed.). London: Bloomsbury.

Eaton, W., Elling, K. \& Galdston, P. (2003). In the Winelight. In Man in the Air (CD Recording). Blue Notes Records.

Efland, A. D. (1995). The spiral and the lattice: Changes in cognitive learning theory with implications for art education. Studies in Art Education, 36(3),134-153.

Foster, D., Graydon, J. \& Champlin, B. (1979). After the Love Has Gone. In The Real Book, Vol. V. Hal Leonard.

Hancock, H. (1980). Tell Me a Bedtime Story. In The Real Book (Rev. ed.) (pp. 424-425). Syosset, NY: The Real Book Press.

Hancock, H. (2005). I Just Called to Say I Love You. In Possibilities (CD Recording). Hear Music.

Harden, R. M. \& Stamper, N. (1999). What is a spiral curriculum? Medical Teacher, 2(2), 141-143.

Legrand, M., Bergman, M. \& Bergman, A. (1971). The Summer Knows. Warner Bros. Music.

McCartney, P. \& Lennon, J. (1966). Eleanor Rigby (The Beatles). In Revolver (Record). London: Parlopohone.

Porter, G. (2013). Wolfcry. In Liquid Spirit (CD Recording). Blue Notes Records.

Robinson, K., Trzetrzelewska, B. \& White, D. (1994). An Olive Tree. Retrieved 26.09.2017 from http://www.lyricsmania.com/an_olive_tree_lyrics_basia_trzetrzelewska.html

Sher, C. (1995). The Real Book. Petaluma, CA: Sher Music.

Wonder, S. (1984). I Just Called to Say I Love You. London: Black Bull Music/Jobete Music UK Ltd. 


\title{
AXIOLOGICAL MODEL OF MASTERING PIANO PLAYING AS A BASIS OF THE COMPETENCE APPROACH
}

\author{
Larisa MALKOVA \\ Latvia \\ e-mail: lara.malkova@gmail.com
}

\begin{abstract}
The processes of globalization of the end of the 20th and the beginning of the $21^{\text {st }}$ century have penetrated not only economy and politics, but also education. Alternative educational programs have been designed, the labour market and the market of educational services have developed and, as the result, the competition between the educational programs has emerged. The need for assessing these programs stimulated the development of a uniform approach to rating the efficiency internationally. The joint report of the European Council and the Commission of 2010 "The Main Competences to the Changing World" proposes competence approach for this purpose.

The programs for mastering piano playing, too, need revising and evaluating, since a serious discrepancy has been detected between the knowledge, skills and activities offered by the program, on the one hand, and those required in real life, on the other hand. The study is concerned with the Axiological Model of Mastering Piano Playing developed by the author as the basis for the competence approach to teaching and learning.

Keywords: learner, mastering piano playing, competence approach, axiological model
\end{abstract}

\section{Introduction}

In Latvia, education constantly responds to the changes in society, to the needs of society. The curricula have been altered depending on the development of technologies and natural sciences or due to ideological changes. The syllabus has been supplemented with new subjects. These changes are oriented towards the extensive development of education, towards expanding the scope of the material to be acquired. However, the contemporary intensive time and constant development interfere with achieving qualitative results in education. In this article the author analyses mastering piano playing by employing the axiological model in the aspect of key competences.

Research aim: by improving the interconnections between mastering piano playing and educational content, to analyze the Axiological Model of Mastering Piano Playing as the basis of the competence approach. 
Research subject: The Axiological Model of Mastering Piano Playing in the context of the competence approach.

Research methods: a) the analysis of philosophical, psychological, pedagogical, methodological literature; b) modeling;

\section{Theoretical background}

The report of the European Council experts of 1996 offers and describes a new conceptual approach to assessing education quality, and emphasizes that the focus will be on learners' ability to apply the acquired knowledge, skills and attitudes in real life situations rather than on testing what they have acquired in specific subjects. This is a competence approach whose origins are to be traced in the USA in the $50-\mathrm{s}$ of the $20^{\text {th }}$ century as seeking for new criteria of human work results, in contrast to IQ tests.

In Latvian the word 'competence' has two meanings: a) competence as a skill; b) competence as a qualification (Tilla, 2004).

This follows from the origin of the English word, where there are two distinct terms:

- Competency - interpreted as a skill in a narrow sense: have competency (one has certain qualities or indication to do this job);

- Competence - interpreted as a general competence, quality: be competence (adequacy for some job) (Hymes, 1972; Raven,1984).

Russian scientists use two concepts as well:

- Competence (компетенция) in a narrow sense;

- Competency (компетентность) in the sense of a general competence, quality (Зимняя, 2004; Хуторской, 2013).

In the $21^{\text {st }}$ century the competence approach is to be understood as a method for modelling and describing education results where the norms of quality are expressed in the form of the features of learner's readiness for a practical action (European Commission/EACEA/Eurydice, 2012).

Though the apparatus of concepts is still changing, several principles of the competence approach, that derive from its aims, content, organization and assessment of the process, can be formulated:

- The aim of education is to develop learners' ability to independently solve problems in different spheres and kinds of activity, based on gaining social experience;

- The content of education includes didactically adopted social experience of solving cognitive, cultural, communicative, moral and other problems;

- The organization of the educational process manifests itself in the form of conditions under which the development of learners' independent experience will be encouraged through solving cognitive, communicative, moral and other problems; 
- The assessment of education results has been done on the basis of the description of different learner's achievement levels reached in a specific educational period.

The competence approach in education has three competence levels: key competencies, general subject competencies and one subject competencies. From the position of a competence approach, the most important result of educational activity is the development of key competencies.

In turn, key competencies fall into seven areas:

- Value sense competence,

- General cultural competence,

- Educational cognitive competence,

- Information technological competence,

- Communicative competence,

- Social competence,

- Self-improvement competence (Хуторской, 2013).

\section{Analysis of Model of Mastering Piano Playing in the context of the competence approach}

The analysis of philosophical, psychological and pedagogical literature allows us to conclude that focusing on and constructing the problems of the subjects of musical axiological pedagogy in the model are related to

- the awareness about the preciousness of learners' personality and to promoting its development;

- the analysis of the content values of mastering piano playing;

- bringing forward those pedagogical conditions that activate the educational process of piano playing.

This enabled us to substantiate the Axiological Model of Mastering Piano Playing within the context of the competence approach (see Appendix 1). The development of the model allowed putting forward and substantiating theoretically pedagogical conditions necessary for its implementation by activating learners' personal and social meanings.

The model envisages promoting the acquisition of a value complex during the process of mastering piano playing. The value complex of the model consists of four blocks:

1. The block of learners' individual features, whose content was revealed by valueorientations, attitudes, consciousness and behavior;

2. The block of content values of mastering piano, which includes a) personally oriented content values of mastering piano playing, which are expressed in the tasks promoting learner's development; b) values of music as art expressed in its functions;

3. The block of the components of the process of mastering piano playing, which consists of motivation, content, organizational-methodological and evaluative components; 
4. The block of pedagogical conditions for mastering piano playing, which brings into focus the context of the axiological approach. Its content is revealed in

- studying and bringing into focus the needs of learner's personality and of the society during the educational process;

- implementation of learner's experience-based educational process;

- the development and acquisition of author's piano playing program which is based on values important for learners, society and piano playing;

- learners' involvement in a value-oriented communication;

- the development of learners' self-assessment skills.

The block of pedagogical conditions as means of achieving the aim of mastering piano playing is created to perfect the content of the components of the educational process of mastering piano playing, for example:

A. The content of the components of motivations can be improved by three pedagogical conditions:

- the results obtained from studying the needs of learners, parents and teachers via surveys, i.e. needs of a person and society, and bringing them into focus during the study process;

- by involving learners' subjective experience;

- the development of author's program based on the axiological approach to mastering piano playing, which is designed on the basis of the results obtained in the survey.

B. The nature of the content component is improved by developing and implementing the author's piano playing program based on the axiological approach.

C. The content of the organizational-methodological component can be improved by

- acquiring author's piano playing program based on the axiological approach;

- involving learners in a value-oriented communication.

D. The content of the evaluative component can be improved by

- involving learners in a value-oriented communication;

- contributing to the development of learners' self-assessment skills.

From the aspect of the competence approach, we are interested in the third and fourth blocks of the model. The content of the third block of the model "The components of the process of mastering piano playing" and the fourth block of the model "Pedagogical conditions which bring the context of axiological approach into focus" are revealed in interaction. The model particularly emphasizes the idea of bringing the content of the educational process components into foreground through creating pedagogical conditions which focus on the context of axiological approach. Each of the components - motivation, content, organizational-methodological, evaluative - is improved by some pedagogical condition based on findings of self-realization theory. The conditions, that improve components of motivation, have been created also by studying the needs of learners and society during the process of mastering piano playing, by filling the educational content with the required musical values and specifying the aims of mastering the piano playing. 
The needs were studied through the surveys of annual Festival participants - young pianists - from Latvian comprehensive schools with professionally-oriented music programs (2004 - 2017). During the establishing stage of the research in 2009, learners, their parents and teachers, who took part in the 2004 Festival, were surveyed. During the research $(2004-2013)$ these participants learnt piano playing in their own schools by the author's piano playing program (Maljkova, 2013).

Among the motivations as pedagogical conditions improving the component of the model block are involving learner's subjective experience during the educational process and designing and studying author's piano playing program. The content of the program addresses the needs of learners, their parents and teachers and is coordinated with the common methodological guidelines for mastering piano playing, which in our research have the role of values. Within the framework of the author's piano playing program, the content and organizational-methodological components of mastering piano playing are also being perfected.

The organizational-methodological component of the model can be improved through studying the author's piano playing program and through involving learners in a valueoriented communication: participation in festivals, concerts. Learners have to feel and experience that the interpretation of a composition they offer is interesting and valuable for listeners as well. Besides, a successful performance at the concert contributes to the development of learner's skills and abilities of overcoming difficulties, since this requires learning to correctly set the aim and to plan time to achieve it.

At developing the ways of increasing the efficiency of the educational process the contemporary sciences of psychology and pedagogy are oriented towards the subjectsubjects approach. This approach interprets learners' learning aims, tasks and their fulfilment as personally significant. Consequently, the assessing component of the model is to be improved by the axiological aspect of promoting the development of learner's skills of self-assessing. Self-assessment - i.e. a personality assesses oneself, one's abilities, qualities and place among other people - being a regulator of human behaviour, influences the efficiency of activity as well as a further development of a personality. Learners' relations with other people, their critical attitude and pretensions towards themselves, their attitude towards success and failures greatly depend on the level of learners' skills of self-assessment. Makarova (Макарова, 2004), scientist of sociological sciences, characterizes self-assessment by the parameters as follows:

- Level - low, average, high;

- Correlation with a real success - adequate/ inadequate or too high/ too low;

- Structural features - conflict or without conflict;

- Sustainability - sustainable/unsustainable.

The skill of self-assessment is one of the indicators of the criterion Self-organization promoting self-realization.

The results of the analysis of interaction between the Pedagogical conditions and key competences in the fourth block of the Axiological Model of Mastering Piano Playing are shown in Table 1. 
Table 1. Interaction between the pedagogical conditions and key competences in the fourth block of the Axiological Model of Mastering Piano Playing

\begin{tabular}{lll}
\hline NR. & $\begin{array}{c}\text { PEDAGOGICAL CONDITIONS OF THE FOURTH } \\
\text { BLOCK OF THE MODEL }\end{array}$ & \multicolumn{1}{c}{ KEY COMPETENCES } \\
\hline 1 & $\begin{array}{l}\text { Studying of the needs of a learner's personality } \\
\text { and society and bringing them into focus during } \\
\text { the process of mastering the piano playing }\end{array}$ & $\begin{array}{l}\text { Social, cognitive, information } \\
\text { technological, general cultural }\end{array}$ \\
2 & $\begin{array}{l}\text { Implementation of a learner's experience-based } \\
\text { educational process }\end{array}$ & $\begin{array}{l}\text { Communicative, self- } \\
\text { improvement }\end{array}$ \\
3 & $\begin{array}{l}\text { The development and acquisition of the author's } \\
\text { piano program based on learning the values } \\
\text { important for a learner, society and piano } \\
\text { playing }\end{array}$ & $\begin{array}{l}\text { Value meaningful, information } \\
\text { technological, social, cognitive }\end{array}$ \\
4 & $\begin{array}{l}\text { The development of learners' self-assessment } \\
\text { skills }\end{array}$ & Self-improvement \\
\hline
\end{tabular}

\section{Conclusion}

The analysis of interconnections between mastering piano playing and the content of music education allows us to conclude that the Axiological Model of Mastering Piano Playing encompasses pedagogical conditions which are the basis of the competence approach to the subject.

\section{References}

Delors, J. (1996). Learning: The treasure within. Paris: UNESCO.

Eiropas Komisija/EACEA/Eurydice (2012). Galveno kompetenču pilnveide Eiropas skolās: rīcībpolitikas uzdevumi un iespējas [The improvement of basic competencies in European schools: Tasks and opportunities of action policy]. Luksemburga: Eiropas Savienības Publikāciju birojs (in Latvian).

Hymes, D. (1972). On communicative competence. In J.B. Pride, \& J. Holmes (Eds.), Sociolinguistics: Selected readings (pp. 269-293). Harmondsworth: Penguin.

Maḷkova, L. (2013). Klavierspēles apguves autorprogramma un tās izveides teorētiskais pamatojums [Author's program for mastering the piano playing and the theoretical basis of its design]. In J. Davidova (Ed.), Problems in Music Pedagogy (pp. 23-47). Daugavpils: Academic Press „Saule” (in Latvian).

Raven, J. (1984). Competence in Modern Society: Its identification, development and release. Unionville, New York: Royal Fireworks Press. Available: www.rfwp.com

Tiḷlla, I. (2004). Pusaudžu sociālkultūras kompetences veidošanās otrās svešvalodas mācību procesā: Promocijas darbs [The Development of Teenagers' Socio-cultural Competence During the Process of Foreign Language Studies]. Rīga: Latvijas Universitāte (in Latvian).

Зимняя, И.А. (2004). Ключевые компетентности как результативно-целевая основа компетентностного подхода в образовании [Key Competencies as a Resultant-target Basis of 
a Competence Approach in Education]. Москва: Исследовательский центр проблем качества подготовки специалистов (in Russian).

Макарова И. (2004) Психология [Psychology]. Москва: ЮРАЙт.

Хуторской, А.В. (2013). Компетентностный подход в обучении [Competence Approach in Education]. Москва: Издательство «Эйдос»; Издательство Института образования человека (in Russian).

Received 09.07.2017

Accepted 17.10.2017 



\title{
PROBLEMS OF MUSIC EDUCATION FOR BLIND AND VISUALLY IMPAIRED PEOPLE IN ESTONIA
}

\section{Tiiu ERNITS}

Tallinn University, School of Educational Sciences, Estonia

\author{
Kadri KUTSAR \\ Tartu Emajõe School, Estonia \\ e-mail: tiiuerni@tlu.ee
}

\begin{abstract}
In Estonia, children with blindness or low-vision can attend either mainstream school or special school. However, there is no organization of musicians with blindness or low-vision in Estonia. The aim of the study is to give an overview about different problems of music education for blind and visually impaired people in Estonia. For mapping and describing the learning problems for Estonian blind musicians, we carried out a survey based on three semi-structured questionnaires: one for blind music learners, the second for former learners of music with blindness and the third for music teachers of blind learners. The survey aims at finding out the learners' and their teachers' opinions about the following aspects: limitations and problems; didactical aspects; content of music education, current opportunities of learning music. This survey is the first of its kind in Estonia.

The results show that attending music school is the most important way for getting specific music education. The main limitations mentioned were connected with Braille music notation, and insufficient availability of modern accessible technology in music teaching/learning for the blind. There is a need for study material in mother language. One of the problems of the blind or visually impaired children attending music schools were related to mobility and need for assistance. Teachers find that blind music learners would need more individual music lessons, they also need opportunities to improve their self-confidence to perform in public. More co-operation is needed between primary, secondary and tertiary musiceducation institutions to facilitate students' successful transition from one stage to the other. In conclusion, there are several problems of learning music for the blind and visually impaired in Estonia. Despite of difficulties, all respondents highlighted the importance of learning music.
\end{abstract}

Keywords: music education, children with blindness and low-vision in Estonia 


\section{Introduction}

In order to make society more coherent and to function better, it is important that every visually impaired child interested in music has the opportunity to acquire musical education. It gives the visually impaired children equal opportunities among others and develops them significantly. Fine arts should have a definite place in education, because dealing with fine arts contributes to the development of a holistic human being. In the learning process, the child uses a variety of media tools (including textbooks) that allow the child to be purposefully engaged mediation of information, communication and various activities. The analogy to the classical triad of the cognitive, emotional and psychomotor domains is here certainly no coincidence, because mediation of information is related to the cognitive processes of a person, communication is related with affective components and activities is related to psychomotor level (Jünger, 2006; Ernits, 2013).

There is pluralism in the terminology of 'music', we bring out a few of them. Music is a sign system and a means to create and influence affective states in themselves and in others (Stadler Elmer, 2015). Different musical cultures embody different ways of imagining sound as music (Cook, 2005). Music is to be considered also a kind of complex language. Music is a manifestation of human culture and a socio-cultural phenomenon, an expression, communication and meaning medium in cultural perception (Bennett, 2005,54 ). In particular, music education is primarily based on a complex relationship system music-person (Schläbitz, 2009), which can be seen from a variety of aspects.

Eyes are one of the most important sensory organs of a human-being. In principal music is the only totally accessible art for blind person and visually impaired people are frequently musically more talented than others. Professor A. Ockelford, Director of the Applied Music Research Centre at the University of Roehampton, in collaboration with the Royal National Institute of Blind People (RNIB), has scientifically investigated the impact of congenital visual impairment on the development of musical abilities (in childhood). The research results by A. Ockelford (2015) have highlighted, there was a substantial difference in the prevalence of absolute pitch among the children who were visually impaired and those who were fully sighted. He emphasized that $47 \%$ of the children with congenital visual impairment have absolute pitch. The studies of A. Ockelford provided evidence that a) children with visual impairment were more likely than their fully-sighted peers to show a particular interest in everyday sounds and music, b) learning difficulties need not impede a child's evolving musicality, and, ultimately, to achievement at the highest level. A. Ockelford emphasized that achieving success in learning is crucial to achieve a balance between the requirements for individual vision of a pupil with a visual impairment and the requirements of a school curriculum.

We emphasize that the blind and visually impaired people have a great advantage - they are easier to focus than the sighted (people seeing).

The master's thesis of K. Virula (2012) gives an overview about the development of visually impaired children and their opportunities to receive pre-school education corresponding to their abilities from kindergartens in Estonia. The study provided evidence that the main problems with an individual development plan were mentioned the lack of experience, time and examples. 
The umbrella organization of blind and visually impaired people in Estonia (Estonian Federation of the Blind) is consisting of 16 member organizations among whereas, there is no organization of musicians with blindness or low-vision/partially sighted in Estonia, which can be considered as the first big problem in the field.

There are more specific problems of music educationfor Estonian blind musicians, which has been an unexplored field of research up to the present time. So this survey is the first of its kind in Estonia.

Aim of the research is to give an overview about problems, different aspects of music education and the learning opportunities of music for blind and visually impaired people in Estonia.

Object of the research: the examination of the situation concerning music education of blind and visually impaired people in Estonia. The term 'visually impaired' denotes people who are blind or have conditions resulting in various degrees of partial sightedness. Among these people, there are visually-impaired young people, who learn music and there are sighted music teachers working with visually-impaired learners or visually-impaired music teachers; there are amateur and professional musicians instrumentalists, singers or composers etc.

\section{Methods and sample}

For mapping and describing the learning problems for Estonian blind musicians, we carried out a survey based on three semi-structured questionnaires: one for blind music learners, the second for former learners of music with blindness and the third for music teachers of blind learners (both visually-impaired music teachers or sighted and working with visually-impaired learners, both teachers from mainstream and special schools). The survey aims at finding out the learners' and their teachers' opinions and assessments about the following aspects: limitations and problems, didactical aspects, content of the music education, current opportunities of learning music. Questions were asked from former learners to find out their retrospective opinions. For instance, the questionnaire for blind music learners included 25 questions and 79 statements which were divided into three subtopics: information about the respondent, questions about music studies, and problems and limitations in learning music (see Appendix).

\section{Profile of the blind learners}

In our sample, 8 of respondents were female and 6 male learners. The most (5) were students aged 15-24 years. The sample included students from both the city and the countryside: Tartu, Tallinn, Võru and Pärnu, in the city and county, most of them studied in Tartu.

\section{Profile of the teachers of blind learners}

In the sample, 12 of respondents were female teachers and one male teacher; 7 of teachers were 55 years or older, having lots (26 years or more) of experience in their works. In our sample, 9 of teachers teach blind and partially sighted in a music school. 10 of them had higher education in the field of music. No one had higher education in special education but they have passed further training courses on special education and have studied on their own reading study materials about this topic. Five teachers 
have completed the course on Braille music reading. For example, teachers from Tartu Emajõe School and Tartu Second Music School took part in a training course where the Braille music notation was taught by Vello Vart in 2013. One of teachers said: "I have participated in two training sessions, but they have not been useful, so there is no special preparation. I have participated with blind student in the master classes at the Tallinn Music High School, where they have helped us a lot" (T2).

\section{Profile of the former music learners with blindness}

According to our survey, among of respondents there were one female and 6 male learner formers. In our sample, 3 of the respondents were over 55 years old, answered the questionnaire. The respondents were from Tallinn, Tartu, Viljandi, Harju County, Tartu County. All respondents are either members of the Northern or Southern Estonian Blind Association. Many former learners of music have been self-taught.

This survey is anonymous. The questionnaires were sent to several schools and other institutions owning any information on the issue. We distributed the questionnaire via e-mail where the director or head of education delivered them to teachers of children with visual impairment. The respondents completed electronic surveys or answered questions on paper. The number of respondents was 34 . Unfortunately, a questionnaire that is implemented electronically does not attract the expected number of respondents. In further studies the number of visually impaired students should be increased.

We used the Google Forms software to collect information and organized data. The data were analyzed by descriptive statistical methods predominantly using the package SPSS for Windows 20.0. Open answers were used to interpret the data according to qualitative content analysis.

The analysis of literary sources and documentation were used as the research methods too. The present research relies mainly on source material collected between 2015 and 2017.

\section{Results of the research}

This paper consolidates the findings from three questionnaires.

\section{A. The reasons and motivation(s) to learn music}

The respondents were asked about the reasons to learn and practice music. Our respondents highlighted that they could not even imagine their life without music: "It's possible to put our joy and sadness into it... I'm glad I have music to share with others" (L5); "It makes me happy" (F6), were just some of the answers. The question "What has motivated you to learn music?" was answered "Great love for music" (L4, L8, L10). In terms of motivation, the keywords dominated: interest, liking and willingness to make music themselves. Recommendations from family members were also important. One of the respondents wrote: "I like and I want to play in the ensemble with four hands" (L8). There were several answers to the question "Why do you want to learn music?”. Among 21 responses, the most frequent claim was: "It's my hobby and a way of self-realization" (see Figure 1). Three blind students consider learning music as preparation for their future profession. Two of the respondents indicated the reason for learning music: to 
meet the other persons interested in music. One respondent stated: "This is the only thing I can, and absolute pitch is a great help in learning" (L2).

\section{Why do you want to learn music?}

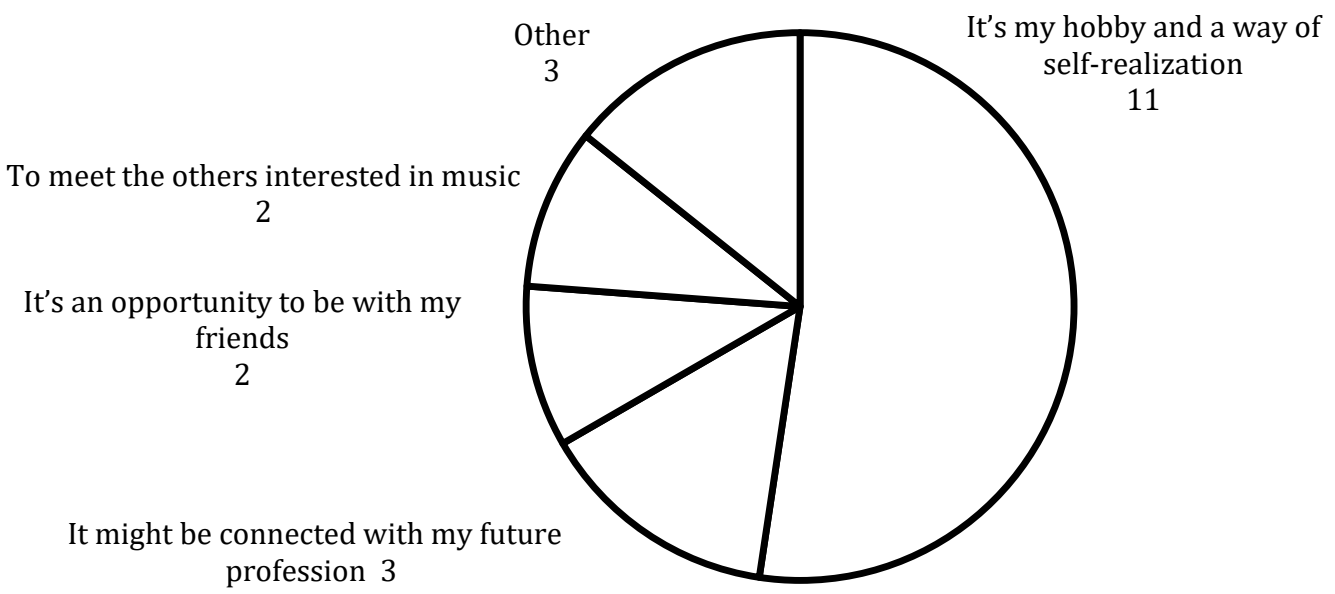

Figure: 1. Statements of the questionnaire to the question "Why do you want to learn music" given by learners/students (count of total responses)

According to our study, the position of the former learners on the importance of music was summarized in the sentence: "All the music is for pleasure" (F4).

\section{B. Music making}

The research indicated that most of the respondents can play more than one musical instrument. According to our research, the piano and synthesizer are most often played by learners. One of the learner respondents mentioned that he can play five different musical instruments (L10). All the former learners can usually play many musical instruments: accordion, piano, guitar, brass instruments etc, but also folk music instruments which have gained popularity in recent years.

The respondents answered that mainly they perform at school concerts (12), but also at concerts outside school, public concerts (10) (for instance, White Cane Day). The Annual Republican Disabled People's Cultural Festival gives a good opportunity to perform for blind people (4). Three pupils have participated in national music contests and one respondent has had a very successful solo concert (L2). The former learners of music with blindness play most often in brass bands.

\section{Limitations and problems}

Respondents were asked about problems of learning music and as it turned out, there are a number of problems. 


\section{A. Problems highlighted by the learners}

Problem 1: The survey indicated that the main problem is the lack of study materials in Braille script, which was a frequent answer to the question "What problems do you feel existing in learning music?". Among the responses to the question "What kind of study materials would you need?", were often written that Braille music books (L1, L2, L3, L10, L11, L12).

The respondents highlighted the need for a handbook of Braille music notation and Braille textbooks for solfeggio, theory, music history.

Problem 2: The co-existing problem is the poor skills of Braille music reading. For instance, one of the respondents complained that, because he was not well trained in Braille music reading, the acquisition of piano music pieces was slow and the writing of dictations in solfeggio was complicated (L5). However, reading music in Braille may be too difficult for multiple disabled visually impaired learners. Even a child studying in a non-simplified curriculum noted: "Reading rhythms in Braille is too difficult" (L10). Musical literacy was considered important. But music Braille notation, which is indispensable for musical literacy, differs far more from conventional musical notation. In fact, the most important elements of a score (pitch, note duration, melodic line) can certainly be represented in a very precise way with Braille. But, due to the fact that Braille is based on 64 dot combinations, a Braille score is a linear representation of the original, and there is no logical analogy between the Braille symbol and its musical meaning (Description, 2012).

Problem 3: According to our survey, the need was for modern technological devices for recording, need for computer based learning equipment, special software and interfaces, basic programmes to convert music into Braille. Those applications that convert a conventional musical notation are even available, but have shortcomings which impede their distribution and specific software programmes are expensive.

Problem 4: There is a special need for study programmes in mother language, among them need for Estonian language music theory programmes for children. However, a programme to convert a text from conventional musical notation into Braille music, is under development at the University of Tartu (Oruste, 2017). The goal of the M.-L. Oruste's Bachelor's thesis is to create a web-based application that translates musical notation in MusicXML format to Braille (Oruste, 2017).

Problem 5: More cooperation is needed between primary, secondary and tertiary music education institutions to facilitate students' successful transition from one stage to the other.

Higher music education can be obtained in Estonian Academy of Music and Theatre but among our respondents no one has used that opportunity. However, there was one respondent who had studied music at higher level at the Viljandi Culture Academy of University Tartu at the department of folk music.

Problem 6: The need for a system and network for musical education of blind were indicated as important (L1).

Problem 7: One of the problems of the blind or visually impaired children attending music schools, was related to mobility and need for assistance. For instance, one 
respondent lives in one town, attends comprehensive school in another town and the music school situates in third one. In that case the assistance is provided by the family. For instance, these children who live in another county can't attend the music lessons on Fridays (at Tartu 2nd Music School) due to transport problems. However, Tartu Emajõe School and its former director have significantly contributed to the solution of transportation problems of their students.

Problem 8: One respondent considered a big problem to be a grandmother demanding that he play only the teachings given by the school and not deal with her own creation (L9). As noted above, A. Ockelford (2015) emphasized that achieving success in learning is crucial to achieve a balance between the requirements of a school curriculum and the requirements for individual vision of a pupil with a visual impairment.

In conclusion, the main mentioned limitations were connected with Braille music reading, the need for study material in mother language and insufficient availability of modern accessible technology in music learning for the blind.

\section{B. Problems highlighted by music teachers}

Problem 1: According to our survey, there is a need for study material in mother language, for textbooks in Braille including the inspiring repertoire for learners. There are no Braille books on music history, solfeggio, music history, learning the musical instrument etc. One of the teachers said: "There is a lack of learning materials, even for advanced students. There is also a need for suitable fittings and a learning environment" (T5).

Problem 2: The need for unified Braille notation was considered very important, to make learning more efficient. The Estonian teachers working with blind children, hope to find a solution to the problem of the Braille music notations, that is, to uniform simplified versions locally existing in different countries. It turned out, however, that there is currently no direction for developing simplified Braille script. Instead, there are intensive searches and experiments in the different worlds to find new technological solutions that support a visually impaired person in music studies.

Only one teacher among others did not consider it necessary to learn the Braille music notation at all.

Problem 3: Teachers find that blind music learners would need more individual music lessons, they also need opportunities to improve their self-confidence to perform in public.

There is a great need for individual curricula, that include movement, dance etc. One of respondents stated: "There is a firm need for 3D perception exercises" (T5). Undoubtedly, moving and feeling the body is very important for the blind, it contributes to learning music. In some countries, there is a teacher for Dispokinesis, which means a movement theory for instrumentalists (Rembeck, 2012). One of the respondents highlighted: "In my opinion, we are in debt to blind person by the developing of sensual perception" (T5). However, for additional individual hours, a financial problem arises, because the local government does not want to supplementary finance individual lessons for children with special needs. 
Problem 4: Teachers would like to have modern technical devices for recording and for computer-based teaching, need for additional software.

Problem 5: On the basis of the data from the Figure 2, the teachers most often feel the lack for creating and adapting learning materials. To the question „Do you feel the need for specific training in some of the following points?" was followed by the answers below:

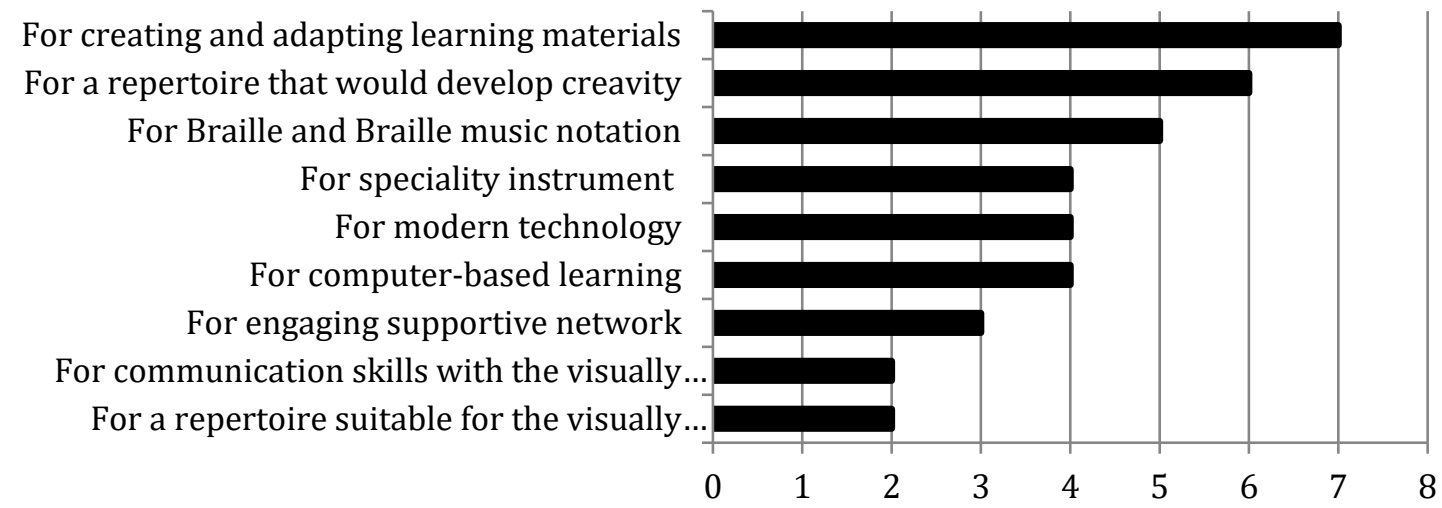

Figure: 2 . The need for specific training mentioned by teachers (count of total responses)

Problem 6: One teacher expressed the need to create a society (an association) or a non-profit organization that brings together music students, their teachers and they potential supporters (T3).

\section{Problems highlighted by former learners}

According to our study, most of former learners were autodidacts who started with music learning relatively late, at the age of $14-15$, one even at the age of 33 . To the question "What were the main problems in acquiring music education?" the former learners mention that getting music education had been quite difficult for them. The main problematic reasons were that teachers exchanged frequently or refused to teach. One respondent claimed that he perceived that blind children were taken as students whom are impossible to teach (F5).

The main mentioned limitation was lack of teaching Braille music notation. Several respondents pointed, that it is definitely necessary to teach the Braille music notation writing. Former learners would like to have modern technical devices for recording and for computer-based teaching: "There could be many more applications designed for smart-phone" (F6). According to our study, the problem was considered to be difficulties in the transport issue and the need for the assistant.

\section{Didactic aspects}

Accordingly to the learners' answers, the main way of learning was listening and memorizing. Almost all the students claimed to use Dictaphone (voice recorder) to learn music. Based on our study, quite frequently was mentioned playing the instrument with teacher's guiding hand (tactile way of learning). Only one respondent 
studying at a university described the used method of writing down into Braille music notation the musical piece dictated by the teacher (L1).

The most common method in learning and teaching the musical instrument was using recordings. Only one of the respondents uses Braille textbooks of solfeggio and audio books for learning the history of music. It was surprising that one very talented respondent with absolute pitch didn't use Braille. Only one of the respondents answered, that he was studying the piano according music Braille (L11). One teacher stressed, that every teacher had to talk to a blind student, justify the actions, not only to show perform the piece (T12).

According to the teachers' and former learners' answers, concerning teaching process, individual one-to-one teaching, which was considered the most appropriate for a blind learner, was most used. One of the respondents appointed that "the individual work is necessary, it brings results, especially in the early stages of learning" (F6). Braille textbooks were used quite rarely; main method of teaching was auditory (10). According to our survey, using tactile guiding was often used (5).

For teaching the musical instruments, 8 of teachers used recordings, especially by Dictaphone. Teachers' explanations about not using Braille varied from insufficient Braille skills to the lack of Braille textbooks. The teacher and former learners emphasized the need to find contact with the student. The lessons have to be divided into small fragments and learned through the repetition several times, an important methodical tool is to move step by step.

Despite of mentioned problems, in general, blind learners were satisfied with their opportunities of learning music. The positives aspects mentioned by our respondents were:

1. Use of modern technological devices for the blind people, e.g. a digital voice recorder;

2. Availability of musical instruments nowadays. The lack of instruments was the main problem in the 1970-1980s (Selke, 2007);

3. Different study materials in the Internet. As a new trend forums and the Internet was mentioned as tools for individual learning;

4. Individual one-to-one learning opportunities, taking into account special needs and abilities of every learner; practising music is a good opportunity for the blind people to be creative, to see the outcome of their work.

\section{Current opportunities of learning music}

In Estonia, children with blindness or low-vision can attend whether comprehensive school or special school. There is one special state school for blind and visually impaired children - Tartu Emajõe School (established 1883) (Kals, 2014), and one municipal school - Helen's School in Tallinn. The number of pupils in every class is six maximum, therefore an individual approach to every child is essential. Important part of the school life is the co-operation with other special schools for visually impaired children. 


\section{A. Comprehensive schools}

In Estonia, children with blindness and low-vision get music education as a part of their national curricula in music lessons in a comprehensive or mainstream school. For example, one of the respondents answered: "I got the essential basic knowledge of music notation and intervals taking part in music lessons at [comprehensive] school" (L1).

According to the Estonian National Curriculum of Basic School, all children have two music lessons in a week in primary schools (forms 1-4), and one lesson in a week in later school years. The curriculum of gymnasium (upper secondary school curriculum) is based on learning cycles. In our new national curricula more attention is paid to teaching the musical instruments and to creative activities in music classes.

Estonian traditional music education is based on singing and theory centred music lessons. The social aspect of the common song and choral singing in the development of national identity should be stressed (Selke, 2007). The conceptual changes at the beginning of the $21^{\text {st }}$ century refer to a new model in music education, and to the genesis of new music education paradigm - from singing-centred doctrine into musical activities centric, including growing part of instrumental activities (Selke, 2007).

\section{B. Music schools in Estonia}

The study has revealed that attending music school is (and was) the most important way for getting specific music education. There are 87 schools united under the Association of Estonian Music Schools. Quite a remarkable network for a country with population less one and a half million. Music schools give basic music education according to their national curricula. The content of curricula describes the requirements which should be achieved. The main subjects in music school are: (training in) musical instruments (string, wind, keyboard, and percussion instruments) or singing, and also solfeggio and history of music. There are two study curricula (or branches): basic and general. The basic curriculum is meant as a preparatory stage for further professional music education. Children have four 45-minute-lessons a week two for the musical instrument and two for solfeggio. The aim of the general branch is to support and develop children's interest to musical hobby activities. Children have one 45-minute lesson a week for both above-mentioned subjects -instrument and solfeggio. From the third year, all children start with lessons of music history and they have opportunities for playing in ensembles and orchestras. Children usually begin their studies at the age of seven and it takes seven years of learning at music school (lower level from first to fourth and higher level from fifth to seventh year to academic year. Children aged from 5 to 7 may attend preparatory classes. There are also classes with free curriculum, only one 45-minute lesson a week for musical instrument.

\section{Some music schools are working at the comprehensive schools}

For example, the main characteristics of a municipal school in Tallinn, Old Town Educational College Music School, are integration of general and art education, as well as integration of education and cultural activity of musicians, artists and actors. 


\section{Additional music education is provided by hobby groups}

There are several hobby groups at schools: song and instrumental ensembles, school orchestras etc. One of the respondents said: "Playing in the band has been very useful for improving my musical skills" (L1).

The brass orchestras of the blind still exist in the South-Estonian and North-Estonian Associations in Tartu and Tallinn and those were highlighted as very important by the former blind music learners through decades. The Brass Orchestra of the Estonian Federation of the Blind was established 1979 on the basis of these two orchestras (Raigna, 2000).

\section{E. Choirs and ensembles}

Singing in choirs has been traditionally very popular in Estonia. Just to remind you our first General Song Celebration (Festival) held in 1869, and our Singing Revolution in 1988 which helped to regain our freedom. We had the 26th [General] Estonian Song Celebration and the 19th Dance Celebration "Touched by Time. The Time to Touch" in summer 2014. The 12th Estonian Youth Song and Dance Celebration "Here I'll Stay” was held in summer 2017 in Tallinn. These are most important cultural events of Estonia and these are UNESCO World Heritage Events. One of former learners is currently singing at the Academic Female Choir of Tallinn University of Technology (F4).

\section{F. Private learning}

Private learning of music was mentioned as one of the options of musical education. Two of our respondents had that experience. For example, one of them said: "I have been taught playing the musical instrument by a private teacher and it was sufficient to become a musician in the orchestra" (F4). One of respondents learns the violin at a private teacher (F5).

In Estonia, every child has the right to receive basic education at nearby school and there are several opportunities of learning music for the blind and visually impaired in Estonia.

\section{Conclusions}

In conclusion, there are several problems of learning music for the blind and visually impaired in Estonia. The research results have indicated that the main limitations are connected with the Braille music notation and insufficient availability of modern accessible technology in music learning and teaching for the blind, the lack of motherlanguage tools. These problems have been highlighted by the all respondent groups (music teachers, present and former learners).

Teachers find that blind music learners would need more individual music lessons, they also need opportunities to improve their self-confidence to perform in public. The survey indicated that the teachers most often feel the need for specific training of creating and adapting learning materials. The study provided evidence that one of the problems of the blind or visually impaired children attending music schools were related to mobility and need for assistance. More co-operation is needed between 
primary, secondary and tertiary music education institutions to facilitate students' successful transition from one stage to the other.

Despite of difficulties, all our respondents emphasized the importance of learning music and practising music for the blind and visually impaired persons.

In Estonia, there is a sufficiently developed school network for children with visual impairment, although the direction towards so-called inclusive education has been taken, which threatens the future of specific schools. The inclusive learning has its bottlenecks. The new trend in learning methodology, as well as the schooling model based on integration of students with disabilities into comprehensive schools, have had a negative impact on music literacy, manual skills as well as other curricular subjects (New Perspectives for Music Studies for Visually Impaired Persons, 2015; Lõvi, 2015/2016).

\section{References}

Bennett, A. (2005). Culture and Everyday Life. London \& Thousand Oaks \& New Delhi: Sage Publication.

Cook, N. (2005). Muusika. Kujutlus. Kultuur [Music, Imagination, and Culture]. Translated K. Sarv. Tallinn: Scripta Musicalia (in Estonian).

Ernits, T. (2013). Muusikaõppekirjandus ja laulmisõpetus saksa óppekeelega koolides Eestis aastatel 1860-1914 [Music Education Literature and Teaching of Singing in Schools with German as the Language of Instruction in Estonia 1860-1914]. Tallinn University, Dissertations on social sciences 61. Tallinn: Tallinna Ülikool (in Estonian).

EU Lifelong Learning Programme „Music for Visually Impaired People“ (2012). Description. Retrieved June 10, 2017 from http://www.music4vip.eu/description

Jünger, H. (2006). Schulbücher im Musikunterricht?: Quantitativ-qualitative Untersuchungen zur Verwendung von Musiklehrbüchern an allgemein bildenden Schulen. Unipress Hochschulschriften Bd. 153. Hamburg: LIT VERLAG.

Kals, A. (Ed.) (2014). Tartu Emajõe Kool sõnas ja pildis 1883-2013 [Tartu Emajõe School in the Words and in the Picture, 1883-2013]. Tallinn.

European Project MUS4VIP Nr. 2012- 4250 (2015). New Perspectives for Music Studies for Visually Impaired Persons. Retrieved July 3, 2017 from mus4vip-conference-verona.pdf

Lõvi, M. (2015). Koostööst Põhja- ja Baltimaadega. [About Cooperation Nordic and Baltic Countries]. Valguse kaja. Eesti Pimedate Liidu infoleht, Autumn 2015 - Winter 2016, 6-8.

Mäesalu, M. (2009). Kuidas, kus ja miks kuulavad noored muusikat? In A. Liimets (Ed.), Muusikalise kontegelikkuse ühendused identiteedi ja diferentsiga (95-108). Tallinn: Tallinna Ülikooli Kirjastus.

Ockelford, A. (2015). Focus on music: The impact of congenital visual impairment on the development of musical abilities Lives (VIML),UCL, in childhood .In Abstracts of a Conference „Visually-impaired Musicians' Institute of Education. London. Retrieved March 15, 2017 from http://vimusicians.ioe.ac.uk/abstracts1.html\#Ockelford 
Oruste, M.-L. (2017). Noodikirja teisendamine punktkirja. Bakalaureusetöö [Translating Musical Notation to Braille: Bachelor thesis]. Tartu: Tartu Ülikool (in Estonia).

Raigna, A. (2000). Teine juubilar [The other jubilarian]. In Valgus kaja: Eesti Pimedate Liidu infoleht, December, 4-6 (in Estonian).

Rembeck, M. H . (2012). Klavier lernen Punkt für Punkt: Für Sehende und Blinde. Zürich: SBS Schweizerische Bibliothek für Blinde, Seh- und Lesebehinderte.

Schläbitz, N. (2009). Obligat: Interdisziplinarität. In: N. Schläbitz (Ed.), Interdisziplinarität als Herausforderung musikpädagogischer Forschung.Musikpädagogische Forschung, Bd. 30, s. 7-12. Essen: DIE BLAUE EULE.

Selke, T. (2007). Suundumusi Eesti üldhariduskooli muusikakasvatuses 20. sajandi II poolel ja 21. sajandi alguses [Music Education in Estonian Comprehensive School: Trends in the 2nd half of the 20th century and at the beginning of the 21st century]. Tallinn University, Dissertations on social sciences 28. Tallinn: Tallinna Ülikool (in Estonian).

Stadler Elmer, S. (2015). Kind und Musik. Das Entwicklungspotenzial erkennen und verstehen. Berlin, Heidelberg: Springer-Verlag.

Virula, K. (2012). Individuaalse arenduskava koostamine nägemispuudega lastele Eesti lasteaedades. Magistritöö. Tartu Ülikool, sotsiaal-ja haridusteaduskond, eripedagoogika osakond.Retrieved June 15, 2017 from http://dspace.ut.ee/bitstream/handle/10062/24174/Kristi_Virula.pdf?sequence=1\&isAllowe $\mathrm{d}=\mathrm{y}$

Received: 03.08.2017

Accepted: 29.11.2017 


\section{Appendix: Questionnaire for Blind and Visually Impaired Learner of Music (2015/2017)}

Thank you for answering the questionnaire and giving your input into the overview on music education of blind and visually impaired people in Estonia. While answering, please tick the appropriate answer or several answers if necessary. Add your comments when possible.

\section{A. Your profile}

1. Your gender

$$
\text { - Female }
$$

- Male

2. Your age

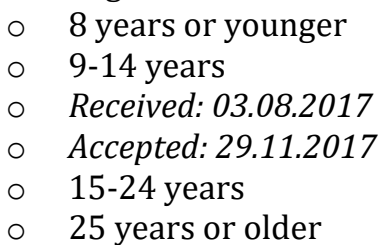

3. You live in (name of the town or county).

4. Your comprehensive school is in (name of the town or county)

5. You learn according to

$\begin{array}{ll}\circ & \text { Adapted simplified curriculum for basic school } \\ \circ & \text { Simplified curriculum for basic school } \\ \circ & \text { National curriculum for basic school } \\ \circ & \text { National curriculum for gymnasium (secondary school) } \\ \circ & \text { Other }\end{array}$

\section{B. Questions about your music education}

6. You get music education in (name of the town or county)

7. You get music education in

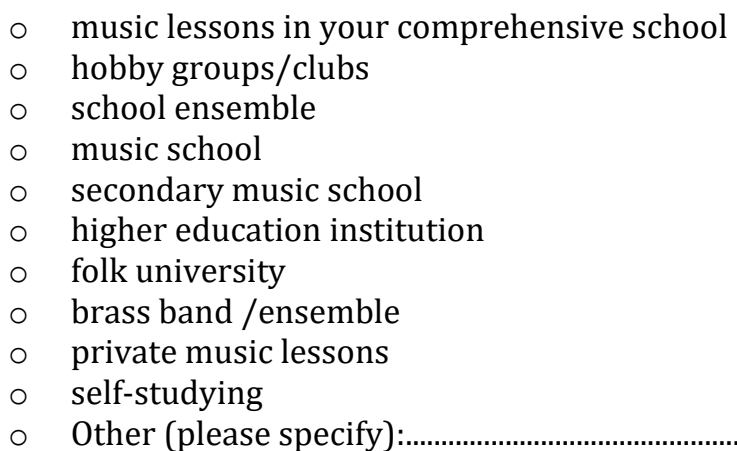

8. You learn

$\begin{array}{ll}\circ & \text { string instrument } \\ \circ & \text { keyboard } \\ \circ & \text { percussion instruments } \\ \circ & \text { wind instrument } \\ \circ & \text { singing } \\ \circ & \text { general subjects of music }\end{array}$

9. Name the musical instruments you are playing

10. Name the first musical instrument you learnt to play

11. You learn in
○ individual (one-to-one) lessons
- group lessons 
- both individual and group lessons

o Other

12. In case you attend a music school, you learn according to
○ basic study programme
- general study programme
- free programme
o Other....

13. How many times a week is a music lesson and how long does it last?

14. Why do you want to learn music?

- It's my hobby and a way of self-realization

$\circ \quad$ It might be connected with my future profession

- It's an opportunity to be with my friends

- To meet the others interested in music

o Other:

15. How do you learn music?
$\circ \quad$ Listening and memorizing
- Writing down in Braille music notation the musical piece dictated by the teacher
- Using study materials in Braille music notation
○ Using a Dictaphone
- Using a smart phone
- Using a computer program
- Playing the instrument with teacher's guiding hand/a teacher physically guiding the learner's hand (tactile way of learning)
o Other

16. Please describe your learning methods

17. What kinds of study materials do you use?

- Braille textbooks of solfeggio

- Brailletextbooks of music history

- Audio books of music history

- Audio books of music theory

- Textbooks in Braille notation for learning the musical instrument

- Audio materials for learning the musical instrument

- I don't use any books/textbooks

o Other:

18. How often do you use Braille study books/textbooks and/or Braille music notation?

○ In every lesson

- Once a week

O Once or twice in a month

- A few times in a year

- Never

19. How often do you use the Estonian Library for the Blind?

o Once a week

O Once or twice in a month

- A few times in a year

- Never

20. How do you practise/make music outside your music lessons?

- Playing the musical instrument in a music collective

- Playing the musical instrument for yourself at home

- Singing in a music collective

- Singing as a soloist

- Singing for yourself at home

o Other:

21. You have performed

- At school concert

- At concerts outside your school

- At national music competitions 


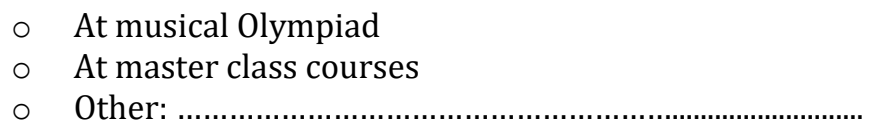

\section{Problems in learning music?}

22. What problems do you feel existing in learning music?

23. What kind of study materials would you need?

24. What has motivated you to learn music?

25. Would you like to add or comment anything?.

\section{Thank you very much for your answers!}

Please rate the questionnaire:

Not sufficient and superficial

$\begin{array}{lllll}1 & 2 & 3 & 4 & 5\end{array}$

Thorough and appropriate 




\section{Notes for contributors}

\section{SUBMISSION OF MANUSCRIPTS}

Manuscripts, ideally between 5000 and 8000 words (including abstract, diagrams, references and tables), should be sent as an attachment in original format or Word document format (DOC). Manuscript should be submitted in English and only for Problems in Music Pedagogy in accordance with the publication manual of the American Psychological Association (APA).

\section{REFEREEING}

All manuscripts are normally reviewed by at least two referees (in addition to the Editor). Refereeing is anonymous unless a referee chooses otherwise. Referee comments are passed intact to authors, apart from editing. Proofs should be returned to the Editor as soon as possible. The Editorial Board has the right to reject a manuscript if after the first review it is submitted repeatedly with unsatisfactory corrections. The selection of articles for inclusion in the journal will be based on these reviews.

\section{SPECIFICATIONS FOR CONTRIBUTIONS}

Manuscript must be typewritten with a font size of 12 points (font Times New Roman) on one side of A4 paper. Contributors are asked to use MS Word 5.0 or a later version.

\section{Style}

Papers must be written in clear, concise style appropriate to an international readership.

\section{Manuscript specification}

Title. Include title of the paper, name(s) of author(s), affiliation, mailing address (include postal codes, e-mail address and fax-number).

Manuscripts should begin with an Abstract of up to 120 words that contains concise factual information on objectives, methods, results, and conclusions.

Key Word Index should follow, including a maximum of 5 Keywords.

The body of the text should begin with a statement of the objectives of the work. It should include citations of published related work and sections on Methods, Results, Discussion and Conclusions of the study.

An Acknowledgement section may follow the Conclusions.

Figures. Graphics files are welcome if supplied as Tiff, JPG. A minimum resolution for images is 600 ppi. The minimum line weight for line art is 0.5 point for optimal printing. When possible, please place symbol legends below the figure image instead of to the side.

Tables, drawing, diagrams and charts with a clear title should be numbered by Arabic numerals. The approximate position of these materials should be indicated in the manuscript.

Footnotes should not be used.

References. References (all reference in English) should be listed in alphabetical order. Each listed reference should be cited in text, and each text citation should be listed in the References. Basic formats are as follows:

\section{For books}

Hallam, S. (1998). Instrumental Teaching: A Practical Guide to Better Teaching and Learning. Oxford: Heinemann Yeric, J., \& Todd, J. (1989). Public Opinion: The Visible Politics. Chicago: Peacock.

For journal articles

Peterson, J., \& Schmidt, A. (1999). Widening the horizons for secondary schools. Journal of Secondary Education, 3(8). 89106.

\section{For published conference paper}

Edwards, K., \& Graham, R. (1992). The all female expedition: A personal perspective. Gender on Ice: Proceedings of a Conference on Women in Antarctica. Canberra: Australian Antarctic Foundation, 75-81.

\section{For chapters in edited books}

Philpott, Chr. \& Carden-Price, Chr. (2001). Approaches to the Teaching of GCSE. Chr. Philpott, (Ed.). Learning to

Teach Music in the Secondary School. London, New York: Routledge, Falmer, 184-195.

Document on the World Wide Web (dated and author or sponsor given)

Brown, H. (1994). Citing computer references. Retrieved April 3, 1995 from

http://neal.ctstateu.edu/history/cite.htm

\section{ALL CONTRIBUTIONS AND CORRESPONDENCE SHOULD BE ADDRESSED TO:}

Professor Jelena Davidova,

Problems in Music Pedagogy,

Daugavpils University,

Parades 1-205,

Daugavpils, LV 5400, Latvia.

Tel.: +37129140287

E-mail: jelena.davidova@du.Iv 


\section{Problems in Music Pedagogy}

\section{Volume 16(2), 2017}

CONSTRUCTION AND VALIDITY OF PEDAGOGICAL TEST

OF MUSICAL ABILITIES

Lidija NIKOLIĆ

MODELS AND SCIENTIFIC MODELLING IN MUSIC CONTEXT

Gerhard LOCK

THEORETICAL FUNDAMENTALS OF THE PROCESS

OF ACQUIRING THE DIDACTIC MODEL FOR STYLE MODELLING IN MUSICAL IMPROVISAION

Jurijs SPIGINS

TEACHING ARRANGING TO CLASSICAL AND

CONTEMPORARY MUSIC STUDENTS IN HIGHER EDUCATION

Annie K. MITCHELL

AXIOLOGICAL MODEL OF MASTERING PIANO PLAYING

AS A BASIS OF THE COMPETENCE APPROACH

Larisa MAḶKOVA

PROBLEMS OF MUSIC EDUCATION FOR BLIND AND

VISUALLY IMPAIRED PEOPLE IN ESTONIA

Tiiu ERNITS \& Kadri KUTSAR 